\title{
AIRBORNE RESISTIVITY MAPPING OF PERMAFROST NEAR FAIRBANKS, ALASKA
}

\author{
P. Hoekstra, P.V. Sellmann and A.J. Delaney
}

September 1974

\author{
PREPARED FOR \\ OFFICE, CHIEF OF ENGINEERS \\ DA PROJECT 4A162121A894 \\ BY \\ CORPS OF ENGINEERS, U.S. ARMY \\ COLD REGIONS RESEARCH AND ENGINEERING LABORATORY \\ HANOVER, NEW HAMPSHIRE
}




\section{PREFACE}

This report was prepared by Pieter Hoekstra, Geophysicist, of the Physical Sciences Branch, Research Division, Paul V. Sellmann, Geologist, of the Northern Engineering Research Branch, Experimental Engineering Division, and Allan J. Delaney, Physical Sciences Technician, of the Physical Sciences Branch, Research Division, U.S. Army Cold Regions Research and Engineering Laboratory (USA CRREL).

The work was performed under DA Project 4A162121A894, Engineering in Cold Environments, Task 03, Expedient Logistic Facilities in a Cold Regions Theater of Operations, Work Unit 008, Site Selection and Subsurface Exploration. The U.S. Army Engineer District, Alaska, also funded a portion of this survey.

The airborne resistivity survey and the computer processing of the flight data were performed under contract by Barringer Research Ltd. of Toronto, Canada. Discussions with Duncan McNeill of Barringer Research Ltd. on many aspects of this work proved valuable.

The Geological Survey of Canada also conducted an airborne E-phase survey in the spring of 1973. The study described in this report benefited much from the cooperation of Mr. L. Collett and Dr. W. Scott of the Electrical Methods Section of the Geological Survey of Canada.

Mr. I. Long of the Corps of Engineers, Alaska District, made available preliminary geological data from the Chena River Dam and Flood Control Project, and his encouragement, and the financial support of the Corps of Engineers, Alaska District, are appreciated.

Steven Mock and Kevin Carey of USA CRREL technically reviewed the report.

The contents of this report are not to be used for advertising, publication, or promotional purposes. Citation of trade names does not constitute an official endorsement or approval of the use of such commercial products.

Manuscript received 24 April 1974 


\section{CONTENTS}

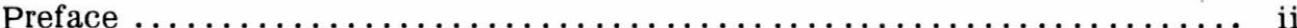

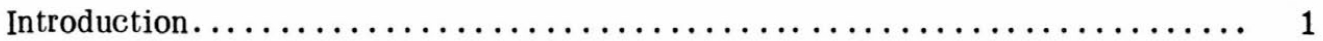

Resistivities of earth materials............................. 3

Dependence of resistivity on soil type $\ldots \ldots \ldots \ldots \ldots \ldots \ldots \ldots \ldots \ldots \ldots, 3$

Relation between resistivity and water content $\ldots \ldots \ldots \ldots \ldots \ldots \ldots \ldots \ldots$

Dependence of resistivity on temperature $\ldots \ldots \ldots \ldots \ldots \ldots \ldots \ldots \ldots \ldots$

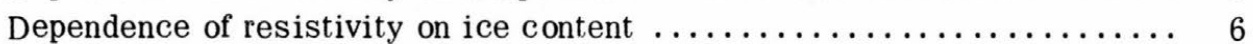

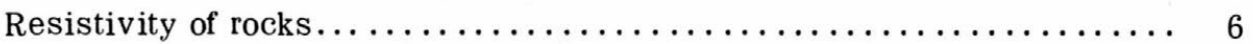

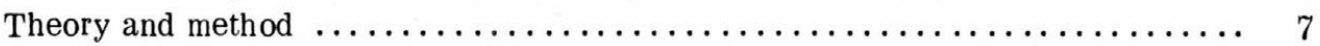

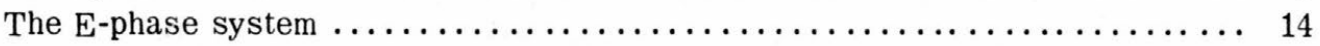

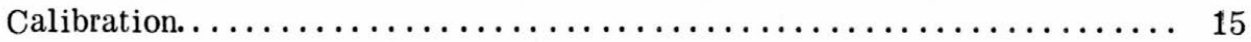

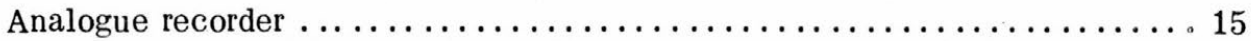

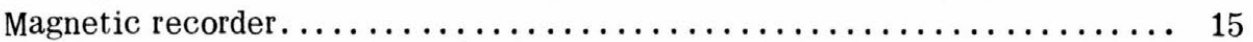

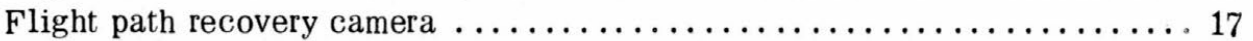

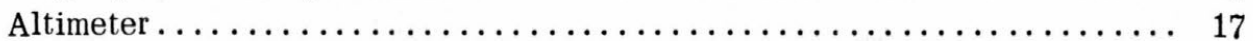

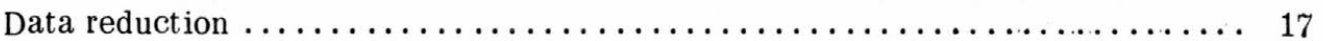

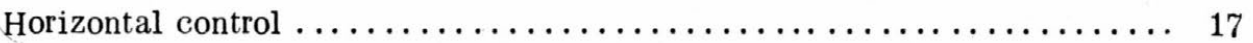

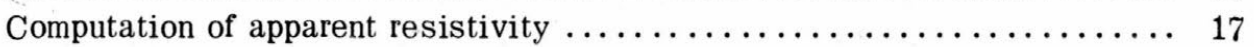

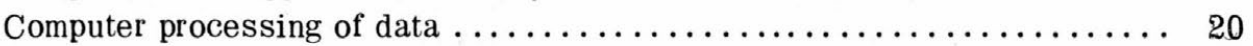

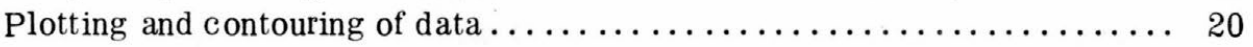

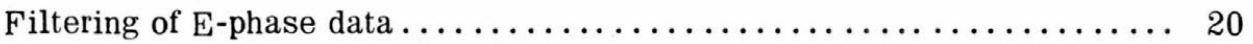

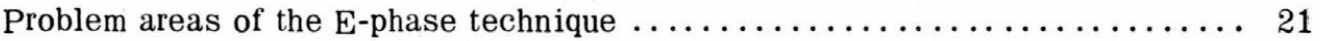

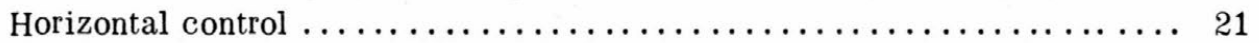

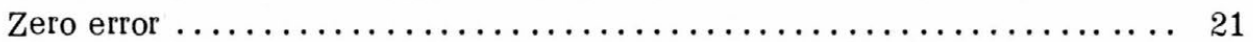

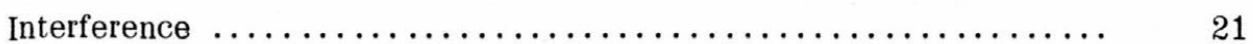

Ground control in study areas............................. 21

Computer modeling of resistivity profiles in central Alaska............ 23

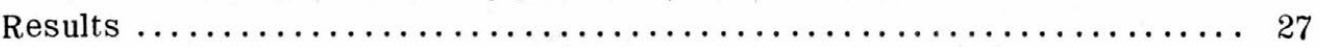

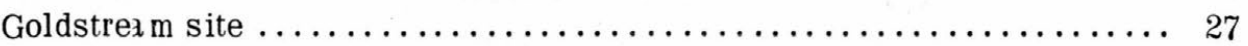

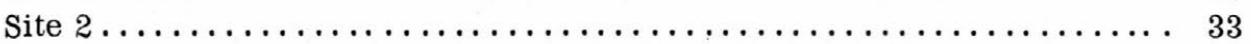

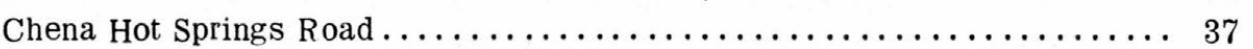

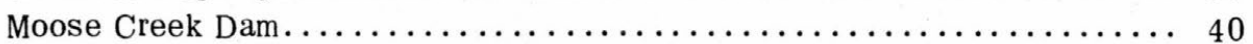

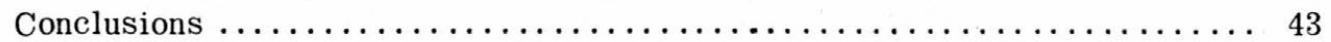

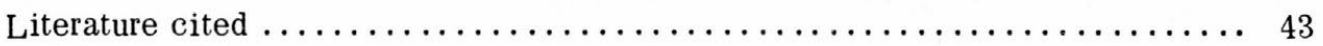

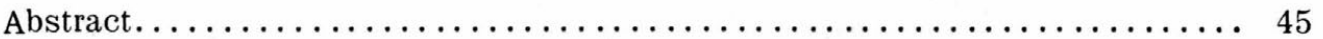

Figure

\section{ILLUSTRATIONS}

1. Map showing the locations and layouts of test sites $\ldots \ldots \ldots \ldots \ldots \ldots 2$

2. The resistivities of soil types in the Unified Soil Classification System measured in exposures in the valley of the Tombigbee River in

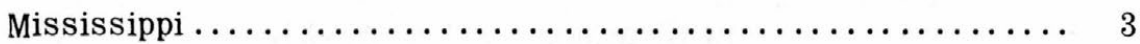

3. The resistivity of a silt soil as a function of water content $\ldots \ldots \ldots \ldots$. 4

4. The resistivities of several saturated soil types and one rock type as a

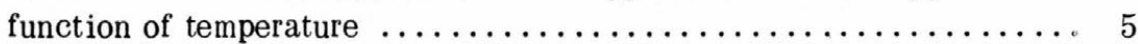


5. Resistivities of saturated organic soils of Fairbanks, Alaska, as a

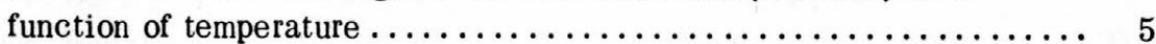

6. Different ice formations in the USA CRREL tunnel in permafrost in Fox, Alaska...................................... 6

7. The relation between ice content and resistivity measured in-situ in the walls of the USA CRREL tunnel in Fox, Alaska.............. 7

8. Electromagnetic field components of a vertically polarized radio surface

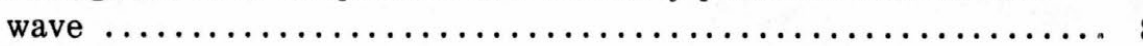

9. Skin depth of electromagnetic plane waves as a function of frequency and

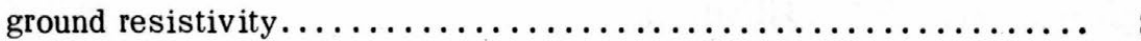

10. Magnitude of wave tilt as a function of frequency for resistivity variations over typical homogeneous earth...................... 10

11. The ratio of apparent resistivity for homogeneous ground, and true resis-

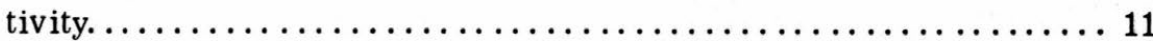

12. The computed in-phase and quadrature-phase components of the wave tilt and its phase as a function for the layered ground conditions shown..

13. The ratio of computed apparent resistivity and the resistivity of the surface layer as a function of thickness of first layer in terms of skin

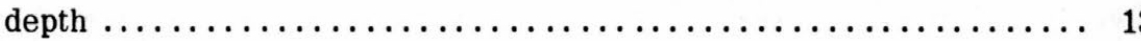

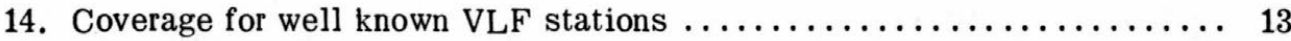

15. STOL aircraft with E-phase antennas in the nose cone and a magnetometer stinger on the tail $\ldots \ldots \ldots \ldots \ldots \ldots \ldots \ldots \ldots \ldots \ldots \ldots \ldots, 14$

16. Sample record of the analogue chart used in flight recorder .......... 15

17. Typical photo strip from flight camera on plane, from an altitude of approxi-

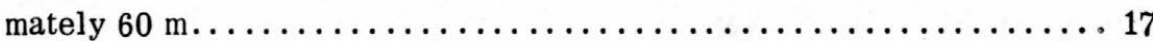

18. Ground measurements of the in-phase and quadrature-phase components of $W$ as a function of compass bearing $\ldots \ldots \ldots \ldots \ldots \ldots \ldots \ldots \ldots, 18$

19. Examples of resistivity profiles along a flight line $\ldots \ldots \ldots \ldots \ldots \ldots \ldots 20$

20. Wenner spreads on several soils near Fairbanks, Alaska ............ 24

21. The computed apparent resistivities for the E-phase method at VLF and LF on the units Qso and Qsu as a function of thickness of the frozen

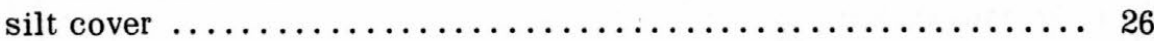

22. The computed apparent resistivity at VLF typical for the unit Qal ...... 26

23. The computed apparent resistivity at LF typical for the unit Qal ....... 26

24. The VLF apparent resistivity contour map of the Goldstream area, with the surficial geological map of the Fairbanks, Alaska, D-1 Geological

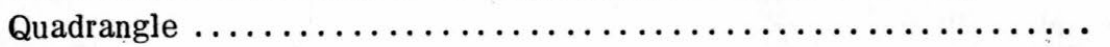

25. The LF apparent resistivity contour map of the Goldstream area, with the surficial geological map of the Fairbanks, Alaska, D-1 Geological

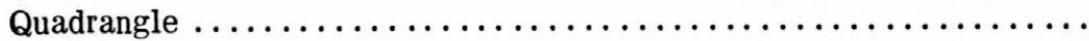

26. A typical cross section of Goldstream Valley along A-A'shown in Figure $24 \quad 30$

27. Normalized distribution histograms of resistivities on the units of Qf, Qsu

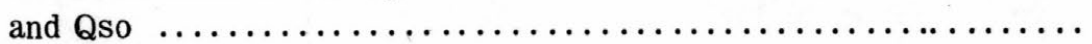

28. The apparent resistivity measured as a function on the geological units

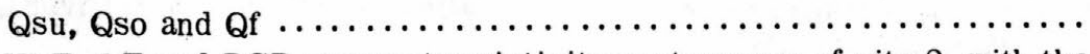

29. The VLF. LF and BCB apparent resistivity contour map of site 2, with the surficial geological map of the Fairbanks, Alaska, D-1 Geological

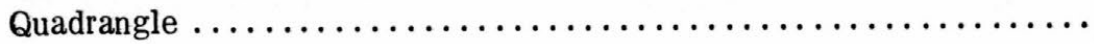


30. The VLF, LF and BCB apparent resistivity contour map of site 2,

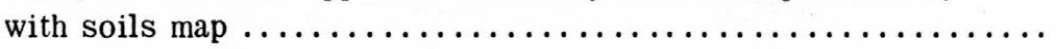

31. Normalized distribution histograms of resistivities on the units Qf, Qsu

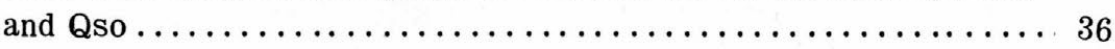

32. Geological cross section across Little Chena Valley, 28 miles along the Chena Hot Springs Road $\ldots \ldots \ldots \ldots \ldots \ldots \ldots \ldots \ldots \ldots \ldots \ldots \ldots$

33. The contoured resistivity map for a section in the Little Chena Valley. . 38

34. Resistivity profiles along the cross section $\mathrm{BB}^{\prime}$ of Little Chena Valley and the geological cross section derived from the measured resistivity data and modeling studies $\ldots \ldots \ldots \ldots \ldots \ldots \ldots \ldots \ldots \ldots \ldots \ldots$

35. A Wenner spread in the Little Chena Valley in section A of Figure $34 \ldots 39$

36. The computed values of apparent resistivity at VLF and LF in section A, Chena Hot Springs Road, for the E-phase method as a function of the thickness of a highly resistant gravel layer $\ldots \ldots \ldots \ldots \ldots \ldots \ldots 40$

37. The apparent resistivity contour maps at VLF, LF and BCB in the Moose Creek Dam area, with a preliminary surficial geological map mainly indicating the depth of silt cover $\ldots \ldots \ldots \ldots \ldots \ldots \ldots \ldots \ldots, 41$

38. The computed apparent resistivity at three frequencies for two layers of silt over gravel as a function of the thickness of silt cover . . . 42

Table

\section{TABLES}

I. Relevant data on the organic samples used in measurements of data

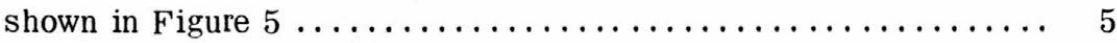

II. Channel designations of magnetic tape recorder $\ldots \ldots \ldots \ldots \ldots \ldots \ldots, 16$

III. Survey specifications and transmitter data $\ldots \ldots \ldots \ldots \ldots \ldots \ldots \ldots . \ldots \ldots$

IV. Summary of ground control available in each survey area $\ldots \ldots \ldots \ldots \ldots 22$

V. Geological units from Fairbanks, Alaska, D-1 and D-1 Geological

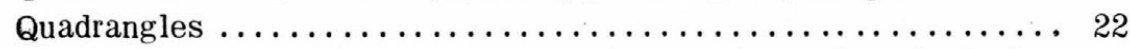

VI. Layering and resistivity ranges expected on major surficial geological

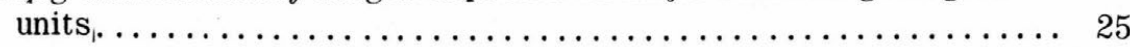

VII. VLF ground-based apparent resistivity measurements on rock sites in the

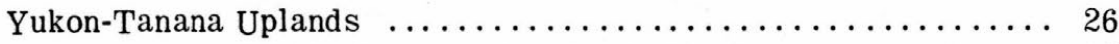

VIII. Mean apparent resistivities in several geological units ........... 32

IX. Grouping of the soil units from the Fairbanks, Alaska, soil survey ..... 36 


\title{
AIRBORNE RESISTIVITY MAPPING OF PERMAFROST NEAR FAIRBANKS, ALASKA
}

\author{
by \\ P. Hoekstra, P.V. Sellmann and A.J. Delaney
}

\section{INTRODUCTION}

Subsurface investigations for geotechnical projects are commonly conducted at two levels of intensity:

1. Reconnaissance investigations. Information is often obtained from existing geological maps and airphotos, which provide a general impression of the engineering and geological aspects of the proposed project.

\section{Detailed drilling and sampling programs at selected locations.}

In the mining and oil industry, it is customary to use ground or airborne geophysical methods (seismic and/or electromagnetic) after reconnaissance work and before drilling. Geophysical techniques in terms of cost and in terms of the detail of information they provide are often intermediate between airphoto mapping and sampling by drilling. Ground and airborne geophysical methods attempt to derive physical properties of substrata from measurements on or above the surface. Physical properties such as electrical resistivity and seismic velocity often correlate with specific soil and rock types. In mineral and oil exploration, geophysical techniques are often used to delineate promising targets for further exploration by drilling and to provide a source of continuous information between drill holes. Geophysical techniques now only find limited use in the gathering of subsurface information for geotechnical endeavors. Two reasons for this are apparent:

1. The differences between the physical properties such as electrical resistivity and seismic velocity in near-surface sediments are often less pronounced than the differences between economic mineral deposits and surrounding rocks.

2. A great degree of sophistication in equipment and signal processing is required to obtain a continuous profile of near-surface physical properties. Therefore, a contour map displaying small nuancés, instead of identifying anomalies, is desired.

Electromagnetic geophysical techniques are the subject of this report. The development of very low frequency (VLF) airborne resistivity mapping techniques by the U.S. Geological Survey (USGS) (Frischknecht 1973), Barringer Research Ltd. (Barringer and McNeill 1969), and the Colorado School of Mines (Keller et al. 1970) opened the possibility of obtaining resistivity data at low frequency at a relatively modest cost and in inaccessible areas. The latest development of multifrequency resistivity sensors further adds to the potential of airborne subsurface mapping. The North American Arctic is one area in which airborne subsurface mapping can fill a large need for route and site selection. Therefore, a study was conducted with the Barringer Research Ltd. 


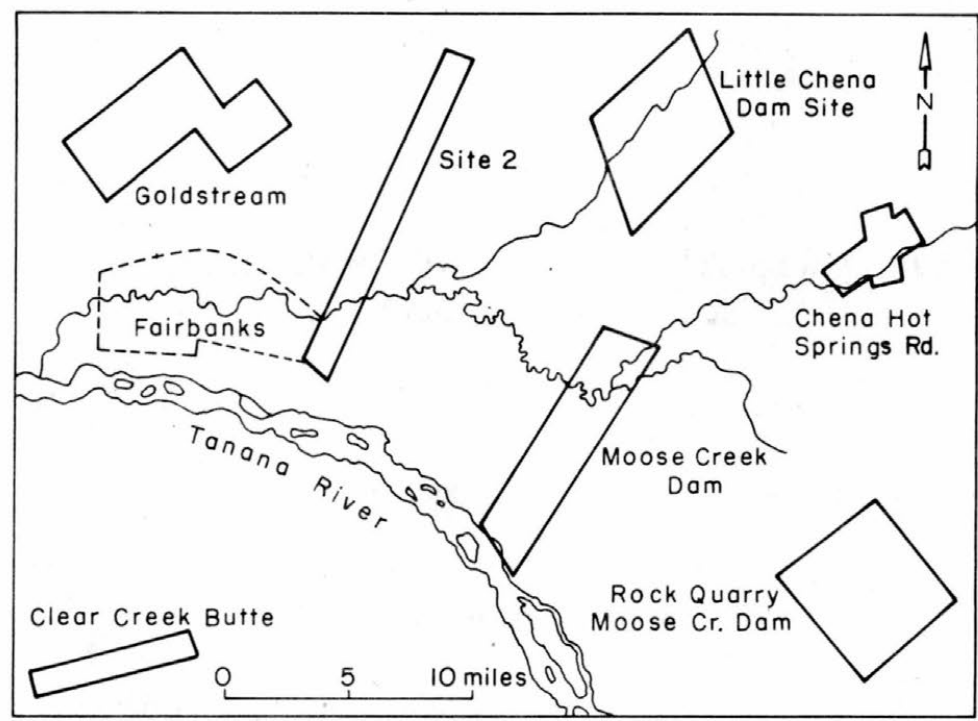

Figure 1. Map showing the locations and layouts of test sites.

multifrequency airborne E-phase equipment in April 1973 in the vicinity of Fairbanks, Alaska. The objectives of this study were:

1. To determine the ability of the E-phase system to delineate various surficial geologic units, in particular to differentiate between perennially frozen and thawed ground.

2. To investigate in detail the advantages of multifrequency mapping, which, in theory, makes it possible to examine ground conditions at various depths.

Several study sites were selected in the vicinity of Fairbanks, Alaska. These sites were selected for several reasons:

1. The sites are in the discontinuous permafrost zone and consequently have a wide range of permafrost conditions: thawed south-facing hillsides and perennially frozen north-facing hills, extensive large sections of thawed ground in the Tanana Valley, and perennially frozen ground in valleys in the uplands near Fairbanks. The permafrost thickness probably varies from several feet to more than 200 feet.

2. The geological settings and associated material types include: a. alluvial silts, sands and gravels; b. colluvial silts and organic silts; c. eolian silts; and d. bedrock that ranges from metamorphic rock to intrusive granitic rock types.

3. Substantial amounts of background information on the local geology and permafrost distribution are available, and information from hundreds of logged drill holes also permits local and regional correlations to be made (Péwé 1958, Williams et al. 1959).

The location and the layout of the areas surveyed are shown in Figure 1. The areas surveyed with the E-phase system fall into two categories: 1) large study areas that cover approximately 20 square miles and include a range of surface and subsurface conditions common to the region, and 2) small sites of approximately 2 square miles chosen because of the availability of detailed ground control. In the seven areas surveyed, more than 1000 line miles of data were obtained at two or three different frequencies. In this report the results of four areas are discussed: Goldstream, site 2, Chena Hot Springs Road and Moose Creek Dam. The Rock Quarry Moose Creek Dam is discussed by Sellmann et al. (1974). 
In addition to the airborne survey, ground resistivity measurements were made at selected sites, and laboratory resistivity measurements were made on selected samples to help translate the resistivity data into geological formation.

The results were examined on a regional scale and no attempt was made to extract quantitative information on local variations, such as permafrost thickness, and gross variations in ground ice volume.

Because an understanding of the relation between resistivity and material types is critical to the interpretation of resistivity data, resistivities of soils and their variations with temperature and other factors are discussed in the following section. In the section Theory and method (p. 7) the principles underlying the methods are discussed.

\section{RESISTIVITIES OF EARTH MATERIALS}

Four major parameters determine the resistivity of soil strata: (a) soil type, (b) water content, (c) soil temperature, and (d) ice content. A large number of less important factors, such as pressure and the free-salt contents of the pore water, also influence the resistivity of soil strata. The parameter soil type is independent of time over long periods, while the parameters water content and temperature are subject to daily and seasonal variations. All parameters often change with depth in a profile as well as laterally.

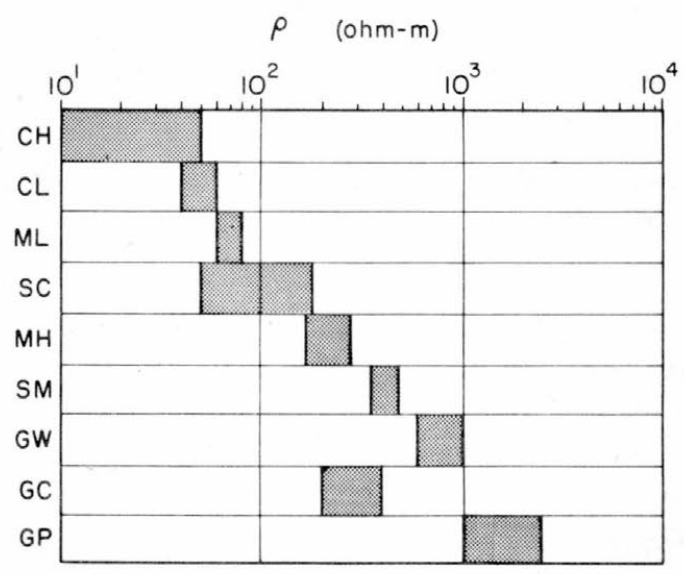

Figure'2. The resistivities of soil types in the Unified Soil Classification System measured in exposures in the valley of the Tombigbee River in Mississippi (after Hoekstra and Delaney 1973).

\section{Dependence of resistivity on soil type}

Figure 2 shows a relation between resistivity and soil units described by the Unified Soil Classification System (U.S. Army Engineer Waterways Experiment Station 1960). The measurements were made in exposures in the valley of the Tombigbee River in Mississippi. The clay soils $(\mathrm{CH})$ have a resistivity $\rho$ less than $50 \mathrm{ohm}-\mathrm{m}$ and, when the clay content of the soil decreases, the value of $\rho$ rises to $200 \mathrm{ohm}-\mathrm{m}$ in typical sandy clay soils (SC). The in-situ amount of water in the exposures probably ranges from 50 to $100 \%$ saturation. The resistivity of gravels also is mainly determined by the amount of fines, so that clean gravels (GP) show resistivities in excess of $1000 \mathrm{ohm}-\mathrm{m}$, while gravels containing a few percent of clay (GC), show resistivities as low as 200 ohm-m. The relation between clay content and resistivity is influenced by the dominant type of clay mineral in the soils, and the actual values within a classification change from one area to another.

\section{Relation between resistivity and water content}

A typical example of the relation between water content and resistivity (the inverse of conductivity) is shown in Figure 3 for a silt soil; the resistivity $\rho$ first sharply decreases when water is added, but at water contents in excess of $5 \%$ the rate of decrease of $\rho$ with water content levels off. 


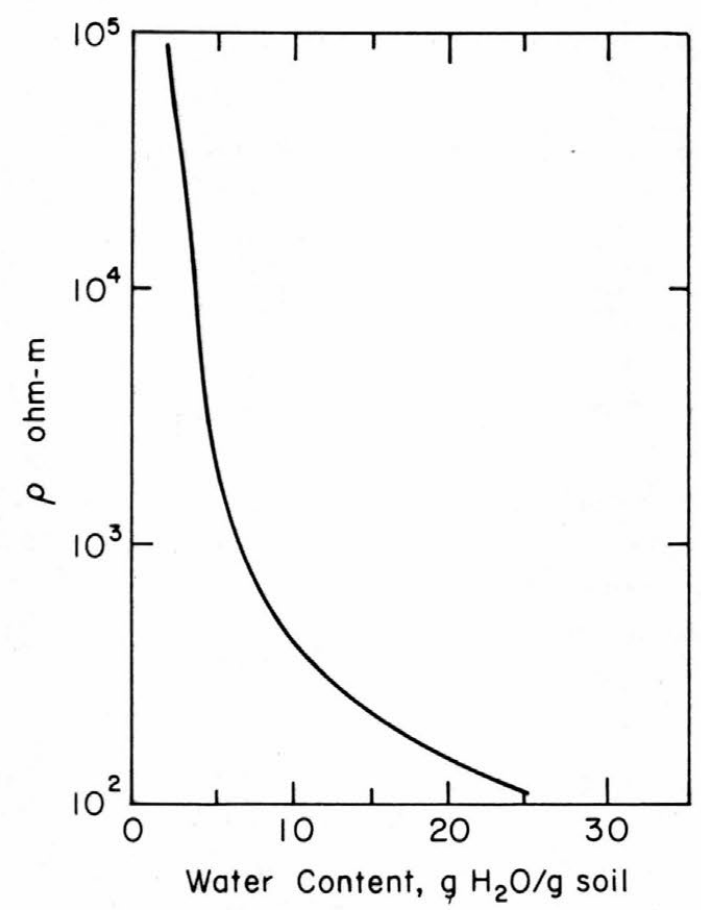

Figure 3. The resistivity of a silt soil as a function of water content ( $\mathrm{g} \mathrm{H}_{2} \mathrm{O} / \mathrm{g}$ soil).

The variation in $\rho$ that can be expected in situ, because of naturally occurring changes in water content, mainly depends on the groundwater regime. In most areas of Alaska, the water content of soil probably does not fall below the water content at field capacity, where the field capacity is defined as the amount of water held in soil after excess water has drained away and the rate of downward movement of water has materially decreased. In Fairbanks silt, resistivity changes from about $100 \mathrm{ohm}-\mathrm{m}$ to $800 \mathrm{ohm}-\mathrm{m}$ can be expected because of changes in water content.

\section{Dependence of resistivity on temperature}

The relation between the resistivity of saturated soil and temperature of the soil is given in Figure 4 for several soil types and one rock type obtained from measurements in the laboratory by several investigators (e.g. Ogilvy 1967, Parkhomenko 1967). At temperatures above freezing, there is a small increase in resistivity with decreasing temperature, and it is only below freezing that temperature causes substantial changes in resistivity. In frozen ground, the resistivity gradually increases when the temperature is lowered, and the changes are directly related to the unfrozen water content of frozen ground (Hoekstra and McNeill 1973, Anderson and Morgenstern 1973). The general trend between soil type and resistivity carries over in the frozen state: the clay-type soils have the lowest resistivity, followed by silt, sand and gravel soils. The resistivity of frozen soils at $-5^{\circ} \mathrm{C}$ is about a factor of 5 higher than the resistivity of the same soil unfrozen; at $-1^{\circ} \mathrm{C}$ no more than a factor of 1.5 separates the resistivity of frozen and thawed clay soils. 


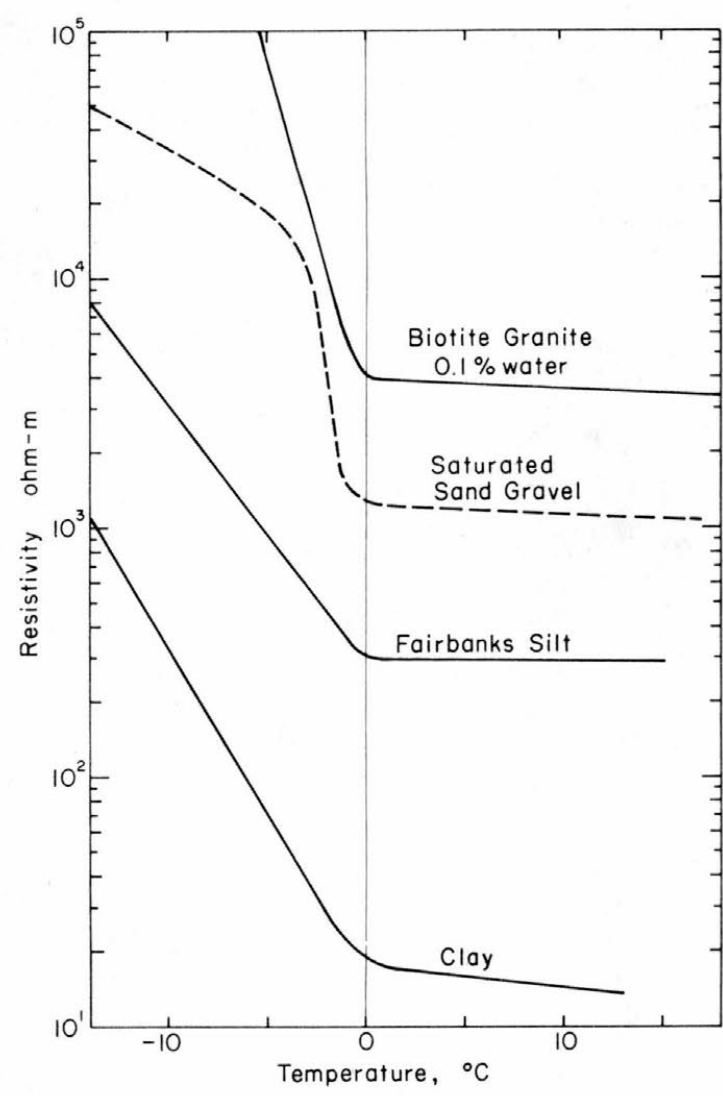

Figure 4. The resistivities of several saturated soil types and one rock type as a function of temperature.

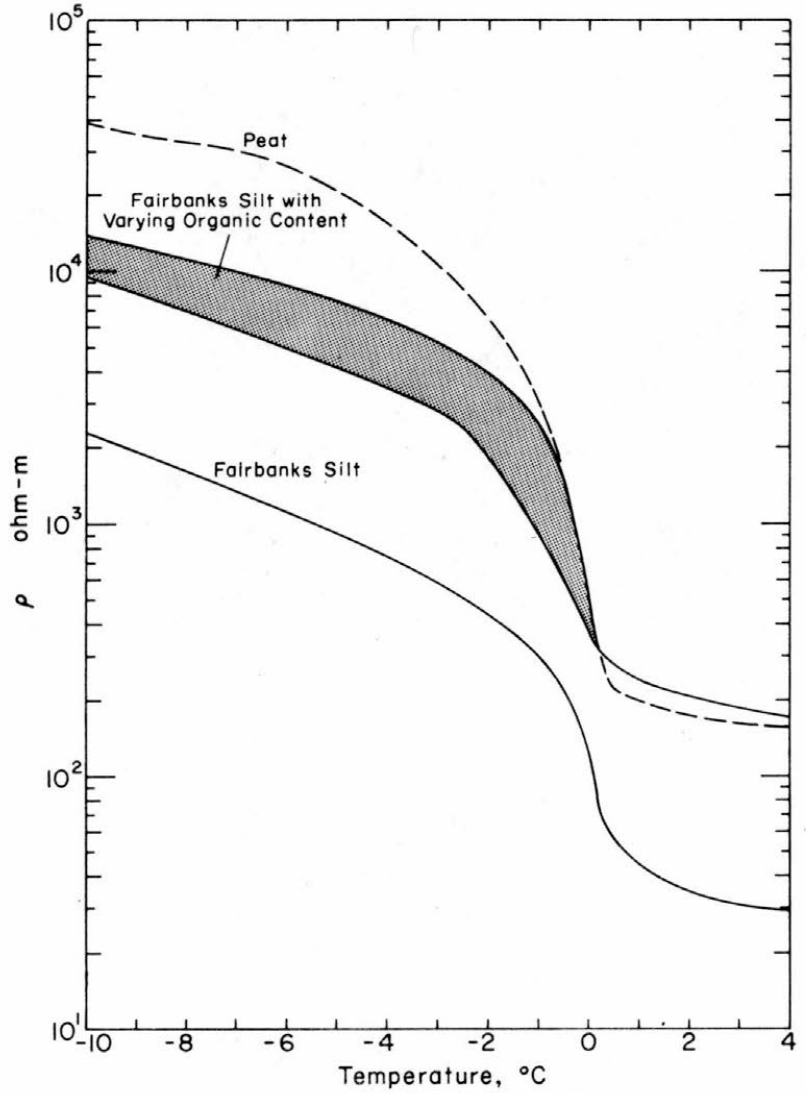

Figure 5. Resistivities of saturated organic soils of Fairbanks, Alaska, as a function of temperature.

Soil layers rich in organic content are common in the first $5 \mathrm{~m}$ of most permafrost ground, and in this $5 \mathrm{~m}$ of surface soil the annual temperature change is most severe. The resistivity on some cores from surface layers of permafrost near Fairbanks, Alaska, was measured as a function of temperature in the laboratory. The relevant data on these saturated soils are given in Table I and the resistivity as a function of temperature is given in Figure 5. Soils high in organic content also often have high water content, which causes a high resistivity when soils are frozen. Therefore, large changes in resistivity between summer and winter are expected for the organic surface soils in permafrost areas.

Table I. Relevant data on the organic samples used in measurements of data shown in Figure 5.

\begin{tabular}{|c|c|c|c|c|}
\hline Sample & $\begin{array}{c}\text { Total } \\
\text { density } \\
\left(\mathrm{g} / \mathrm{cm}^{3}\right)\end{array}$ & $\begin{array}{l}\text { Organic } \\
\text { content } \\
\left(\mathrm{g} / \mathrm{cm}^{3}\right)\end{array}$ & $\begin{array}{c}\text { Water } \\
\text { content } \\
\left(\mathrm{g} / \mathrm{cm}^{3}\right)\end{array}$ & $\begin{array}{l}\text { Mineral } \\
\text { content } \\
\left(\mathrm{g} / \mathrm{cm}^{3}\right)\end{array}$ \\
\hline Organic silt 1 & 1.02 & 0.03 & 0.82 & 0.17 \\
\hline 2 & 1.27 & 0.04 & 0.81 & 0.42 \\
\hline 3 & 1.37 & 0.04 & 0.91 & 0.37 \\
\hline Fairbanks silt & 1.21 & $<0.001$ & 0.61 & 0.60 \\
\hline Peat 1 & 0.94 & 0.12 & 0.82 & 0.003 \\
\hline 2 & 0.94 & 0.13 & 0.95 & 0.003 \\
\hline
\end{tabular}




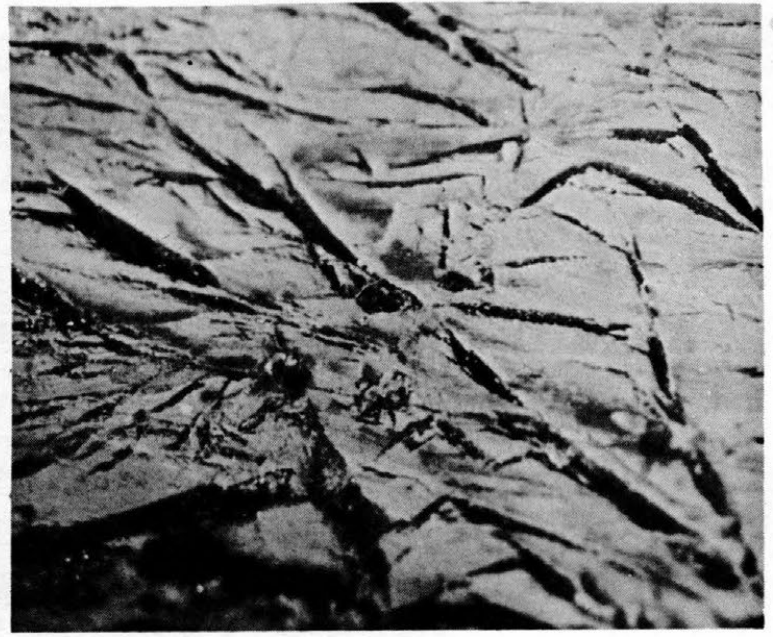

a. Lenses of ice up to $7.5 \mathrm{~cm}$ in width.

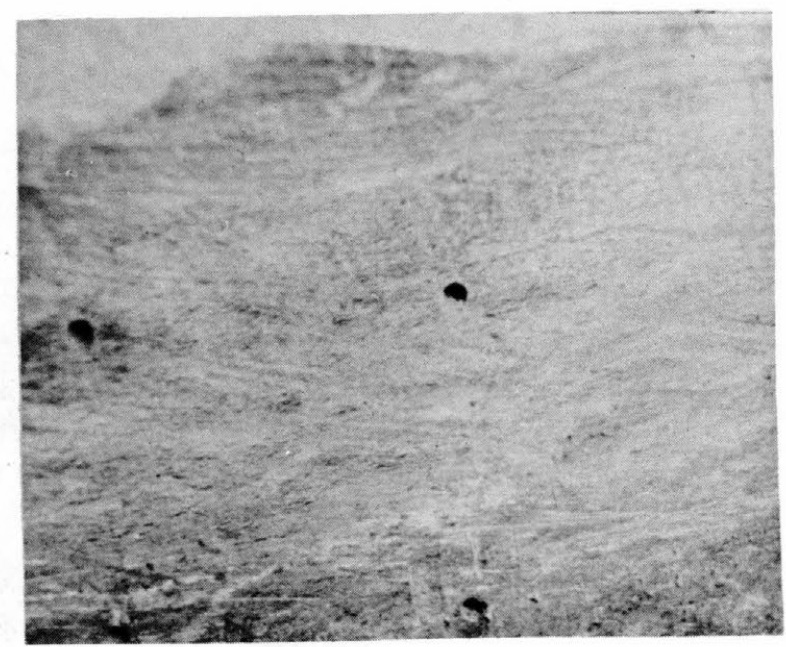

c. Closely spaced small lenses of ice up to $2 \mathrm{~mm}$ thick.

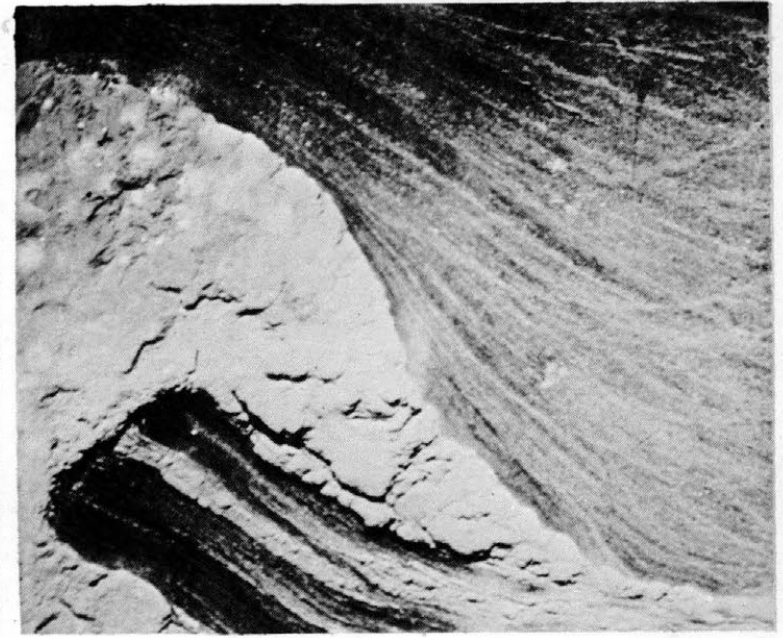

b. Massive structure of an ice wedge.

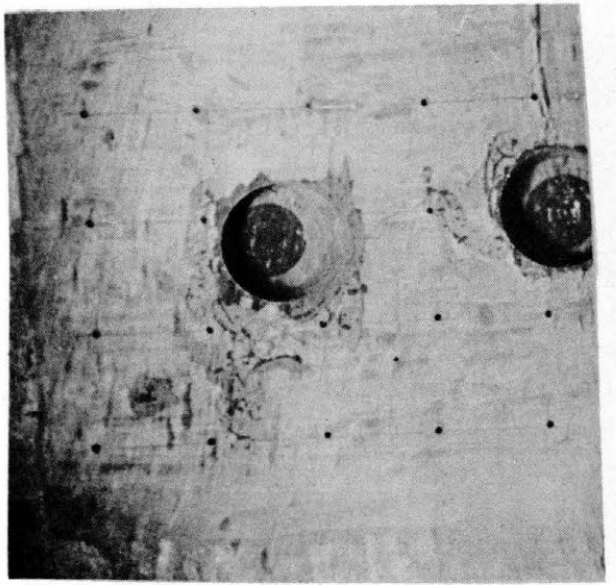

d. Pore ice.

Figure 6. Different ice formations in the USA CRREL tunnel in permafrost in Fox, Alaska.

\section{Dependence of resistivity on ice content}

Frozen ground in permafrost regions can have ice contents far in excess of saturation, and ice lenses and massive wedges are common in fine-grained frozen sediments. The USA CRREL tunnel in Fox, Alaska, contains exposures of silt with different ice types and contents at a temperature of about $-3^{\circ} \mathrm{C}$; examples of ice formations in the USA CRREL tunnel are shown in Figure 6 . The relation between ice content and resistivity was measured by a four-probe method with the probes inserted in the tunnel walls; the results are shown in Figure 7. Frozen silt can thus have a resistivity varying from about $1000 \mathrm{ohm}-\mathrm{m}$ to about $100,000 \mathrm{ohm}-\mathrm{m}$ depending on the ice content.

\section{Resistivity of rocks}

The resistivities of rocks are generally more difficult to classify than those of soils because of the dependence of rock resistivities on the degree of fracturing and weathering, grain size and 


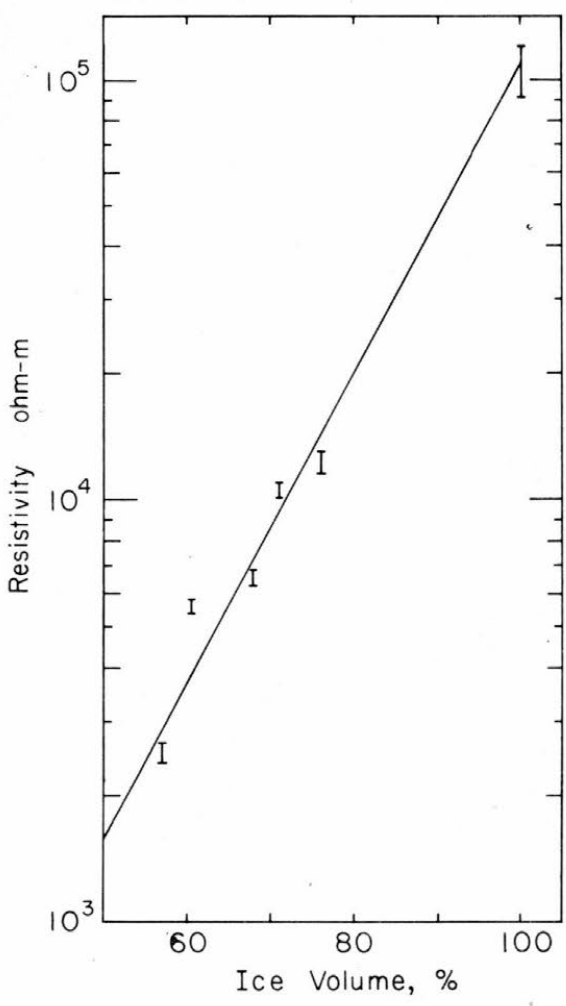

Figure 7. The relation between ice content and resistivity measured insitu in the walls of the USA CRREL tunnel in Fox, Alaska. mineralogical composition, as well as temperature and water content of the rocks. Some in-situ measurements on rock types in the Fairbanks area were made at VLF on the ground. The Birch Creek schist showed resistivities ranging from 100 to $2000 \mathrm{ohm}-\mathrm{m}$, and the local intrusive rocks displayed resistivities in excess of $2000 \mathrm{ohm}-\mathrm{m}$ (Sellmann et al. 1974). Extensive tables on rock resistivities, in general, are given by Parkhomenko (1967), Heiland (1940) and Keller et al. (1970).

\section{THEORY AND METHOD}

In the Barringer E-phase method, the electrical properties of the ground are derived from measurements of the groundwave of vertically polarized radiowaves. This technique has been known for a long time and several investigators have reported on its use (Eliassen 1956, King 1968, Blomquist 1970, Keller et al. 1970, Hoekstra and McNeill 1973).

The electromagnetic field vectors of the groundwave at grazing incidence are shown in Figure 8. There is at the surface a horizontal electric field $E_{x}$ in the direction of propagation, a horizontal magnetic field $H_{\mathrm{y}}$ perpendicular to the direction of propagation, and a vertical electric field $E_{\mathrm{z}}$. Both $E_{\mathrm{x}}$ and $H_{\mathrm{y}}$ are continuous across the ground surface. Thus, at grazing incidence a wave prop-

agates vertically into the ground with field vectors $E_{\mathrm{x}}$ and $H_{\mathrm{y}}$. Beneath the surface of a homogeneous ground the horizontal electric field components decay with increasing depth $z$ as

$$
E_{\mathrm{x}}(z)=E_{\mathrm{x}}(0) \mathrm{e}^{-\gamma z}
$$

where $\gamma$ is the propagation constant in the earth given by (e.g. Kraichman 1970):

$$
\gamma=\left[j\left(\frac{\mu_{0} \omega}{\rho}\right)-\epsilon_{\mathrm{r}} \epsilon_{0} \mu_{0} \omega^{2}\right]^{1 / 2}
$$

where $\quad j=(-1)^{1 / 2}$

$\mu_{0}=$ magnetic permeability of free space $=4 \pi \times 10^{-7}$ henry $/ \mathrm{m}$

$\epsilon_{0}=$ permittivity of free space $=1 / 36 \pi \times 10^{9} \mathrm{farad} / \mathrm{m}$

$\omega=$ angular frequency $(\mathrm{rad} / \mathrm{s})$

$\rho=$ ground resistivity (ohm-m)

$\epsilon_{\mathrm{r}}=$ ground relative dielectric constant.

The terms $j\left(\mu_{0} \omega / \rho\right)$ and $\left(\epsilon_{\mathrm{r}} \mathrm{t}_{0} \mu_{0} \omega^{2}\right)$ in eq 2 are the conduction currents and displacement currents, respectively, and in many situations encountered in the ground and at frequencies below $10^{6} \mathrm{~Hz}$ 


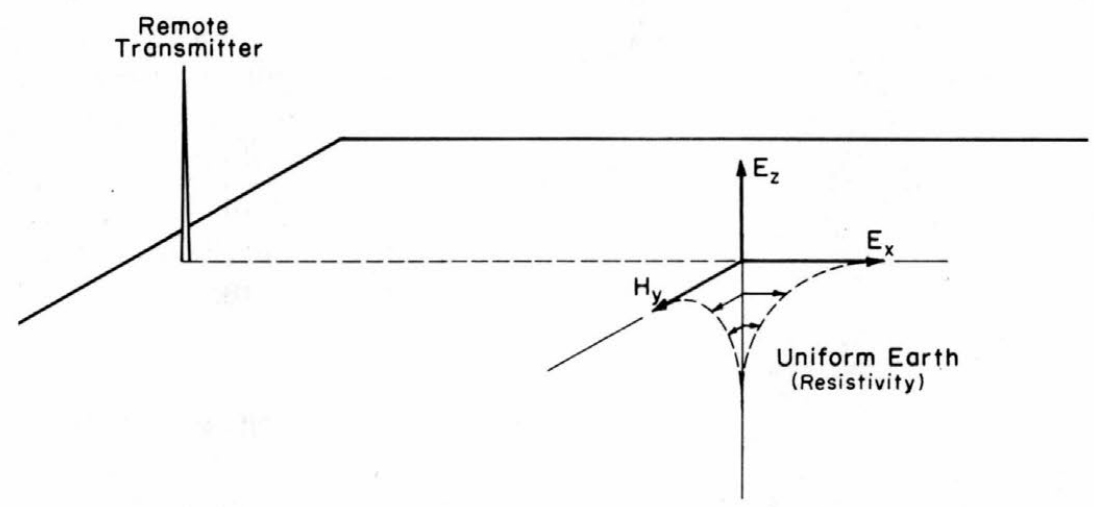

Figure 8. Electromagnetic field components of a vertically polarized radio surface wave.

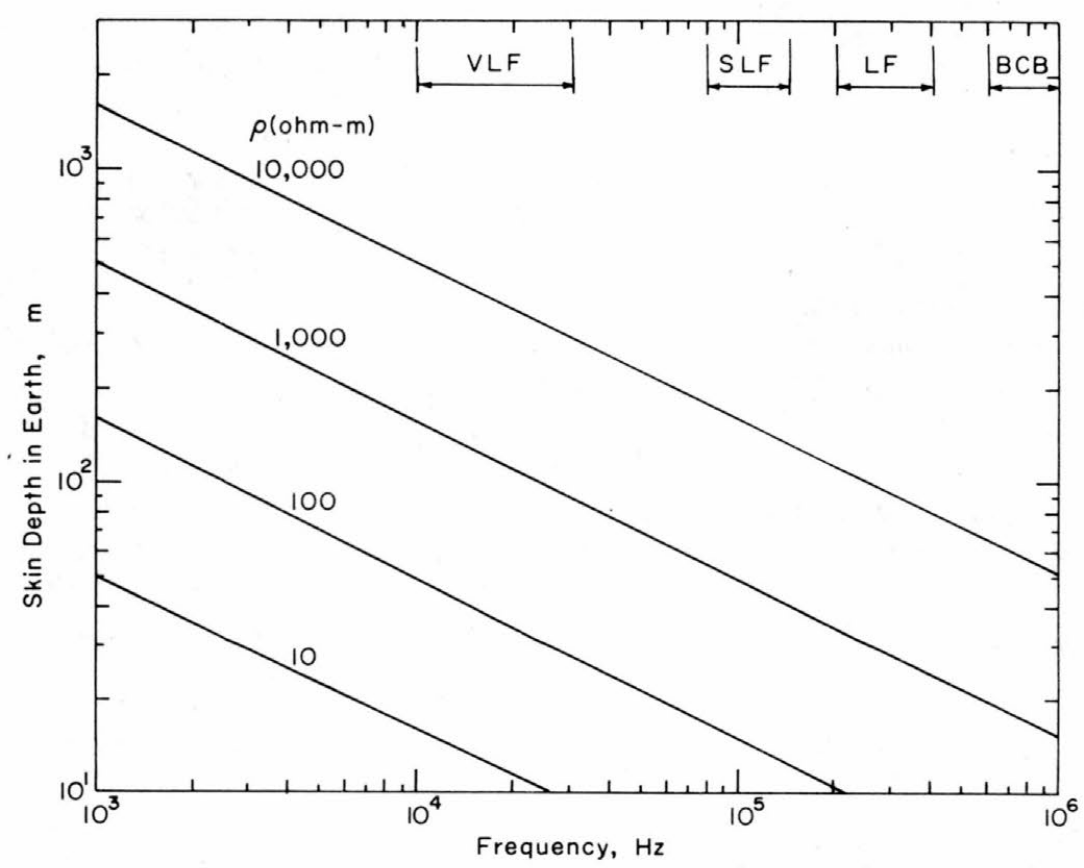

Figure 9. Skin depth of electromagnetic plane waves as a function of frequency and ground resistivity.

$$
\left|\frac{\mu_{0} \omega}{\rho}\right| \gg\left|\epsilon_{\mathrm{r}} \epsilon_{0} \mu_{0} \omega^{2}\right| .
$$

The skin depth of the wave propagating into the ground is defined as the depth in which the electromagnetic field decays to $e^{-1}$ of its value at the surface. The skin depth $\delta$ is given by

$$
\delta=\operatorname{Re}(y)^{-1} \approx\left(\frac{2 \rho}{\mu_{0} \omega}\right)^{+1 / 2} .
$$

where $\operatorname{Re}(\gamma)$ indicates the real part of the propagation constant. 
The skin depth is a significant parameter in that it indicates the effective depth of electromagnetic wave penetration into the earth, and thus the effective depth to which resistivity is sensed, since large changes in resistivity occurring at depths greater than 1 skin depth do not greatly affect the field vectors at the earth's surface. Figure 9, which shows the behavior of the skin depth as a function of frequency and ground resistivity, illustrates that the effective depth of investigation can be altered by changing the frequency. Conversely, a survey may be made with several frequencies, simultaneously sensing the resistivity to selected depths.

Local changes in the electrical properties of the ground cause perturbations in amplitude and phase of the horizontal electric field. Measurements of these perturbations at or near the surface are the basis of the method. Perturbations in $E_{z}$ and $H_{y}$ occur in the vicinity of fairly abrupt lateral changes in the conductivity of the earth, but these fields over a limited area provide no information about the properties of the earth when gradual variations take place. However, the horizontal electric field is dependent on the electrical properties of a horizontally stratified ground and is useful in mapping gradual variations in resistivity and thickness of flat-lying strata (Frischknecht 1973).

Diurnal and temporal fluctuations in field strength occur in accordance with events in the ionosphere. To eliminate the effects of temporal variations in field strength, the horizontal electric field $E_{\mathrm{x}}$ is normalized by the orthogonal component of the magnetic field $H_{\mathrm{y}}$ to obtain the surface impedance $Z_{\mathrm{s}}$

$$
Z_{\mathrm{s}}=\frac{E_{\mathrm{x}}}{H_{\mathrm{y}}}
$$

or by the vertical electric field $E_{\mathrm{z}}$ to obtain the wave tilt $W$

$$
W=\frac{E_{\mathrm{x}}}{E_{\mathrm{z}}} .
$$

This normalization by $H_{\mathrm{y}}$ or $E_{\mathrm{z}}$ works for resistivity mapping because $E_{\mathrm{z}}$ and $H_{\mathrm{y}}$ are virtually unaffected by gradual resistivity changes. Both $Z_{\mathrm{s}}$ and $W$ are characteristic of the refracted wave penetrating into the earth at the location of the receiver and are independent of the resistivity variations found in the path traveled by the wave from transmitter to receiver.

The theory which relates the measurement of the surface impedance and the wave tilt to the resistivity of homogeneous or layered ground has been well developed (e.g. Wait 1962, Kraichman 1970). For a homogeneous half space $Z_{\mathrm{s}}$ is given by

$$
Z_{\mathrm{s}}=\eta\left(j-\frac{\gamma_{0}^{2}}{\gamma^{2}} \sin ^{2} \theta\right)
$$

where $\quad \eta=\left[j \mu_{0} \omega /\left(1 / \rho+j_{\mathrm{r}_{\mathrm{r}}} \epsilon_{0} \omega\right)\right]^{1 / 2}$, the characteristic impedance of ground

$$
\begin{aligned}
\gamma_{0} & =\text { propagation constant of free space }\left(\mu_{0} \epsilon_{0}\right)^{1 / 2} \\
\rho & =\text { resistivity of ground (ohm-m) } \\
\theta & =\text { angle of incidence. }
\end{aligned}
$$

For all values of frequency and dielectric constants likely to occur 


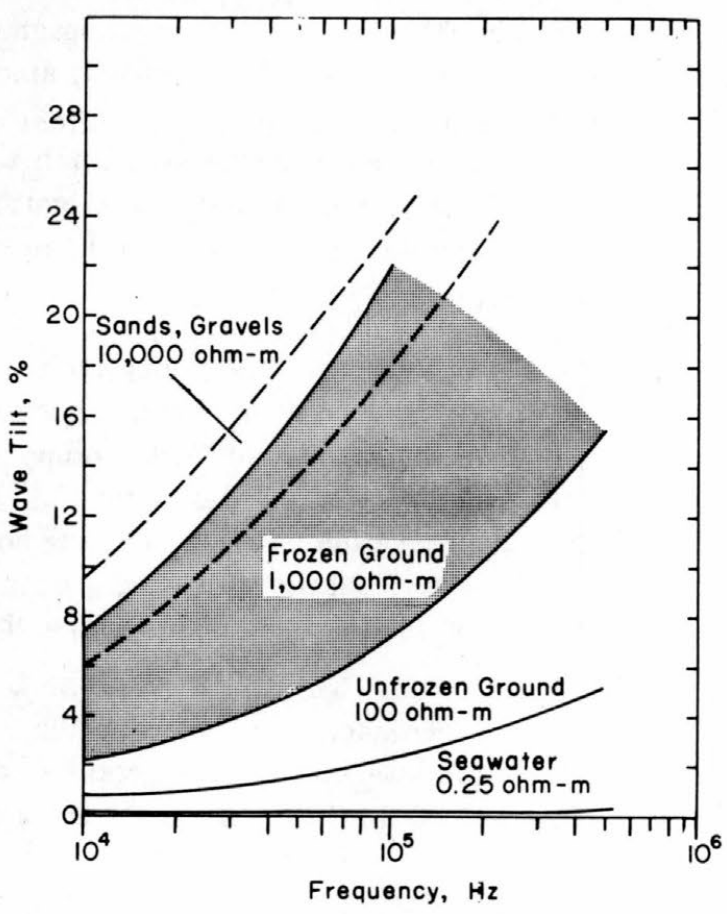

Figure 10. Magnitude of wave tilt as a function of frequency for resistivity variations over typical homogeneous earth.

$$
\gamma^{2} \gg \gamma_{0}^{2}
$$

so that eq 7 , at grazing incidence, reduces to

$$
Z_{\mathrm{s}}=j \eta
$$

The relation between the wave tilt $W$ and the surface impedance is given by

$$
W=\frac{E_{\mathrm{x}}}{E_{\mathrm{z}}}=\frac{E_{\mathrm{x}} / H_{\mathrm{y}}}{E_{\mathrm{z}} / H_{\mathrm{y}}}=\frac{Z}{\eta_{0}}=\left(\frac{\epsilon_{0}}{\mu_{0}}\right)^{1 / 2} Z_{\mathrm{s}}
$$

where $\eta_{0}$, the characteristic impedance of free space, has been substituted for the ratio $E_{\mathrm{z}} / H_{\mathrm{y}}$.

In many situations, conductive currents dominate displacement currents, so that eq 9 can be approximated by

$W=\left(\frac{\epsilon_{0}}{\mu_{0}}\right)^{1 / 2}\left(j \rho \mu_{0} \omega\right)^{1 / 2}=(1+j)\left(\frac{\epsilon_{0} \rho \omega}{2}\right)^{1 / 2}$

The wave tilt has, thus, equal in-phase and quadrature-phase components for homogeneous

ground if displacement currents can be neglected. This also means that the phase of $E_{\mathrm{x}}$ leads that of $E_{\mathrm{z}}$ by $45^{\circ}$. Figure 10 gives the wave tilt in percentage as a function of frequency for resistivity variations encountered on earth. The wave tilt is in most instances less than $10 \%$, so that $E_{z}$ is often at least an order of magnitude larger than $E_{\mathrm{x}}$.

In the E-phase equipment, $E_{\mathrm{x}}$ and $E_{\mathrm{z}}$ are measured by two perpendicular short dipole antennas. In an aircraft, roll of the plane frequently causes leakage of $E_{\mathrm{z}}$ into the horizontal antenna, but all of the leaked signal is in phase. Therefore, by measuring the quadrature-phase component of $W$ and basing the computation of resistivity only on that component, errors caused by leakage are avoided. Hence, resistivity $\rho$ can be computed from:

$$
\rho=\frac{2 W_{\text {quad }}^{2}}{\epsilon_{0} \omega}
$$

where $W_{\text {quad }}$ indicates the quadrature-phase component of $W$.

Many instances are encountered in which the in-phase and quadrature-phase components of the wave tilt are unequal. In these instances an apparent resistivity $\rho_{\mathrm{a}}$ is defined by eq 11. It is called an apparent resistivity because when the in-phase and quadrature-phase components of the wave tilt differ $\rho_{\mathrm{a}}$ is unequal to the true resistivity of the ground. Often the true resistivity can be arrived at by computation.

In permafrost situations, high resistivity values can be encountered, and neglecting displacement currents can result in errors in the computation of $\rho_{\mathrm{a}}$; this error is, moreover, amplified by using the quadrature-phase component only. Figure 11 shows the ratio of the true value of resistivity $\rho_{\text {real }}$ and $\rho_{\mathrm{a}}$ as a function of frequency for several values of $\rho_{\text {real }}$ for homogeneous ground; a 


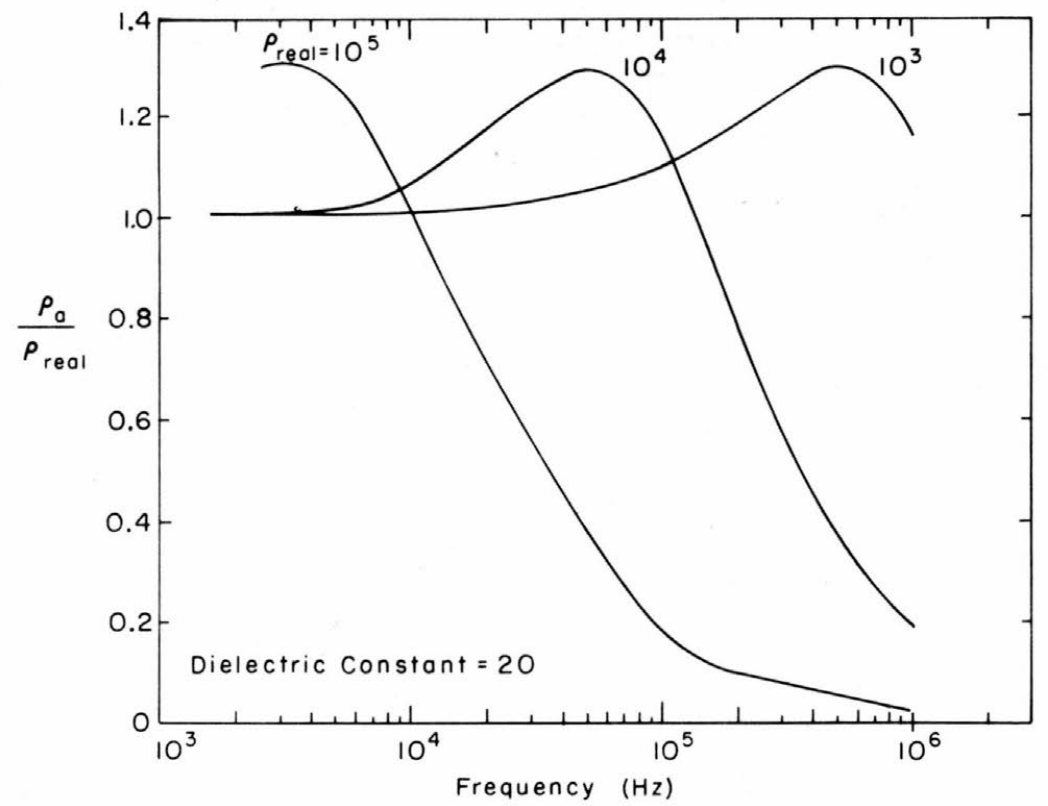

Figure 11. The ratio of apparent resistivity, computed from eq 11 for homogeneous ground, and true resistivity.

dielectric constant of 20 was assumed in all situations. For homogeneous ground with a resistivity of $1000 \mathrm{ohm}-\mathrm{m}$, there is a close correspondence between $\rho_{\mathrm{a}}$ and $\rho_{\text {real }}$ at VLF, but at broadcast band (BCB) frequency $\rho_{\mathrm{a}}$ can exceed $\rho_{\text {real }}$ by as much as a factor 1.3. At higher resistivities, the errors become progressively worse, and at a resistivity of $10^{5} \mathrm{ohm}-\mathrm{m}$, the E-phase yields at $200 \mathrm{kHz}$ a resistivity of about $10^{4} \mathrm{ohm}-\mathrm{m}$. Fortunately, uniform ground with resistivity values in excess of $10^{4} \mathrm{ohm}-\mathrm{m}$ is not common, and often there is little practical use for differentiating between resistivities in excess of $5000 \mathrm{ohm}-\mathrm{m}$.

When the earth is not homogeneous, but layered, and consists of several layers of different resistivities and thicknesses, the surface impedance can be written as the product of the characteristic impedance of the surface layer $\eta_{1}$ and a correction factor $Q$ accounting for layering (e.g. Kraichman 1970).

$$
Z=\eta_{1} \cdot Q
$$

For example, for a ground that is stratified in three layers, $Q$ takes the form

$$
Q=\frac{\gamma_{1} \hat{Q}+\gamma_{2} \tanh \gamma_{1} d_{1}}{\gamma_{2}+\gamma_{1} \widehat{Q} \tanh \gamma_{1} d_{1}}
$$

where

$$
\widehat{Q}=\frac{\gamma_{2}+\gamma_{3} \tanh \gamma_{2} d_{2}}{\gamma_{3}+\gamma_{2} \tanh \gamma_{2} d_{2}}
$$

and $\gamma_{1}, \gamma_{2}$, and $\gamma_{3}$ are the propagation constants of the three layers; $d_{1}$ and $d_{2}$ are the thicknesses of media 1 and 2 ; and the thickness of medium 3 is considered of infinite depth. 


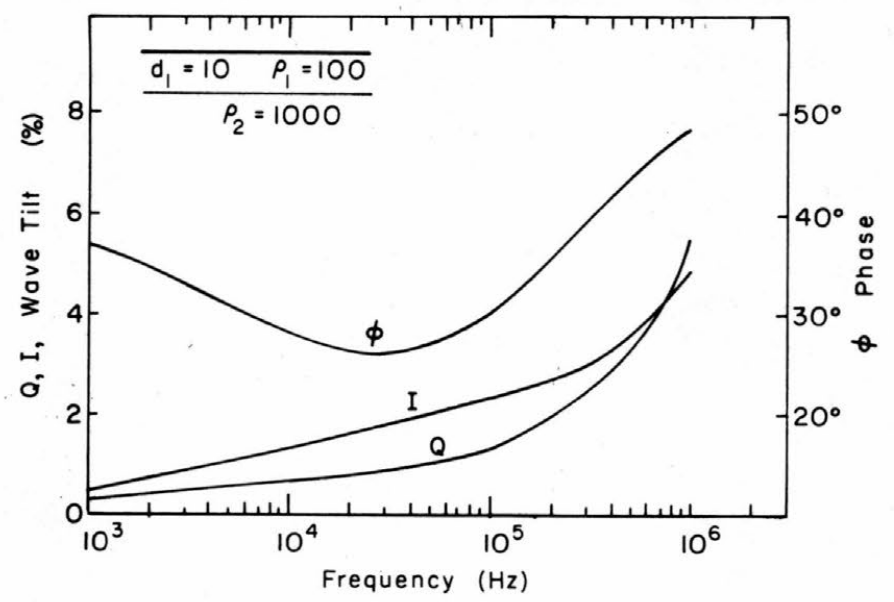

a. $\rho_{1} / \rho_{2}=0.1$.

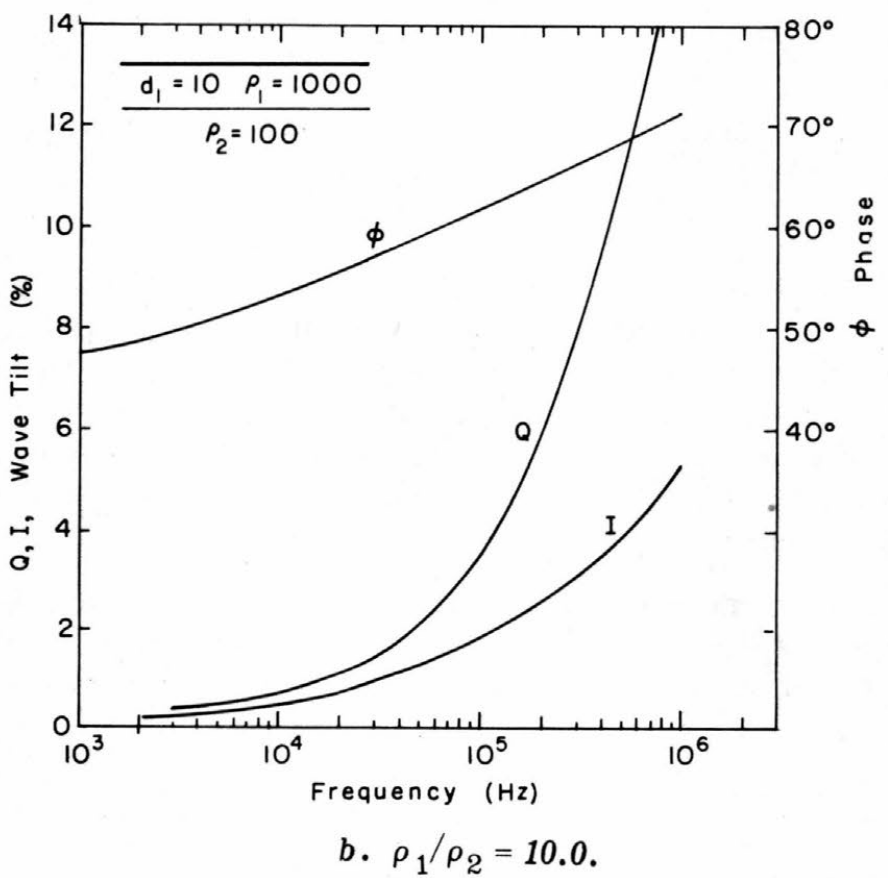

Figure 12. The computed in-phase $I$ and quadraturephase $Q$ components of the wave tilt and its phase $\phi$ as a function of frequency for the layered ground conditions shown.

The wave tilt over layered ground has unequal in-phase and quadrature-phase components; in Figure 12 values of the in-phase $I$ and quadrature-phase $Q$ components of $W$ and its phase $\phi$ are given for typical two-layer situations. In one case, the ratio of the resistivity in media 1 and 2 , $\rho_{1} / \rho_{2}$, is 0.1 , typical of sites where soil overlies a granitic bedrock, or where silt of clay overlies a gravel deposit; in the other case, $\rho_{1} / \rho_{2}$ is 10 , which is, for example, found in permafrost situations.

The phase of $W$ is quite diagnostic: when $\rho_{1}>\rho_{2}$, the phase is greater than $45^{\circ}$; and as a corollary, when $\rho_{1}<\rho_{2}, \phi$ is less than $45^{\circ}$. Unfortunately, the airborne E-phase system does not measure the phase of $W$. 


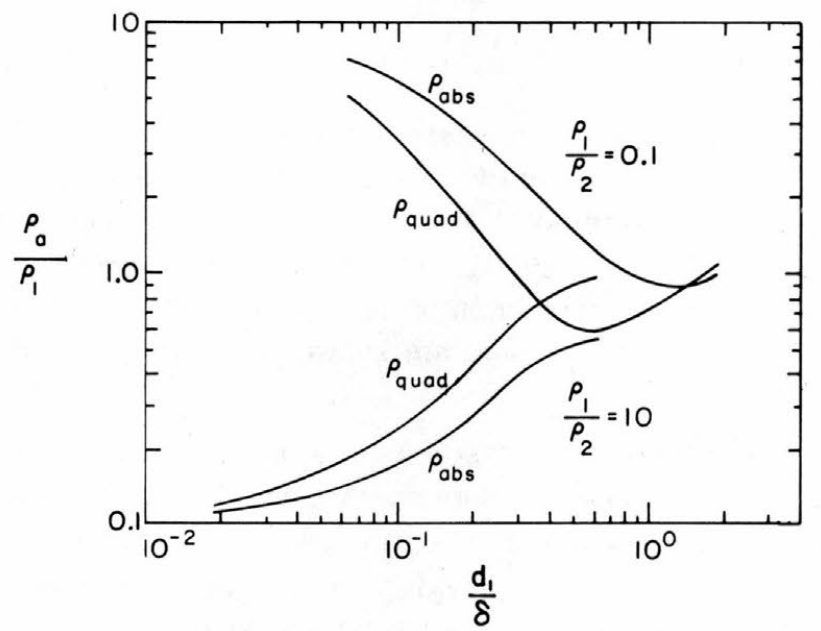

Figure 13. The ratio of computed apparent resistivity $\rho_{\mathrm{a}}$ and the resistivity of the surface layer $\rho_{1}$ as a function of thickness of first layer in terms of skin depth.

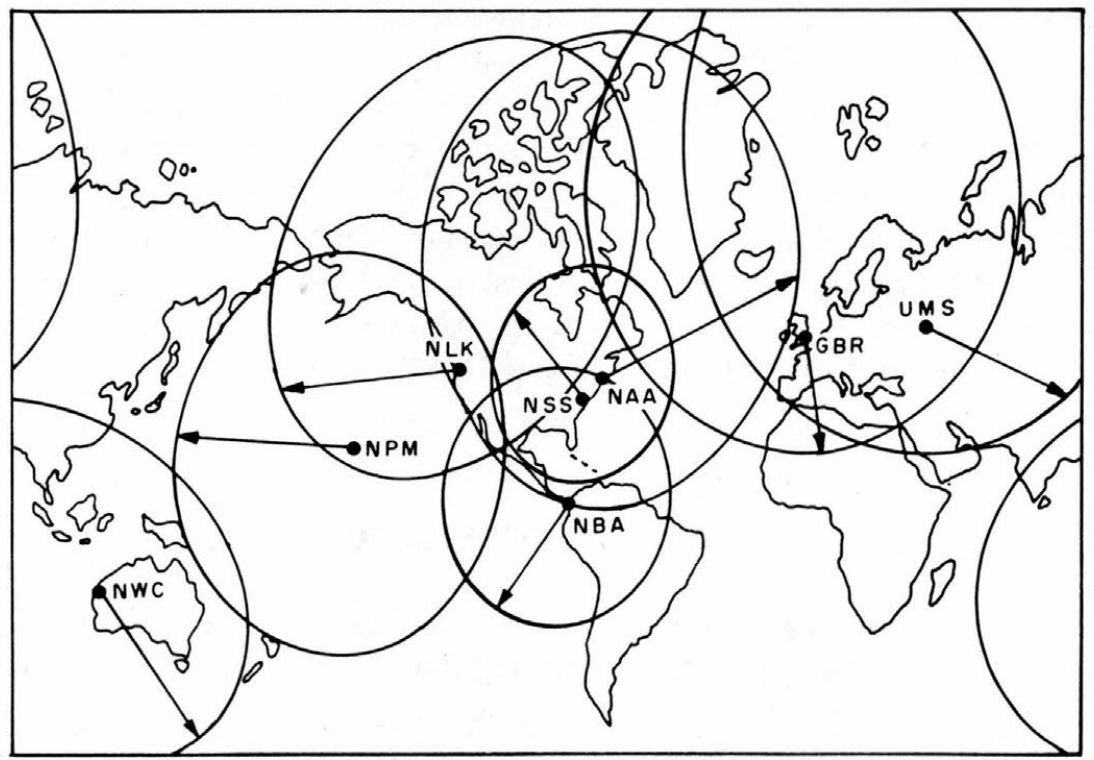

Figure 14. Coverage for well known $V L F$ stations. Circles enclose approximate areas where field strengths exceed $100 \mu \mathrm{V} / \mathrm{m}$.

\begin{tabular}{llc}
\multicolumn{1}{c}{ Call } & \multicolumn{1}{c}{ Location } & Frequency $(\mathrm{kHz})$ \\
\cline { 3 - 3 } NAA & Cutler, Maine & 17.8 \\
NLK & Jim Creek, Washington & 18.6 \\
NSS & Annapolis, Maryland & 21.4 \\
NBA & Balboa, Canal Zone, Panama & 24.0 \\
GBR & Rugby, England & 16.0 \\
UMS & Gorky, USSR & 17.15 \\
NWC & Northwest Cape, Australia & 23.3 and 15.5 \\
NPM & Lualualei, Hawaii & 23.4
\end{tabular}

The apparent resistivity of a two-layer ground measured with the system depends on the frequency; in particular, it depends on the ratio of the thickness of the first layer and the skin depth of the radiation in the first layer. The apparent resistivities of two-layer situations are shown as a function of the ratio $d_{1} / \delta$ in Figure 13. In Figure 13 the apparent resistivities are computed in two ways: $\rho_{\text {quad }}$, based on the quadrature phase component of $W$; and $\rho_{\text {abs }}$, based on $|W|$. The value of $\rho_{\mathrm{a}}$ is generally bounded by the resistivities of the two layers, although $\rho_{\text {quad }}$ falls at cer- 
tain frequencies below the value of $\rho_{1}$ for $\rho_{1} / \rho_{2}=0.1$. The trends in the values of $\rho_{\text {quad }}$ andi, $p_{\text {abs }}$ are similar: $\rho_{\text {abs }}>\rho_{\text {quad }}$ for $\rho_{1} / \rho_{2}=0.1$ and the opposite occurs for $\rho_{1} / \rho_{2}=10$.

Since both $\rho_{\text {quad }}$ and $\rho_{\text {abs }}$ are apparent resistivities, and as long as it is understood that an interpretation requires fitting a solution to the experimental data, the behavior of the curves in Figure 13 shows that $\rho_{\text {quad }}$ is a satisfactory parameter with which to characterize the resistivity of a layered medium. A multifrequency survey yields 2 or 3 experimental points and a satisfactory interpretation of the layering in the ground can often be made. If, moreover, through other independent measurements the values of $\rho_{1}$ and $\rho_{2}$ are known, a realistic interpretation of the ground profile can often be made.

The existence of a strong theoretical base for the E-phase method is also used in preliminary work to decide on the merits of an airborne survey. A general idea of the range of resistivities and geologic conditions in an area can be obtained on the ground in a matter of a few days, and using these resistivities in computer modeling, an evaluation can be made of the ability of the E-phase method to meet certain geotechnical objectives. A typical example of such an evaluation is the work in the area of the Tennessee-Tombigbee River (Hoekstra and Delaney 1973).

Surface waves of the type described above are generated by vertical dipole antennas situated on the earth's surface. Powerful VLF transmitters situated around the world provide sufficient field strength for wave tilt measurements in the range of $15-25 \mathrm{kHz}$ over a large part of the land area of the world. Figure 14 shows coverage for well known VLF stations. The circles around each station indicate the areas in which there is sufficient field strength for measurements. In Alaska the station NLK operating at $18.6 \mathrm{kHz}$, and situated in Jim Creek, Washington, was used. Military transmitters are often found within the frequency band 50 to $100 \mathrm{kHz}$, and navigational transmitters are often found within the frequency band 200 to $400 \mathrm{kHz}$. Thus, in most instances surveys can be made at three frequencies ideally separated for effective resistivity sounding. Moreover, in the band 200 to $400 \mathrm{kHz}$, inexpensive local transmitters can be erected near the survey site, if necessary.

\section{THE E-PHASE SYSTEM}

A horizontal and a vertical antenna are installed in a cone extending from the nose of a short takeoff and landing (STOL) aircraft (Britton Norman Islander) as shown in Figure 15. The E-phase

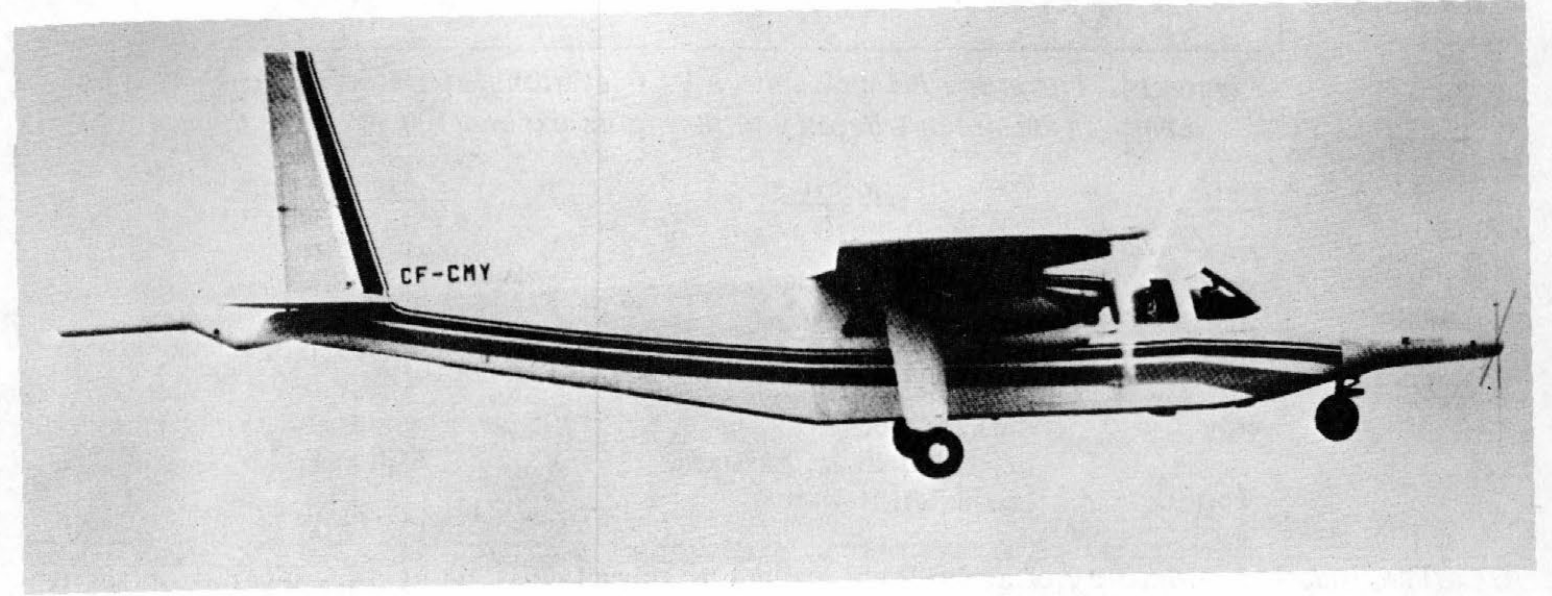

Figure 15. STOL aircraft (Britton Norman Islander) with $E$-phase antennas in the nose cone and a magnetometer stinger on the tail. 
instrument is capable of measuring the vertical and horizontal components of the electric field in four frequency ranges. Of the four ranges, only three are used simultaneously on any one survey. The instrument can be continuously tuned within the frequency bands, and phase-lock loop circuitry is utilized to keep the receiver on the selected frequency. The frequency bands are as follows:

$$
\begin{array}{rc}
\text { VLF - range: } & 15-25 \mathrm{kHz} \\
\text { SLF - range: } & 70-140 \mathrm{kHz} \\
\text { LF - range: } & 200-400 \mathrm{kHz} \\
\text { BCB - range: } & 550-1100 \mathrm{kHz}
\end{array}
$$

After amplification, the signals are recorded on an analogue chart and on magnetic tape. The following components can be measured at each frequency:

$$
\begin{aligned}
& E_{\mathrm{z}}(I)=\text { In-phase component of the vertical electric field. } \\
& E_{\mathrm{x}}(I)=\text { In-phase component of the horizontal electric field. } \\
& E_{\mathrm{x}}(Q)=\text { Quadrature-phase component of the horizontal electric field. }
\end{aligned}
$$

\section{Calibration}

Calibration of the $E_{\mathrm{x}}(Q)$ and $E_{\mathrm{x}}(I)$ channel is accomplished by tilting the horizontal antenna.
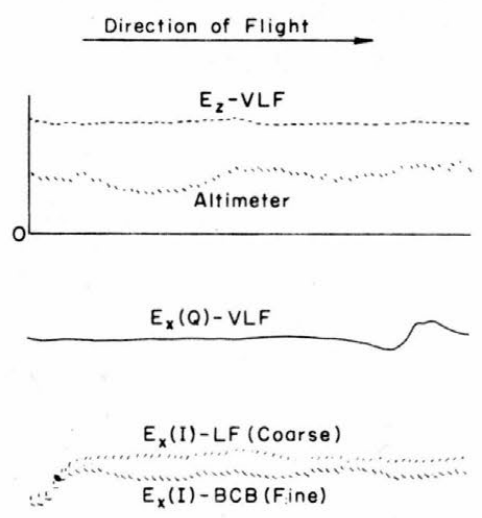

-- Manual Fiducials
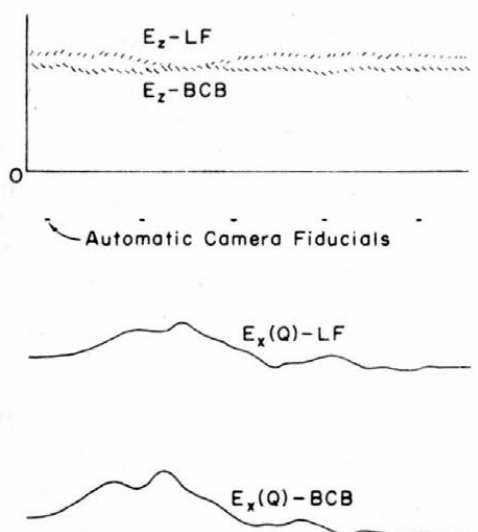

Figure 16. Sample record of the analogue chart used in flight recorder. The multiplexing of the $\mathrm{E}_{z}$ and $\mathrm{E}_{\mathrm{x}}$ channels is shown in coarse and fine traces.
The $E_{\mathrm{x}}(Q)$ channel is switched to read $E_{\mathrm{x}}(I)$ and the antenna is tilted $20^{\circ}$. The signal picked up in the tilted antenna is $E_{\mathrm{z}}$ $\sin 20^{\circ}$, and the percentage of wave tilt $W$ it represents is:

$$
W=\frac{E_{\mathrm{z}} \sin 20^{\circ}}{E_{\mathrm{z}}} \times 100=34 \% .
$$

The $E_{\mathrm{x}}(I)$ and $E_{\mathrm{x}}(Q)$ channel RF gains are set during calibration to give a reasonable deflection on the chart recorder for the $20^{\circ}$ rotation of the antenna, and changes in output gain settings during flight are recorded on the analogue charts. The calibration of the signal strength of the horizontal antenna in terms of wave tilt is dependent on the signal strength of $\mathrm{E}_{\mathrm{z}}(I)$. If $E_{\mathrm{z}}(I)$ changes during the course of the flight, then a correction must be made accordingly. The output gain at the $E_{\mathrm{x}}(I)$ channel during calibration is directly proportional to $E_{\mathrm{z}}$.

\section{Analogue recorder}

The signals are recorded on a six-channel recorder. A built-in multiplexer has the capability in this system of multiplexing all 6 of the chart recorder channels, thus doubling its recording capability. This multiplexer has been set to switch at approximately twice per second with a mark space ratio of approximately 5 to 1 . This gives two very distinct traces and removes a great deal of confusion (traces are defined as fine or coarse). A sample record of the analogue chart (Fig. 16) indicates the designation of each trace.

\section{Magnetic recorder}

The data generated during a survey flight are also recorded on a 24-channel magnetic tape recorder manufactured by 
Table II. Channel designations of magnetic tape recorder.

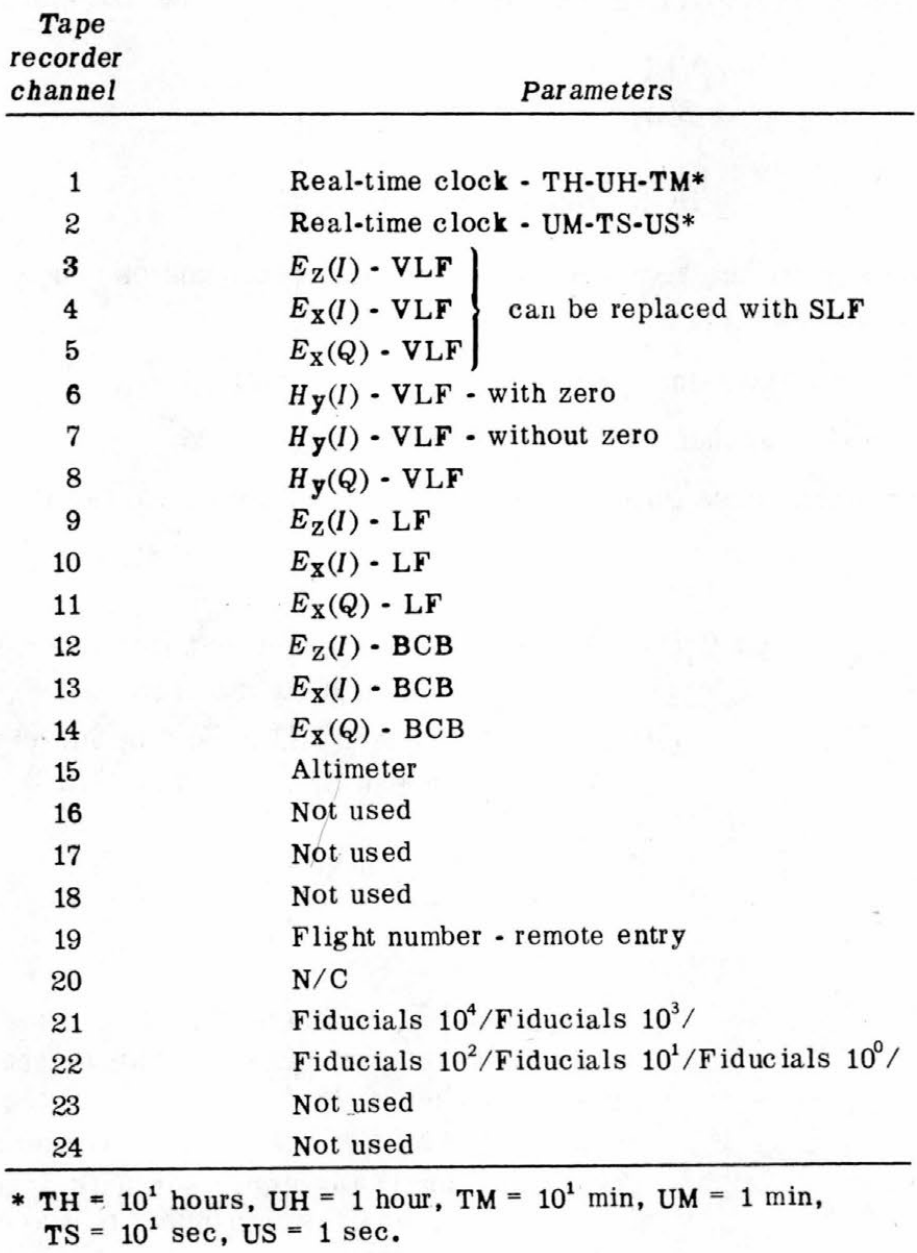

Metrodata. Each channel on the tape recorder records dipolar information in a three-digit format plus sign information. Thus, the sensitivity of the system is one part in 999 . All $9 \mathrm{E}$-phase channels and the altimeter are recorded on the tape.

The tape-recorder has a clock which is reset to local real time at the start of a flight and increments in seconds. It is internally formatted onto the tape and appears on channels 1 and 2. Channel 1 records 10 's of hours/unit hours/10's of minutes, and channel 2 records unit minutes/10's of seconds/unit seconds.

The fiducial system is based around a 5-digit clock. Parallel with this clock, a 5-digit counter is mounted in front of the navigator and a 5-digit counter is mounted in the camera to mark the film. The 5 digits of the fiducial information are also recorded directly onto the tape. The entire system is binary code digital (BCD) generated. The drive information for the clock comes from an intervalometer which gives a clock pulse every 1.1 seconds. Each pulse increments the clock by one count and cycles the tape recorder. Every tenth pulse flashes the fiducial count onto the flight path camera film and places a fudicial on the chart recorder. Channel 19 is used to indicate the flight number, which is entered manually.

The navigator has the capability to indicate on or of line and to place manual fudicials on the chart recorder and on the flight path recovery film. The designations of channels are listed in Table II. 


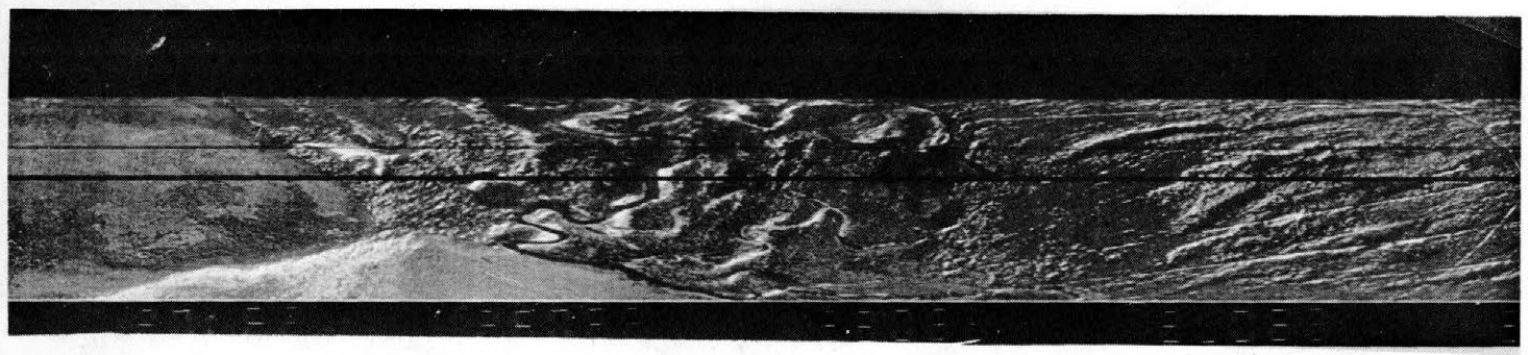

Figure 17. Typical photo strip from flight camera on plane, from an altitude of approximately $60 \mathrm{~m}$. Landmarks such as rivers and roads were used to place flight lines correctly on base map.

\section{Flight path recovery camera}

A 35-mm flight path camera. manufactured by Flight Research is used to record the flight path of the survey aircraft. The camera is equipped with a fish-eye lens and was modified to give continuous strip film. An example of a photo strip is shown in Figure 17. Timing marks as well as the manual fiducials made by the navigator are placed on the film.

\section{Altimeter}

The height of the aircraft above ground is determined by a Bonzer radio altimeter. The output of this altimeter is recorded on the analogue chart recorder as well as on magnetic tape.

\section{DATA REDUCTION}

\section{Horizontal control}

The position of the survey aircraft along the survey lines is determined from the 35 -mm flight path recovery film. Recognizable landmarks on the film are identified on the photomosaic or topographic base, and the appropriate fiducials are identified on the analogue record and on magnetic tape. A straight flight path between recognized landmarks and a constant speed between fiducial points are assumed.

\section{Computation of apparent resistivity}

The first step in the calculation of the apparent resistivity is the determination of the ratio $E_{\mathrm{x}}(Q) / E_{\mathrm{z}}(I)$ from calibration data and flight data. During the survey a quick approximation of resistivity can often be made from the analogue chart. In the determination of $E_{\mathrm{x}}(Q) / E_{\mathrm{z}}(I)$, several factors must be taken into account:

1. The direction of the flight line with respect to the direction towards the transmitter. The horizontal component is a sinusoidal function of the coupling angle between the flight direction and the direction to the transmitter. This is illustrated in Figure 18, in which data from groundbased measurements of in-phase $E_{\mathrm{x}}(I)$ and quadrature-phase $E_{\mathrm{x}}(Q)$ are plotted as a function of compass bearing (instrument magnetic bearing). Since the horizontal antenna is at $90^{\circ}$ to the flight direction, maximum coupling occurs when the angle between flight line and the direction to the transmitter is $90^{\circ}$. 


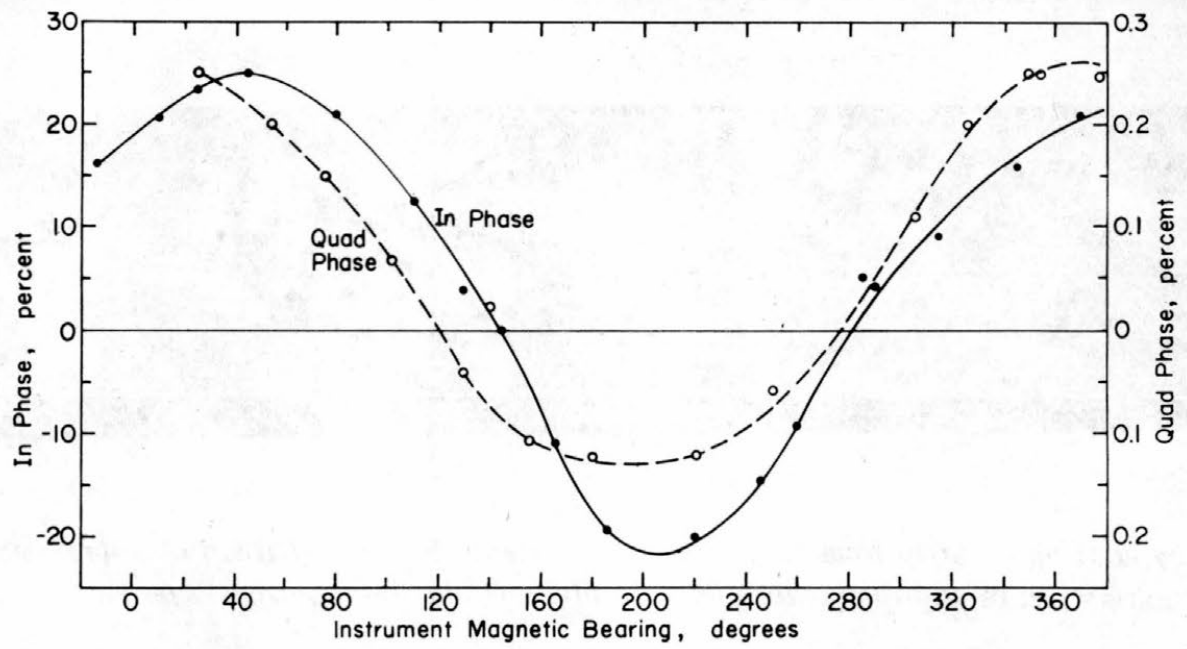

Figure 18. 'Ground measurements of the in -phase and quadrature-phase components of $\mathrm{W}$ as a function of compass bearing.

2. The gain settings during calibration and operation.

3. The field strength of the vertical electric field $E_{\mathrm{z}}$ during calibration and operation. relation:

Taking all these factors into account, the ratio $E_{\mathrm{x}}(Q) / E_{\mathrm{z}}$ is computed from the following

$$
\frac{E_{\mathrm{x}}(Q)}{E_{\mathrm{z}}}=\frac{0.34}{E_{\mathrm{x}}(Q) \text { cal }} \times \frac{A \text { cal }}{A \text { oper }} \times \frac{E_{\mathrm{z}} \text { cal }}{E_{\mathrm{z}} \text { oper }} \times \frac{E_{\mathrm{x}}(Q) \text { oper }}{\sin \alpha}
$$

where $E_{\mathrm{x}}(Q) \mathrm{cal}=$ the quadrature-phase component of $E_{\mathrm{x}}$ at calibration (in millimeters on the analogue record)

$A$ cal $=$ attenuator setting during calibration

$A$. oper $=$ attenuator setting during survey

$E_{\mathrm{z}} \mathrm{cal}=E_{\mathrm{z}}$ at time of calibration of $E_{\mathrm{x}}(Q)$ cal (in millimeters on the analogue record)

$E_{\mathrm{z}}$ oper $=E_{\mathrm{z}}$ during the survey at the position where the resistivity is being calculated (in millimeters on the analogue record)

$E_{\mathrm{x}}(Q)$ oper $=E_{\mathrm{x}}(Q)$ at the position where the resistivity is calculated (in millimeters on the analogue record)

$\alpha=$ the angle between the average true azimuth of a flight line and the true azimuth from the center of the survey area to the transmitter. In case of maximum coupling $\alpha=90^{\circ}\left(\sin 90^{\circ}=1\right)$.

These quantities are registered as volts on the magnetic tape or, when determined from the analogue records, in millimeters. When the transmitters are close to the survey area, as was the case in some BCB and LF surveys, the value of $\sin \alpha$ may vary along the flight line. This is taken into consideration during computation; the true azimuth of the flight line is determined between fiducial points and a new $\alpha$ is determined for each section of the flight line, but between fiducials $\alpha$ is assumed constant. For a given calibration and $\alpha$, eq 10 reduces to

$$
\frac{E_{\mathrm{x}}(Q)}{E_{\mathrm{z}}}=C \frac{E_{\mathrm{x}}(Q) \text { oper }}{E_{\mathrm{z}} \text { oper }}
$$

where 
Table III. Survey specifications and transmitter data.

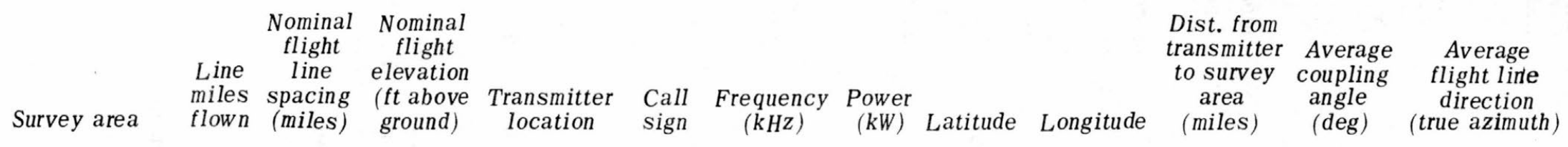

\section{Moose Creek Dam}

\begin{tabular}{|c|c|c|c|c|c|c|c|c|c|c|c|}
\hline VLF & 206 & 0.125 & 250 & Jim Creek & NLK & 18.6 & 250 & $48^{\circ} 12^{\prime} \mathrm{N}$ & $121^{\circ} 55^{\prime} \mathrm{W}$ & 1400 & 71 \\
\hline LF & 206 & 0.125 & 250 & Fairbanks & FI & 257 & - & $64^{\circ} 50^{\prime} \mathrm{N}$ & $147^{\circ} 29^{\prime} \mathrm{W}$ & 10 & 84 \\
\hline $\mathrm{BCB}$ & 206 & 0.125 & 250 & Fairbanks & KFAR & 660 & 10 & $64^{\circ} 52^{\prime} \mathrm{N}$ & $147^{\circ} 49^{\prime} \mathrm{W}$ & 20 & 89 \\
\hline
\end{tabular}

\section{Chena Hot}

\section{Springs Road}

NE-SW lines

VLF

$\mathrm{N}-\mathrm{S}$ lines

LF

$\mathrm{BCB}$

\section{Goldstream}

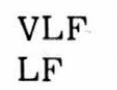

LF

Site 2

VLF
LF
BCB

$\begin{array}{lll}27 & 0.25 & 250 \\ & & \\ 27 & 0.125 & 250 \\ 27 & 0.125 & 250 \\ & & \\ & & \\ 234 & 0.25 & 250 \\ 234 & 0.25 & 250 \\ 234 & 0.25 & 250 \\ & & \\ & & \\ 174 & 0.25 & 250 \\ 174 & 0.25 & 250 \\ 174 & 0.25 & 250\end{array}$

$\begin{array}{llcc}\text { Jim Creek } & \text { NLK } & 18.6 & 250 \\ & & & \\ \text { Fairbanks } & \text { FOX } & 356 & 0.04 \\ \text { Fairbanks } & \text { KFAR } & 660 & 10 \\ & & & \\ & & & \\ \text { Jim Creek } & \text { NLK } & 18.6 & 250 \\ \text { Fairbanks } & \text { FI } & 257 & - \\ \text { Fairbanks } & \text { KFAR } & 660 & 10\end{array}$

$45^{\circ} 12^{\prime} \mathrm{N} \quad 121^{\circ} 55^{\prime} \mathrm{W}$

1400

84

50

$\begin{array}{lll}24 & 65 & 350 \\ 30 & 80 & 350\end{array}$

Fairbanks

$\begin{array}{llcccc}\text { Jim Creek } & \text { NLK } & 18.6 & 250 & 48^{\circ} 12^{\prime} \mathrm{N} & 121^{\circ} 55^{\prime} \mathrm{W} \\ \text { Fairbanks } & \text { FOX } & 356 & 0.04 & 64^{\circ} 58^{\prime} \mathrm{N} & 147^{\circ} 34^{\prime} \mathrm{W} \\ \text { Fairbanks } & \text { KFAR } & 660 & 10 & 64^{\circ} 52^{\prime} \mathrm{N} & 147^{\circ} 49^{\prime} \mathrm{W}\end{array}$

$48^{\circ} 12^{\prime} \mathrm{N} \quad 121^{\circ} 55^{\prime} \mathrm{W}$ $64^{\circ} 50^{\prime} \mathrm{N} \quad 147^{\circ} 29^{\prime} \mathrm{W}$ $64^{\circ} 52^{\prime} \mathrm{N} \quad 147^{\circ} 49^{\prime} \mathrm{W}$

$\begin{array}{cc}1400) & 70 \\ 9.5 & 90 \\ 5.5 & 16\end{array}$

$\begin{array}{cc}1400 & 84 \\ 7.5 & 67 \\ 11 & 60\end{array}$




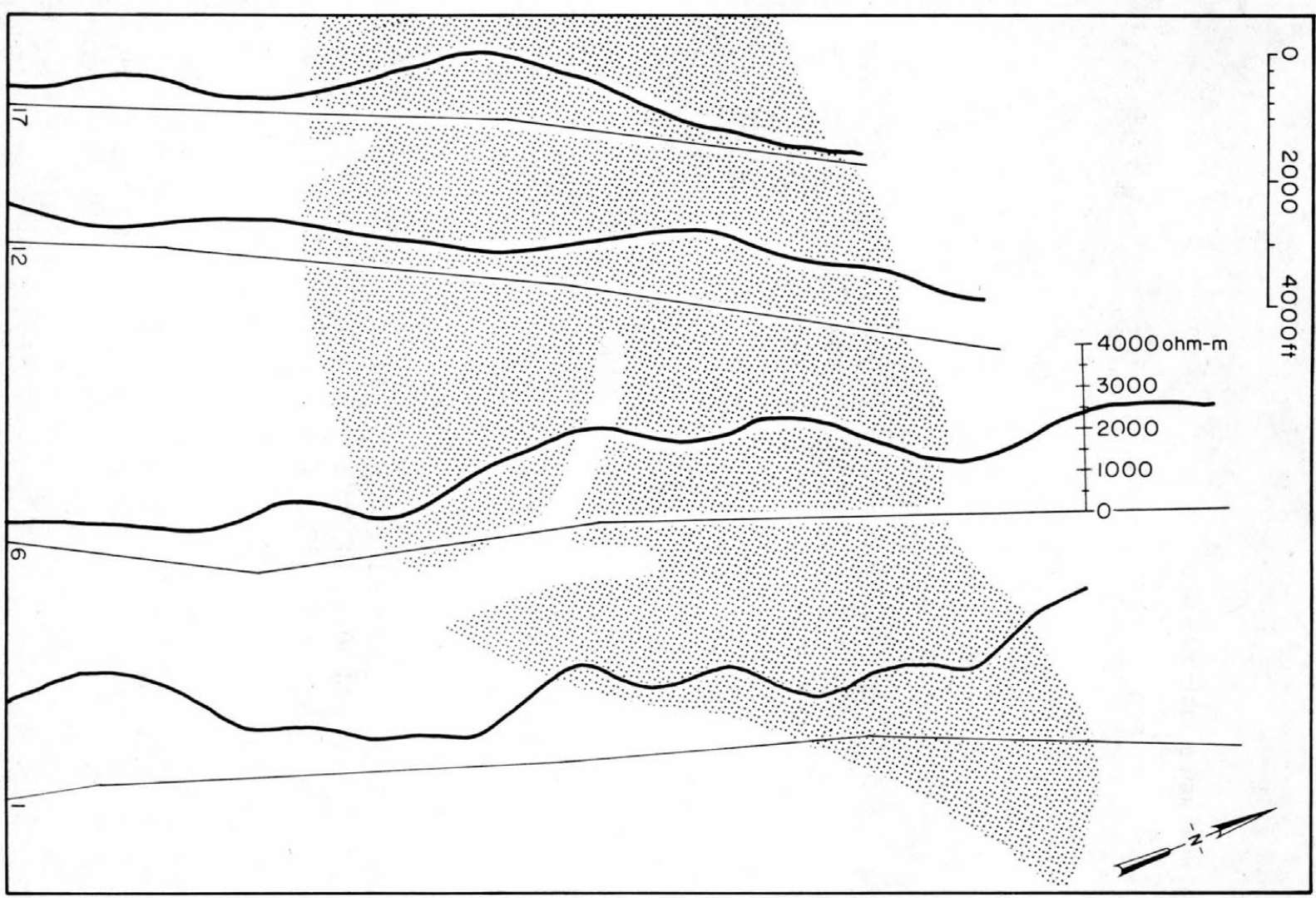

Figure 19. Examples of resistivity profiles along a flight line.

$$
C=\frac{0.34}{E_{\mathrm{x}}(Q) \mathrm{cal}} \times \frac{A \mathrm{cal}}{A \text { oper }} \times \frac{E_{\mathrm{z}} \mathrm{cal}}{\sin \alpha} .
$$

The apparent resistivity is subsequently computed from eq 11.

In Table III the specifications of the various study areas discussed in this report are listed.

\section{Computer processing of data}

The computed apparent resistivities at each fiducial point are listed in the form of resistivity profiles for each survey line $(P$-plot). The fiducial points are given on the vertical axis and the three resistivities are printed above the corresponding fiducial points using three different symbols. The vertical scale of the fiducial marks is arbitrary. Whenever the calculated value of $\rho_{\mathrm{a}}$ is negative - which may be due to powerline interference, scattering, and zero error - negative values are plotted on the printouts.

\section{Plotting and contouring of data}

The fiducial points common to the base maps and magnetic tape are merged and the computed resistivity data are plotted along the flight lines. From these plots the data are contoured by hand. Examples of resistivity profiles along a flight line are given in Figure 19.

\section{Filtering of E-phase data}

To smooth the observed vertical electric field, a low pass filter is applied to the field before computing the apparent resistivity; the computed apparent resistivities are also filtered. The vertical electric field data and the resistivity data were filtered for each survey area. 


\section{PROBLEM AREAS OF THE E-PHASE TECHNIQUE}

The three major problems with the system at present are horizontal control (navigation), zero errors and interference.

\section{Horizontal control}

The flight lines are located on the map by merging recognizable landmarks on the film strip with flight time locations marked by the navigator on the topographic or mosaic base at the time of the survey. The error in this technique clearly depends much on the character of the terrain: when a few landmarks stand out as, for example, in the Moose Creek Dam area, the navigator has great difficulty in spacing the flight lines. In the Chena Dam area flight lines often cross. The error in the horizontal control, therefore, varies much from one area to another. In these surveys no effort was made to set out special markers or navigational beacons to help reduce the error in horizontal control. This problem naturally increases greatly with very closely spaced flight lines. The surveyed areas were as a general rule flown at $1 / 10$-mile $(0.16-\mathrm{km})$ intervals.

\section{Zero error}

Calibration is accomplished at the beginning and end of a survey by tilting the antennas, and this calibration is assumed constant during the survey. Drift in the instrument is very small, but other factors affecting calibration, such as the direction of $E_{z}(I)$ and $E_{\mathrm{z}}(Q)$, may change due to scattering of the field and mixed-path propagation. Negative resistivities did occur on approximately $1 \%$ of the total line mileage and they were probably partly due to zero error. One way to reduce zero errors is to use a continuously rotating antenna, so that a zero is obtained and the wave tilt is calibrated at each point in the survey.

\section{Interference}

Interference is encountered 1) whenever the flight path encounters man-made objects that alter the local electric field, and 2) whenever topographic features diffract or scatter the electric field. The interference caused by man-made objects is easily recognized and results in large anomalies in the records. The data in such instances are discarded. The interference caused by topographic features is more difficult to recognize and the effects of these features must await further studies. In general, no systematic variation of the apparent resistivity with topography was noticed, but further investigations on this aspect are planned.

\section{GROUND CONTROL IN STUDY ARE AS}

The sites were selected because of the availability of ground control. The amount of ground control available consisted of geological maps prepared by the U.S. Geological Survey (USGS) and soils maps published by the U.S. Department of Agriculture; in addition, in some areas the Alaskan District, Corps of Engineers, provided results from the preliminary site surveys for the Chena Flood Control Project.

The control information varied from one site to another. In some cases, no detailed surficial geological mapping was available and control was based on information from widely spaced drill logs. The study areas and the type of control available in them are listed in Table IV.

The geological units used in developing the comparisons between surficial geology and resistivity were directly taken from the geological maps prepared by the USGS; the characteristics 
of the units are listed in Table V (Péwe 1958, Williams et al. 1959). In order to use the soil map (Rieger et al. 1963), soil units were grouped in larger classes; this grouping will be discussed later.

Table IV, Summary of ground control available in each survey area,

Study area

Goldstream area

Site 2

Chena Hot Springs Road

Moose Creek Dam area
Control

Surficial geology maps, soils maps, and drill logs Surficial geology maps, soils maps, and drill logs Drill logs

Geology and limited drill logs

Table V. Geological units from Fairbanks, Alaska, D-1 and D-2 Geological Quadrangles.

Unit

Material type

Thickness

Permafrost

Qsu

Perennially frozen undifferentiated silt

Qso

Perennially frozen

organic silt

Qs

Flood plain swale and slough

deposits

Qf

Fairbanks

silt

Qg

Creek gravel

incl tailings

Qal

Flood plain

alluvium
Silt-organic

ground ice

1 to $30 \mathrm{~m}(\mathrm{D}-1)$

15 to $>30 \mathrm{~m}(\mathrm{D}-2)$

Organic-silt

ground ice

Silt and organic material

Generally $<3 \mathrm{~m}$ Rarely 3 to $7.6 \mathrm{~m}$

Low density silt

Gravel with

local fine lenses

Silts over sand and gravel

on hill tops, and as much as $30 \mathrm{~m}$ on midslopes

1 to $76 \mathrm{~m}$
Silt 0.3 to $4.6 \mathrm{~m}$ thick over sand and gravel of varying thickness up to approx $213 \mathrm{~m}$ near the Tanana River.
Depth to permafrost 0.45 to $1.20 \mathrm{~m}$ on lower slopes and creek valley bottoms, 1.5 to $6.10 \mathrm{~m}$ near contacts with $\mathrm{Qf}$ and $\mathrm{p} \in \mathrm{bc}$. Active layer 0.45 to $1.20 \mathrm{~m}$. Permafrost 1 to $>52 \mathrm{~m}$.

Active layer 0.45 to $1 \mathrm{~m}$. Permafrost at least 30 $\mathrm{m}$ thick.

Permafrost depth 0.45 to $6.1 \mathrm{~m}$. Permafrost 1.5 to $9.1 \mathrm{~m}$ thick.

No permafrost.

Only locally frozen.

Permafrost discontinuous, unfrozen lenses, layers and vertical zones. 
Table V. Continued

Unit

Material type

Thickness

Less than $1 \mathrm{~m}$ of silt over rock
pEbc

Bedrock Birch

Creek schist

gr

Granite
Less than $1 \mathrm{~m}$

of silt over rock
Permafrost

Permafrost generally not found except under Qsu and Qg in valley bottoms.

\section{COMPUTER MODELING OF RESISTIVITY PROFILES IN CENTRAL ALASKA}

Natural ground usually consists of several layers of different resistivities and the area in Fairbanks, Alaska, is no exception. Typical resistivity profiles of the major surficial geology units found in the vicinity of Fairbanks, Alaska, are schematically listed in Table VI. Seasonal changes in the resistivity profile occur in the top $3 \mathrm{~m}$ of soil and are most severe when an organic surface layer is present. The variations in thickness of the units listed in Table VI correspond to the variations suggested for the surficial geological units by the local geological studies. The ranges of resistivity listed are based on laboratory and field measurements. The results of the laboratory measurements were given in section Resistivities of earth materials (p. 3). Some of the field measurements are discussed next.

Galvanic resistivity measurements (Keller and Frischknecht 1966) were made with the electrodes in a Wenner array on each of the units listed in Table V. In the Wenner method, the spacing between the electrodes ("a spacing") is plotted versus the apparent resistivity.

Increasing the spacing between the electrodes increases the depth to which subsurface information may be obtained. The depth of penetration is about equal to the distance between the electrodes. When the earth is not homogeneous, but has several layers of different resistivities, $\rho_{1}, \rho_{2}, \rho_{3} \ldots$, and of thicknesses, $d_{1}, d_{2}, d_{3} \ldots$, the value of the apparent resistivity changes with electrode spacing. In the field $\rho_{\mathrm{a}}$ is measured, and $\rho_{1}, \rho_{2}, \rho_{3}, \ldots$ and $d_{1}, d_{2}, d_{3}, \ldots$ are obtained by fitting a computer solution to the field data.

In Figures 20a-d the solid lines represent the computed curves for the ground conditions indicated on the figures. In the computer program, the apparent resistivity obtained in a Wenner electrode configuration can be simulated for ground of up to four layers. A best fit is obtained by successive trial inputs of layer resistivities and thicknesses.

Figures 20a and b are representative of Wenner spreads on the units Qsu and Qso under summer conditions. In Figure 20a the Wenner spread is shown for a thawed organic mat, $0.3 \mathrm{~m}$ thick and with a resistivity of $140 \mathrm{ohm}-\mathrm{m}$, overlying permafrost with a resistivity of $7000 \mathrm{ohm}-\mathrm{m}$. In this case the spacing between the electrodes was not opened far enough to indicate the bottom of the permafrost. Because of the high resistivity of the permafrost layer, the frozen ground most likely has a high ice content. In Figure $20 \mathrm{~b}$ two Wenner spreads are shown for permafrost sites where the resistivity of the frozen ground is between 500 and $700 \mathrm{ohm}-\mathrm{m}$ and the depth to the permafrost table is deeper. 


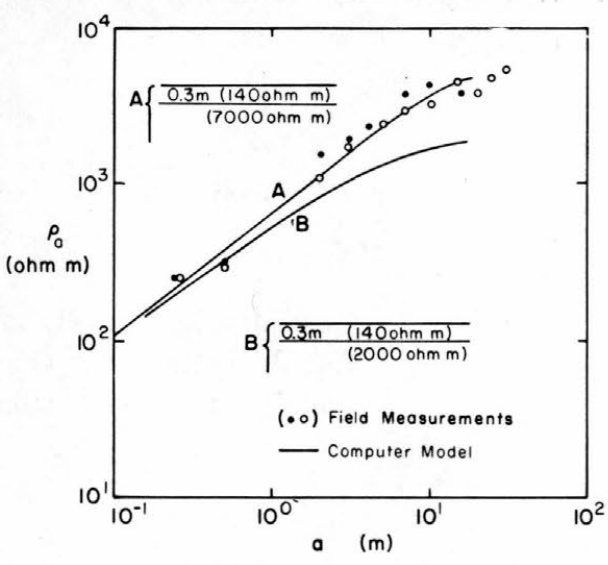

a. Qsu, in summer.

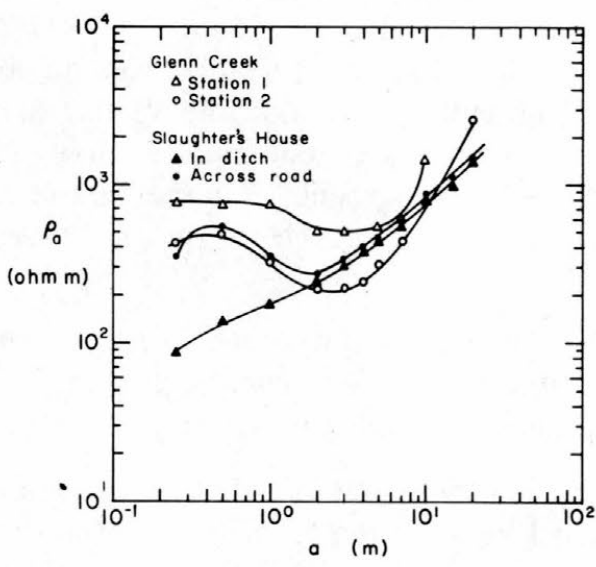

c. $Q f$, in summer.

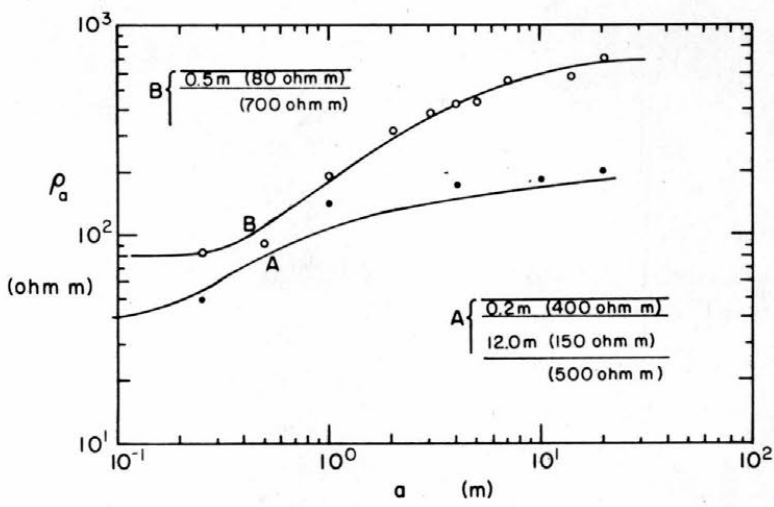

b. Qso, in summer.

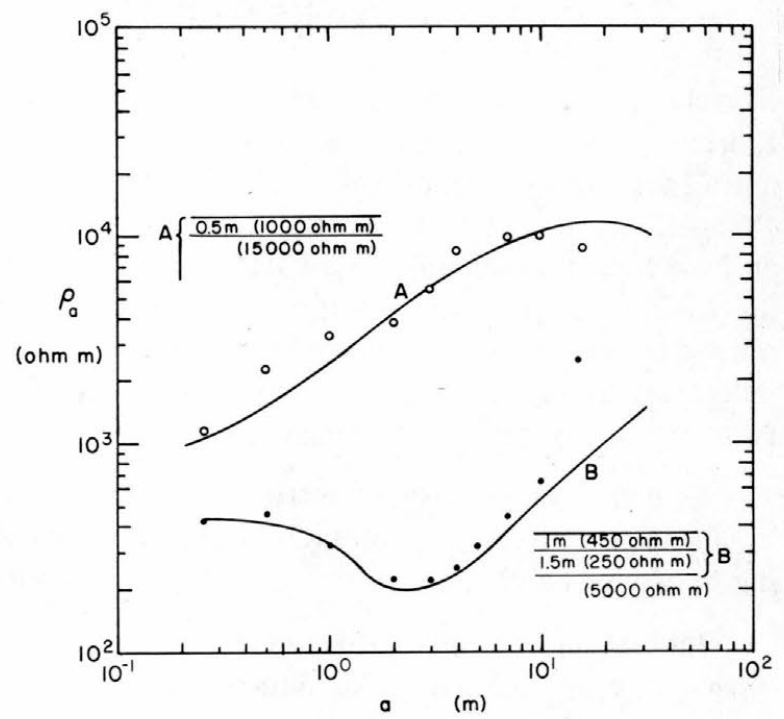

d. Qal, in summer.

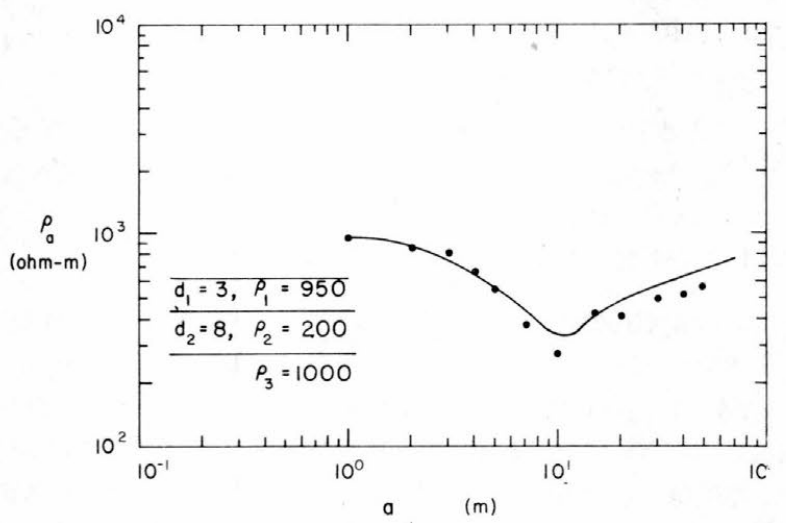

e. Qal, in winter.

Figure 20. Wenner spreads on several soils near Fairbanks, Alaska. The solid and open circles represent the computed apparent resistivities for the ground conditions indicated. The solid and open circles represent two separate measurements. 
Table VI. Layering and resistivity ranges expected on major surficial geological units.

\begin{tabular}{|c|c|c|c|}
\hline & & Thickness & Resistivity (ohm-m) \\
\hline Unit & Layer & (m) & Winter Summer \\
\hline Qsu, Qso & $\begin{array}{l}\text { Active layer } \\
\text { Unfrozen silt } \\
\text { Frozen s ilt } \\
\text { Bedrock (schist) }\end{array}$ & $\begin{array}{l}0.2 \text { to } 3 \\
0 \text { to } 5 \\
5 \text { to } 60 \\
\text { Basement* }\end{array}$ & $\begin{array}{c}>1,000 \quad 50 \text { to } 150 \\
100 \text { to } 800 \\
500 \text { to } 10,000 \\
100 \text { to }>2,000\end{array}$ \\
\hline Qf & $\begin{array}{l}\text { Seasonal frost layer } \\
\text { Unfrozen silt } \\
\text { Bedrock (schist) }\end{array}$ & $\begin{array}{c}1 \text { to } 3 \\
1 \text { to } 30 \\
\text { Basement }\end{array}$ & $\begin{array}{c}>1,000 \quad 100 \text { to } 800 \\
100 \text { to } 800 \\
100 \text { to } 2,000\end{array}$ \\
\hline Qal & $\begin{array}{l}\text { Seasonal frost layer } \\
\text { Unfrozen silt } \\
\text { Gravel } \\
\text { Bedrock (schist) }\end{array}$ & $\begin{array}{c}1 \text { to } 3 \\
0 \text { to } 7 \\
0 \text { to } 200 \\
\text { Basement }\end{array}$ & $\begin{array}{c}>1,000 \quad 100 \text { to } 1,000 \\
100 \text { to } 800 \\
1,000 \text { to } 10,000 \\
100 \text { to } 2,000\end{array}$ \\
\hline
\end{tabular}

Typical Wenner spreads on the units Qf are shown in Figure 20c. These units are most frequently situated on the south-facing hillsides and have in general a silt cover less than $30 \mathrm{~m}$ thick; the apparent resistivities of these units at "a" spacings (separation distance between electrodes in a Wenner array) larger than $30 \mathrm{~m}$ are, therefore, mainly determined by bedrock resistivity.

Figures 20d and e are typical examples of Wenner spreads on the Qal units. Curve A of Figure 20d represents virtually no silt cover over the gravel; curve B represents an unfrozen silt cover about $2.5 \mathrm{~m}$ thick. An example of a Wenner spread on a unit Qal in the winter is shown in Figure 20e. The seasonal frost is evidenced by a layer of high resistivity $d_{1}$ at the surface, followed by a layer of unfrozen silt and gravel $d_{2}$.

Table VI and the Wenner spreads demonstrate the large variation in resistivity that can occur in the surficial geological units of the D-1 and D-2 Fairbanks, Alaska, Geological Quadrangles. The ranges in values are due both to variation in material type (e.g. ice content) and to variation in the thickness of each layer.

Using the limits of the resistivities and thicknesses of each unit listed in Table VI, the variation in the apparent resistivity expected from an E-phase survey can be computed from eq 11 at each desired frequency.

In the units Qsu and Qso, the main variations at VLF are caused by the thickness of the silt cover, the resistivity of the basement, and the thickness and resistivity of the active layer. In Figure 21 the computed apparent resistivity at VLF and LF in the units Qsu and Qso is given as a function of the thickness of frozen silt cover $d_{1}$ at two values of the resistivity of the basement ( $\rho_{4}=1000 \mathrm{ohm}-\mathrm{m}$ and $\rho_{4}=300 \mathrm{ohm}-\mathrm{m}$ ) in the presence of an active layer. The apparent resistivity at VLF in the unit Qsu is bounded by a low of $400 \mathrm{ohm}-\mathrm{m}$ and a high in excess of $2500 \mathrm{ohm}-\mathrm{m}$. The variation in apparent resistivity is less at LF because of the screening effect of the conductive surface layer. Also, because the thickness of the silt cover in the unit Qso is often in excess of $15 \mathrm{~m}$, a narrower resistivity range is expected for Qso than for Qsu.

The expected resistivity variation in the unit $\mathrm{Qf}$ is more difficult to model because of the limited amount of silt cover over bedrock. Because of the thin $(<5-\mathrm{m})$ silt cover over bedrock, 


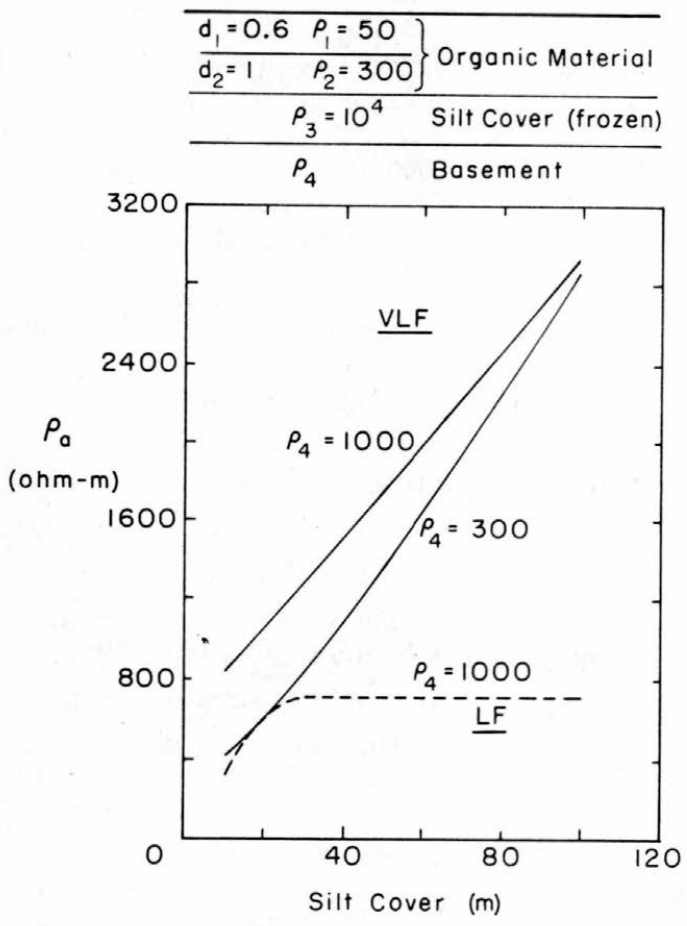

Figure 21. The computed apparent resistivities for the E-phase method at $V L F$ and $L F$ on the units $Q$ so and $Q$ su as a function of thickness of the frozen silt cover.

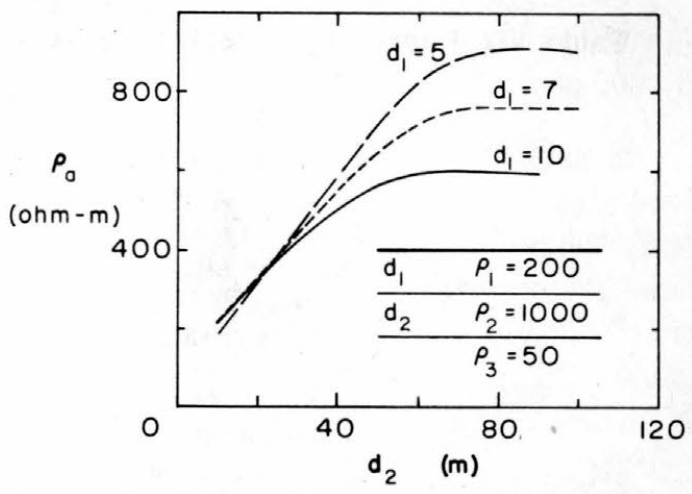

Figure 22. The computed apparent resistivity at VLF typical for the unit Qal. The thickness of the silt cover $d_{1}$ is varied from 5 to 10 $m$ and $\rho_{\mathrm{a}}$ is plotted as a function of the thickness of gravel $\mathrm{d}_{2}$. The bedrock $\rho_{3}$ is assumed conductive at 50 ohm-m.

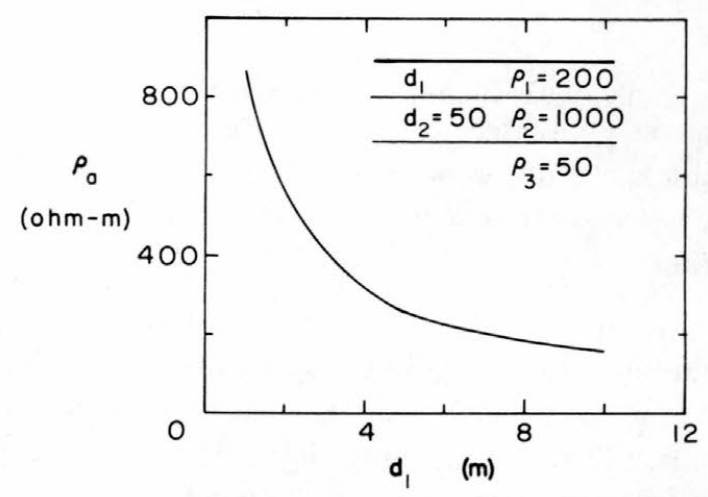

Figure 23. The computed apparent resistivity at LF typical for the unit Qal. The resistivity is plotted as a function of the thickness of the silt cover $\mathrm{d}_{1}$.

\section{Table VII. VLF (NLK, $18.6 \mathrm{kHz}$ ) ground-based a pparent resistivity} measurements on rock sites in the Yukon-Tanana Uplands.

$\begin{array}{cc}\text { Site } & \begin{array}{c}\text { Apparent } \\ \text { resistivity } \\ \text { (ohm-m) }\end{array} \\ 1 & 160 \text { to } 180 \\ 2 & 130 \text { to } 160 \\ 3 & 400 \text { to } 500 \\ 4 & 500 \text { to } 1100 \\ 5 & 2000 \\ 6 & 4000 \text { to } 5000\end{array}$

Remarks

Schist, severely decomposed Schist, severely decomposed Schist, badly weathered Schist, badly fractured Intrusive rock, weathered and fractured Granitic intrusive rock, jointed and fractured

the VLF values are mainly determined by bedrock resistivities. Table VII shows VLF ground-based measurements on rock outcrops in the Yukon Tanana Uplands (Sellmann et al. 1974). Since some of these values are from rock quarries where the quality of rock may perhaps be better thar normally encountered, VLF apparent resistivities on Qf probably fall between 50 and 1000 ohm-m. 
The LF resistivity values should correspond to the apparent resistivities obtained with the Wenner method at spacings between 10 and $20 \mathrm{~m}$. In the summer these values vary from $500 \mathrm{ohm}-\mathrm{m}$ to $2000 \mathrm{ohm}-\mathrm{m}$ (see Fig. 20c), and may be higher in the winter.

In the Qal unit, the thickness of the unfrozen silt cover, the thickness and resistivity of the flood plain gravels, and the resistivity of the basement are the main parameters influencing $\rho_{\mathrm{a}}$ at VLF. Figure 22 shows the dependence of the computed apparent resistivity at VLF on two of these factors: the thickness of the silt cover and the thickness of gravel. In Figure 23 the computed apparent resistivity is given at LF as a function of the thickness of the silt cover over gravel. The resistivity of the basement has no effect in the situation shown because of the thick intermediate gravel layer.

The major findings from the computer modeling studies as they apply to dəlineating the surficial geological units of the Fairbanks, Alaska, D-1 and D-2 Geological Quadrangles are summarized below:

1. Apparent resistivities between $400 \mathrm{ohm}-\mathrm{m}$ and $>2500 \mathrm{ohm}-\mathrm{m}$ are expected at VLF on the units Qso and Qsu. The resistivities increase with the depth of permafrost. The VLF resistivities on the units Qf are expected to be less than $500 \mathrm{ohm}-\mathrm{m}$; this expectation is mainly based on ground measurements.

2. In the units Qso and Qsu, the apparent resistivity at VLF is greater than the value at LF because of the screening effect of the conductive surface layer. Based on data from Wenner spreads, the values at LF are greater than $700 \mathrm{ohm}-\mathrm{m}$ on the unit Qf.

3. In the unit Qal, apparent resistivities are mainly determined by the thickness of the silt cover.

\section{RESULTS}

Although the resistivity data were often contoured at 50 ohm-m, all maps in this report have only 3 contour lines: 250,500 and $1000 \mathrm{ohm}-\mathrm{m}$. This provides four resistivity ranges, which were found to correspond well to the natural limits expected for various ground conditions, permafrost and geological settings.

A problem in comparing geological maps with apparent resistivity data is the large degree of variation in resistivity allowed within a geological unit, as illustrated in Figures 21 and 22. Frozen silt covers in the units Qso and Qsu range in thickness from $1 \mathrm{~m}$ to $60 \mathrm{~m}$. Even though these variations exist, the overall differences of ten appear significant enough to allow a distinction between units on the basis of resistivity. This type of approach to evaluating the data was also considered in keeping with the intended application of the airborne data as a regional tool.

\section{Goldstream site}

The Goldstream area has a geological setting typical of many stream valleys in the uplands between Fairbanks and the Yukon Valley; in it are found several common geologic and permafrost associations:

1. Silt units, which are further subdivided into:

(a) thawed silt of wind-blown origin common on south-facing exposures, indicated by Qf

(b) frozen silt units common to north-facing hills, indicated by Qsu

(c) frozen silt units common to valley bottoms, indicated by Qsu or Qso

2. Gravel ünits, which are associated with:

(a) contemporary streams

(b) old channels, which may be found reworked in local tailing piles. The older gravel deposits may be perennially frozen. Gravel units are indicated by Qg. 


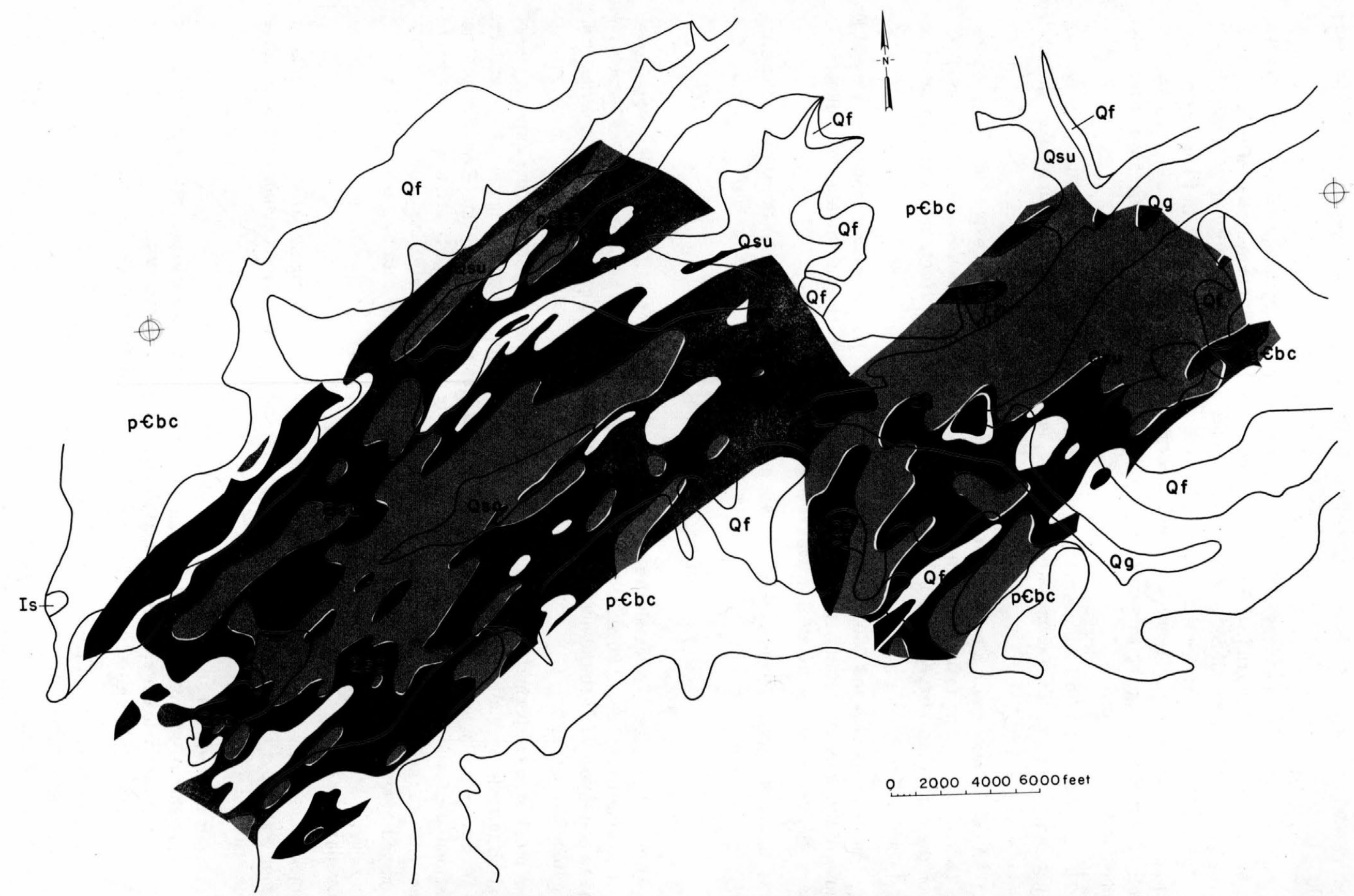

Figure 24. The VLF apptrent resistivity contour map of the Goldstream area, with the surficial geological map of the Fairbanks, Alaska, $D-1$ Geological Quadrangle. Blue $=<250$, white $=250-<500$, yellow $=500-1000$, red $=>1000$ ohm $-\mathrm{m}$. 


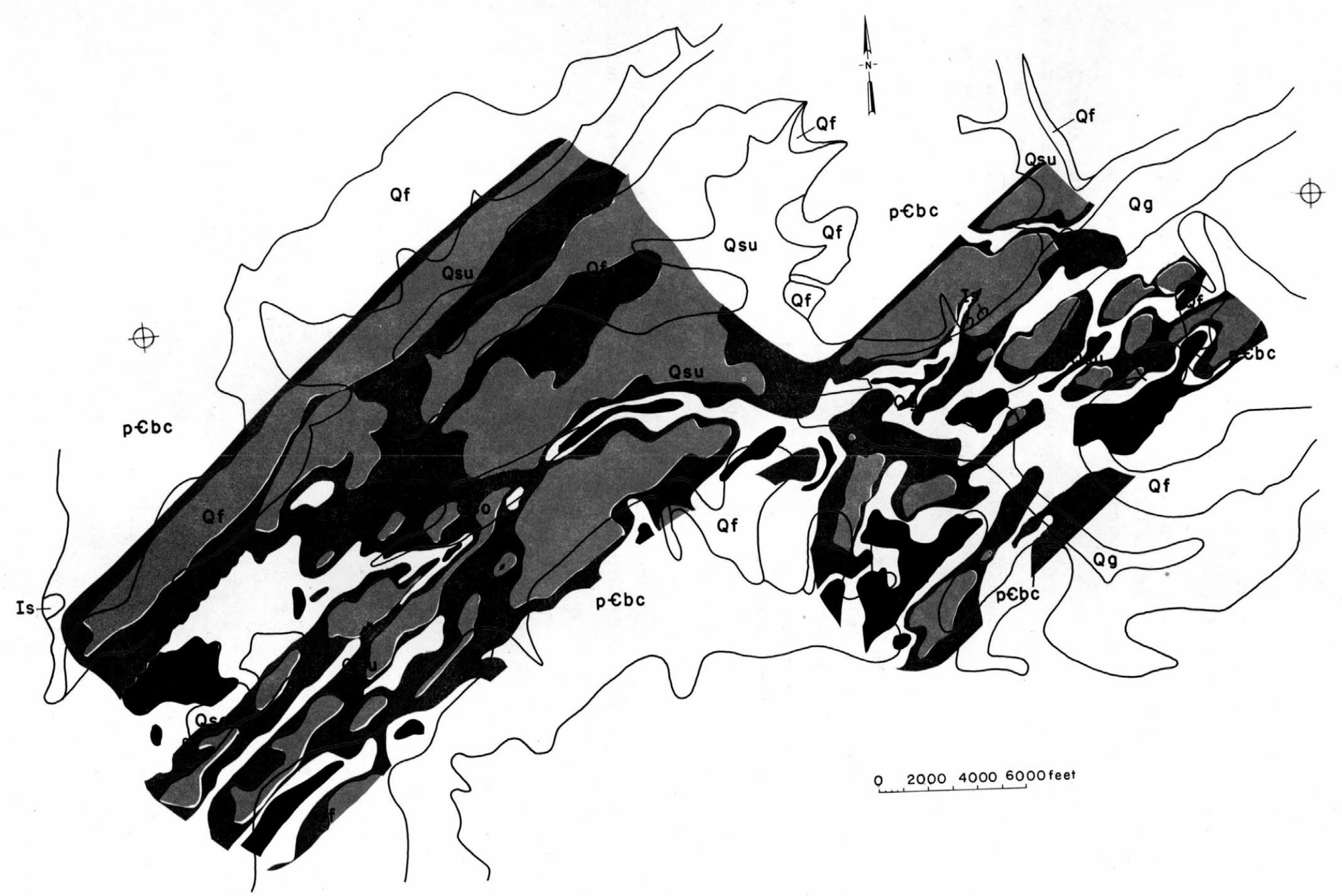

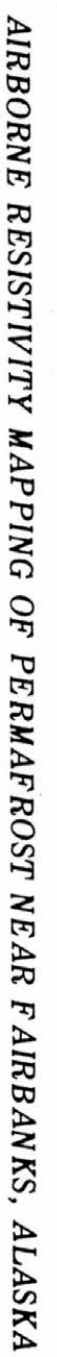

Figure 25. The LF apparent resistivity contour map of the Goldstream area, with the surficial geological map of the Fairbanks, Alaska, $D-1$ Geological Quadrangle. Blue $=<250$, white $=250-<500$, yellow $=500-1000$, red $=>1000$ ohm $-\mathrm{m}$. 
3. Bedrock units. Bedrock is generally covered by silt or gravel, but may be exposed on steep slopes and on some ridge tops. The common bedrock is metamorphic, often weathered, and badly decomposed; but intrusive rock occurs locally. Exposed bedrock sites with Birch Creek schist are indicated by pebc and when the exposed rock is intrusive by gr.

The VLF and LF resistivity contour maps with the surficial geological map of the D-1 Fairbanks Quadrangle (Péwé 1958) are given in Figures 24 and 25, respectively.

$V L F$ resistivities. In comparing the contoured VLF data with the geological map, a noticeable degree of correlation is evident. Signif icant differences are observed between the resistivities of the thawed units Qf and those of the perennially frozen silt units Qsu and Qso.

The western half of the Goldstream study area is largely a broad valley with an extensive silt cover. The silts extend across the valley from ridge top to ridge top. The perennially frozen silts are common in the valley bottoms and north-facing hillsides, and grade into the thawed silts on the more south-facing exposures. Figure 26 is a typical cross section of the valley along A-A'; it illustrates the general relation between the geological units. The cross section is based on the topographic map and the results of 7 drill holes (Péwé 1958).

The frozen silts in the valley (Qso, Qsu) are characterized by high resistivities, often in excess of $1000 \mathrm{ohm}-\mathrm{m}$. The values decrease at the valley margins, where the thawed silt units commonly have apparent resistivities of less than $500 \mathrm{ohm}-\mathrm{m}$, and of ten below $250 \mathrm{ohm}-\mathrm{m}$. The $500-\mathrm{ohm}-\mathrm{m}$ contour is often near the mapped surficial, geological boundary of the units Qf and Qsu.

The Qf units at the northern margin of the valley are interrupted by a unit of Qsu situated in a small tributary of Goldstream. The resistivity values also reflect this interruption with a break from the low resistivities to the higher values indicative of perennially frozen ground in the tributary valley. Several other smaller low resistivity zones are found associated with the Qf unit on the southern valley margin.

Resistivities in excess of 500 ohm-m are not restricted to frozen silt sections, but are also found associated with gravel in the northern part of the study area and often with bedrock on the northwestern valley margin.

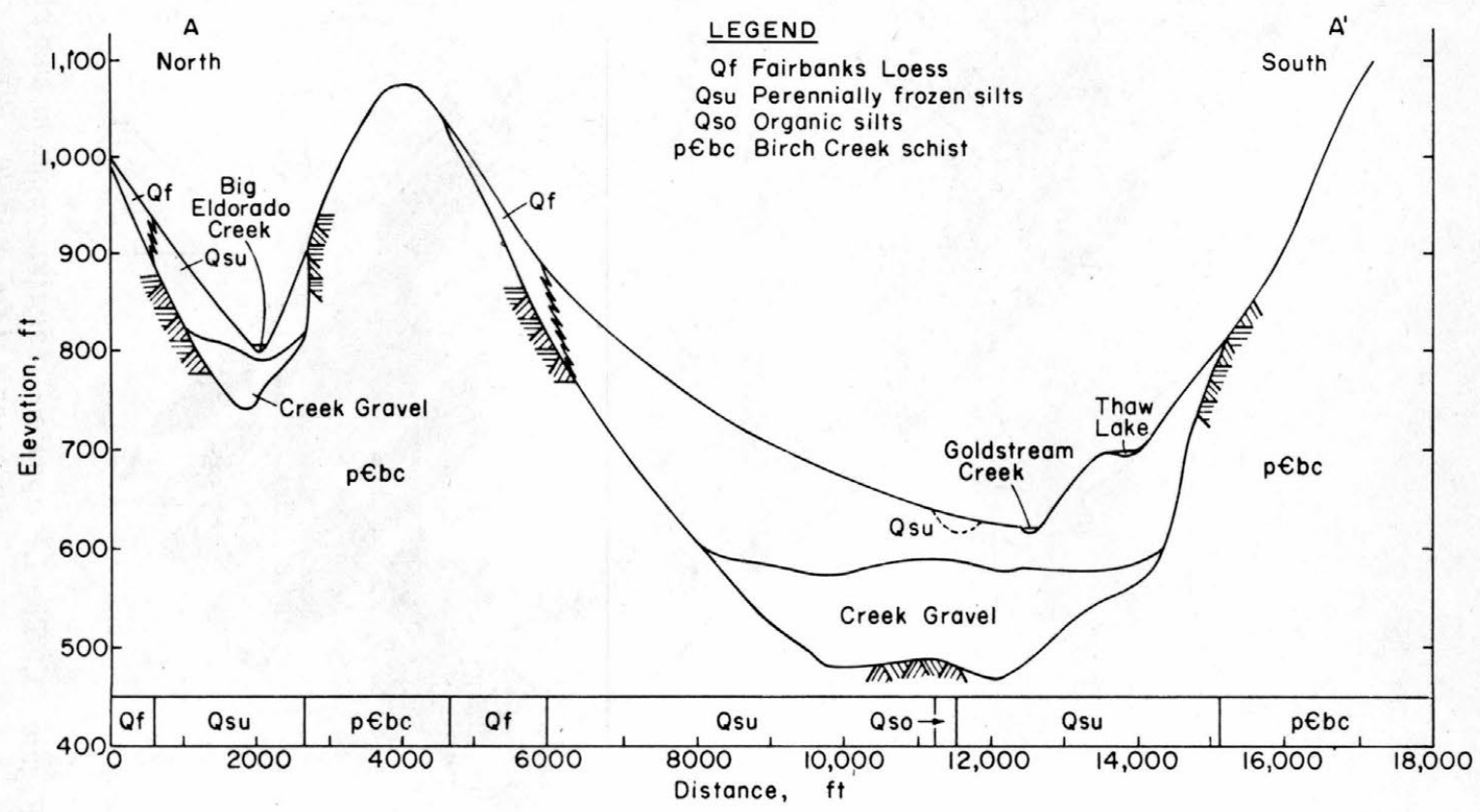

Figure 26. A typical cross section of Goldstream Valley along A-A' shown in Figure 24. 
There are also zones of apparent disagreement, such as the small zones of low resistivities in the valley bottoms mapped as Qsu. In some cases, it is possible that the resistivity data are more accurate than the contour map in terms of permafrost, particularly since permafrost is subject to change in areas of human activity such as the Fairbanks area. Only more detailed work will permit explanations of these anomalies found throughout the study area.

In summary, the VLF map in Goldstream Valley shows in general a good correlation between the apparent resistivities and the mapped geological boundaries of the frozen and thawed silt units. The major problem in making these ground correlations is the extreme variation within the geological units discussed in the preceding section.

$L F$ resistivities. When the LF map is compared with the VLF map several differences are observed:

1. In the unit Qf the resistivities at LF are higher than those at VLF; whereas at VLF values are in general lower than $500 \mathrm{ohm}-\mathrm{m}$, at LF in several sections resistivities are higher than 1000 ohm-m.

2. In the perennially frozen units Qsu and Qso, the trend is reversed: the resistivities at LF are lower than those at VLF.

To investigate these resistivity trends at VLF and LF further, normalized distribution histograms were made by tabulating every other resistivity value of a P-plot with the geological units under the flight path. The data were stored in computer files and the resistivity distribution curves were made from the files with a sorting program. Figure 27 gives the normalized distribution histograms for the units Qf, Qso and Qsu at LF and VLF resistivities, respectively. In addition to the resistivity intervals 0-250, 250-500 and 500-1000 ohm-m used on the maps, the intervals 1000-2000 and greater than $2000 \mathrm{ohm}-\mathrm{m}$ are given. These distribution curves confirm the remarks made in the preceding discussion: 1) at VLF the units Qso and Qsu have a higher density of resistivities in

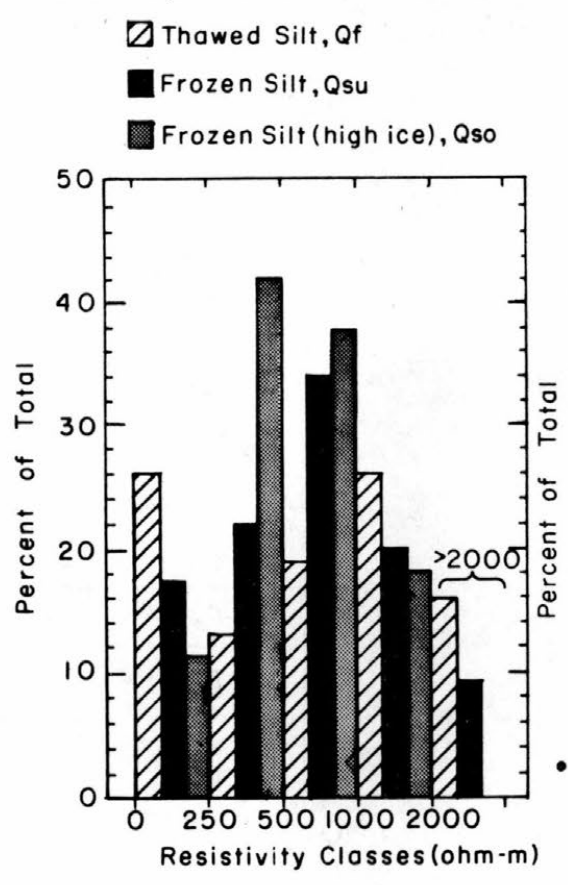

a. $L F$.

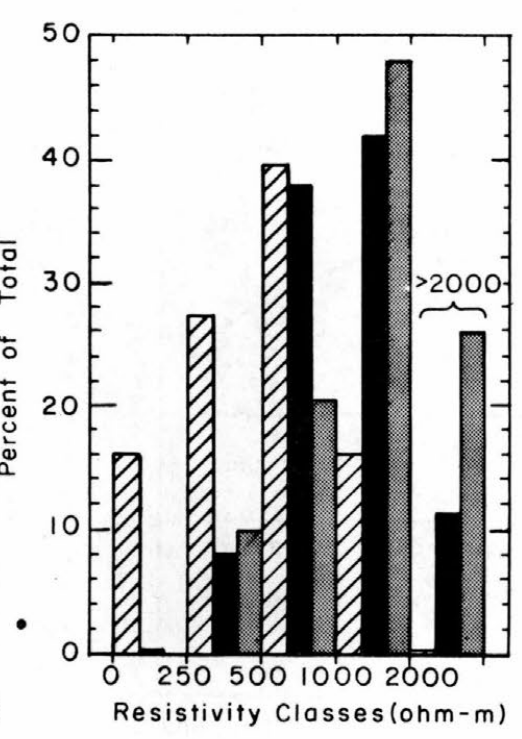

b. VLF.

Figure 27. Normalized distribution histograms of resistivities on the units of Qf, Qsu and Qso. 
Table VIII. Mean apparent resistivities in several geological units.

\begin{tabular}{|c|c|c|c|c|}
\hline \multirow[b]{2}{*}{$\begin{array}{c}\text { Geological } \\
\text { unit }\end{array}$} & \multicolumn{2}{|c|}{ Goldstream area } & \multicolumn{2}{|c|}{ Site 2} \\
\hline & $V L F, 18.6 \mathrm{kHz}^{\rho_{\mathrm{a}}}$ & $\mathrm{LF}, 276 \mathrm{kHz}$ & $V L F, 18.6 \mathrm{kHz}^{\rho_{\mathrm{a}}}$ & $L F, 357 \mathrm{kHz}$ \\
\hline Qso, high ice & 1538 & 702 & & \\
\hline Qsu & 1163 & 980 & 711 & 306 \\
\hline Qf & 697 & 1145 & 345 & 424 \\
\hline
\end{tabular}

excess of $1000 \mathrm{ohm}-\mathrm{m}$ than the unit Qf. 2) At LF the density of resistivities in excess of $1000 \mathrm{ohm}-\mathrm{m}$ decreases for the units Qsu and Qso and increases for the unit Qf compared with the density of resistivities at VLF. This reversal is further conf irmed by the mean values of resistivity listed in Table VIII.

In Figure 28 the apparent resistivities of the units Qsu, Qso and Qf are plotted as a function of frequency. A value for BCB was obtained from sites where the quality of the data was good. The shaded area indicates the range of values observed and the mean values fall within this range. The dotted line gives the computed values for the ground conditions indicated. Thus, in the frozen units Qsu and Qso, where $\rho_{\mathrm{a}}$ decreases with frequency, a conductive surface layer $d_{1}$ and $d_{2}$ overlies a layer $d_{3}$ of high resistivity $\rho_{3}$, followed by a basement resistivity $\rho_{4}$ of $300 \mathrm{ohm}-\mathrm{m}$. The computed value of $\rho_{\mathrm{a}}$ is sensitive to all the parameters in the model. For example, if the thickness of frozen silt is increased, the value of $\rho_{\mathrm{a}}$ at VLF becomes larger. Also, the resistivity $\rho_{3}$ must be in excess of $5000 \mathrm{ohm}-\mathrm{m}$ to yield the strong decrease in resistivity with frequency observed in the data.

Since the survey was made in early spring, when there was only a very small amount of thaw, the presence of a conductive layer at the surface was initially difficult to explain. Later laboratory work on samples from the organic surface layer common to permafrost showed that the resistivities decrease rapidly when the temperature approaches $0^{\circ} \mathrm{C}$.

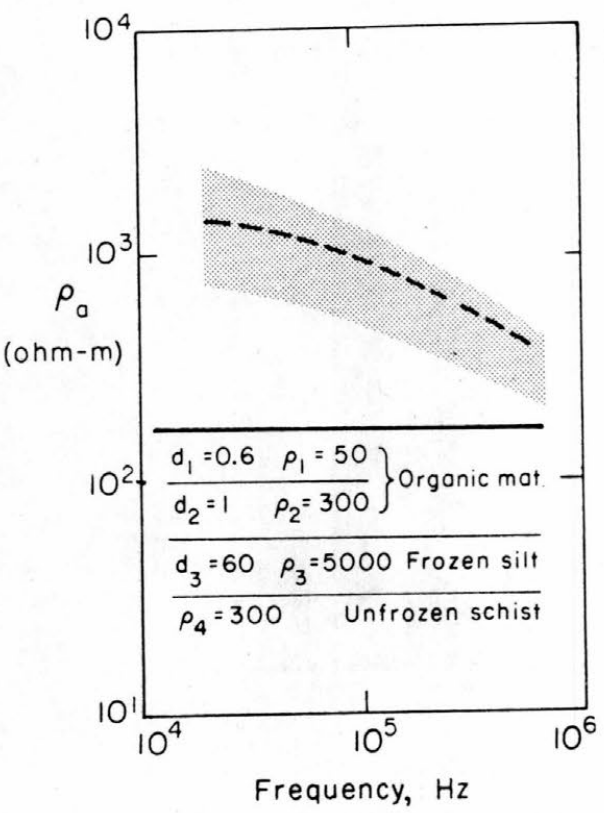

a. Qsu and Qso.

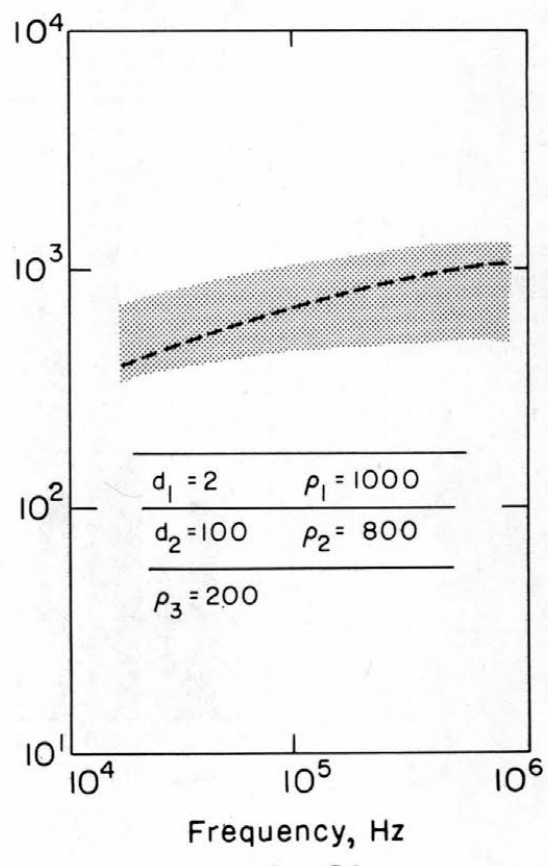

b. $Q f$.

Figure 28. The apparent resistivity measured as a function of frequency on the geological units $Q \mathrm{su}, Q \mathrm{~s} o$ and $Q f$. The shaded area gives the range of values encountered. The dotted line gives the computed values for the ground condition indicated. 
In summary, the multifrequency airborne resistivity survey in the Goldstream area has shown that the VLF resistivity map shows good correlation between the mapped boundaries of frozen and thawed silt units. The correlation between resistivity at LF and surficial geology is less evident. Large resistivity changes occur between VLF and LF; on frozen units the resistivity decreases with increasing frequency, and on thawed units the opposite is the case.

\section{Site 2}

This study area (Fig. 1) is situated on the northeast of Fairbanks and has a general N-S trend. It covers a swath that makes the transition from the uplands including Gilmore Dome into the low flood plains of the Tanana Valley. The surficial geology includes the fine-grained soils of the uplands, some of which are perennially frozen, and the mixed alluvial material in the Tanana Valley. Also, bedrock types are variable, including both metamorphic and igneous rock types.

The area was flown at LF, VLF and BCB; both detailed surficial geological and soil maps are available for this area, providing considerable detailed control for assessing the results.

The VLF, LF and BCB resistivity maps of site 2 are shown in Figure 29 with a geological map and in Figure 30 with a soils map.

$V L F$ resistivities. The VLF data again provide the most obvious correlation between the perennially frozen units Qsu and Qso, and the thawed unit Qf. The central part of the study area between the Chena River and the uplands is mapped as Qsu. This area also has consistently high resistivity values. The 500-ohm-m contour has the same general limits as the mapped Qsu. Immediately to the northeast is a mapped unit of Qf, which has consistently low values of resistivity. However, the adjacent Qsu unit to the north contains no resistivity highs as would be expected. This zone and others like it will be subjected to further field work to determine the actual conditions. There is a possibility that the mapped limits of some of these units have changed or are in error. The resistivity distribution histograms for the units Qf, Qsu and Qso at VLF and LF shown in Figures 31a and b, respectively, again substantiate the general conclusion that the resistivities are higher in units Qsu than in units Qf, and the mean values listed in Table VIII also reflect this trend.

In the southern end of this study area, the surficial geological units associated with the Tanana flood plain are found. There is no apparent correlation between resistivity contours and the mapped boundaries of the units Qal and Qs and perhaps little ought to be expected. The units Qal consist of a silt layer 1 to $5 \mathrm{~m}$ thick over gravel, and the units Qs are in old river channels, with probably similar material types. What the resistivity map might indicate is the thickness of silt over gravel, but the surficial geology map provides no control on that.

$L F$ and $B C B$ resistivities. When the $\mathrm{LF}$ and $\mathrm{BCB}$ resistivity data are compared with VLF data, the same reversal in resistivity with frequency observed in the Goldstream area is found: in the unit Qsu the resistivity decreases with frequency, and in the unit Qf the resistivity increases with frequency. The resistivity distribution histograms shown at LF in Figure 31b and the mean values of resistivity listed in Table VIII again confirm this conclusion. However, the reversal in this area is not as pronounced as in the Goldstream area. There are no apparent correlations between the resistivity contours and the surficial geology at LF and BCB.

Some trends between resistivity at LF and BCB and data from the Fairbanks soils map can be discerned from the resistivity contour map with the soil map in Figure 30. The soils were grouped in classes according to permafrost distribution and thickness of active layer. Table IX lists the classifications used and their characteristics. Classes $\mathrm{Ab}$, Ta and $\mathrm{Tb}$ include nonpermafrost soils, and soils with permafrost at a depth greater than $4.6 \mathrm{~m}$. These soils are associated with the higher resistivities in the central and northern parts of the area. The soil units with the permafrost table within about $1 \mathrm{~m}$ from the surface, Aa and $\mathrm{Pa}$, have resistivities less than 500 ohm-m at LF and less than 250 ohm-m at BCB. 


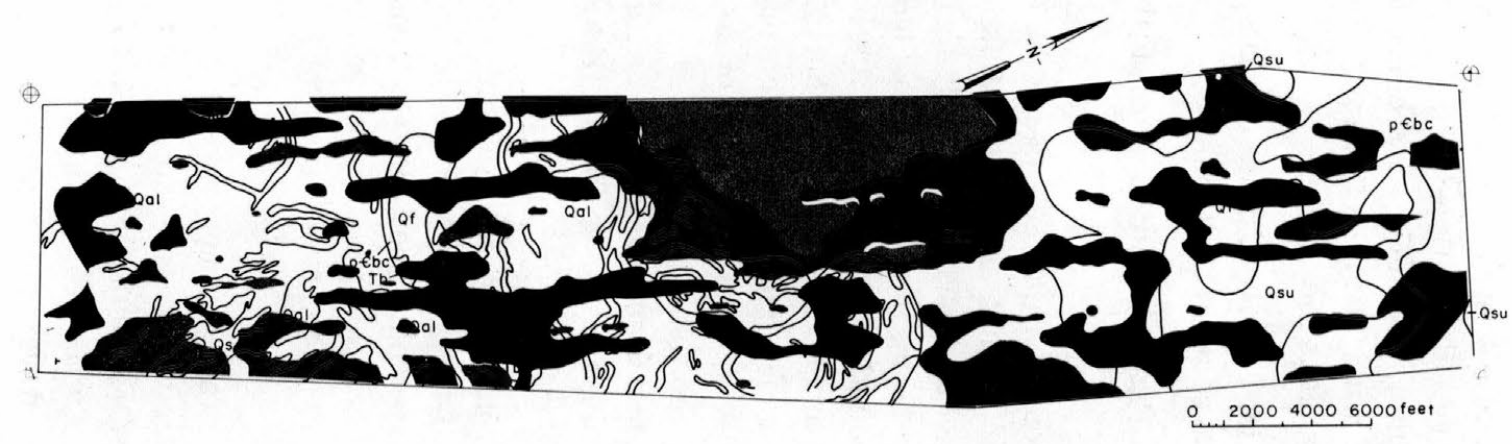

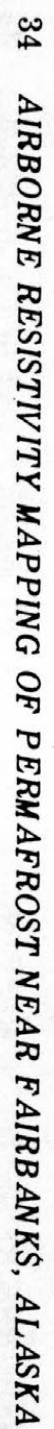

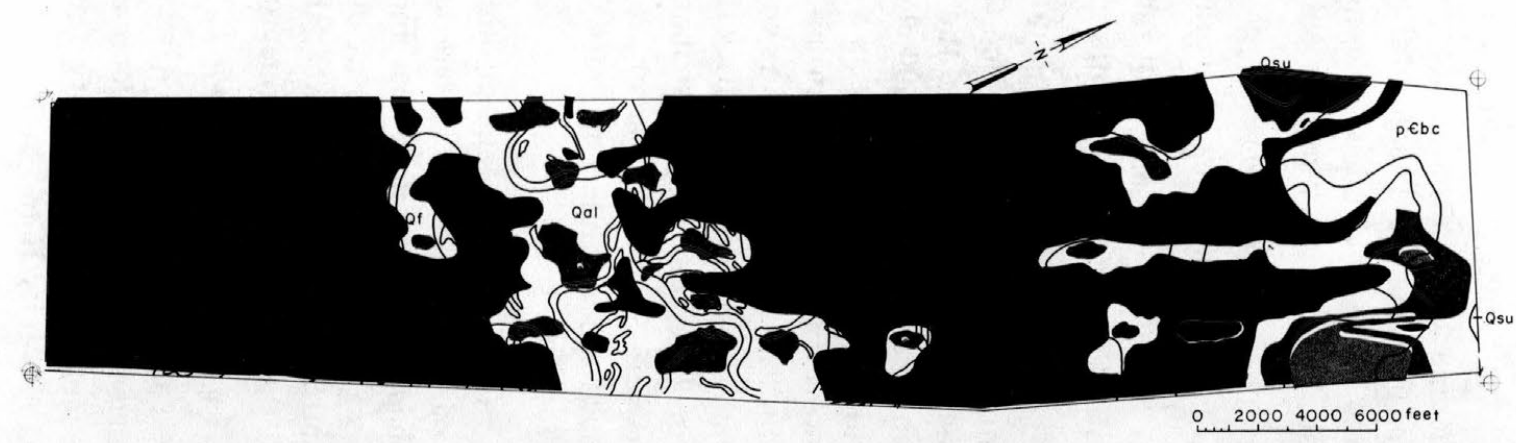

Figure 29. The $V L F, L F$ and $B C B$ apparent resistivity contour map of site 2, with the surficial geological map of the Fairbanks, Alaska. $D-1$ Geological Quadrangle. Blue $=<250$, white $=250-<500$, yellow $=500-1000$, and red $=>1000$ ohm $-\mathrm{m}$. 

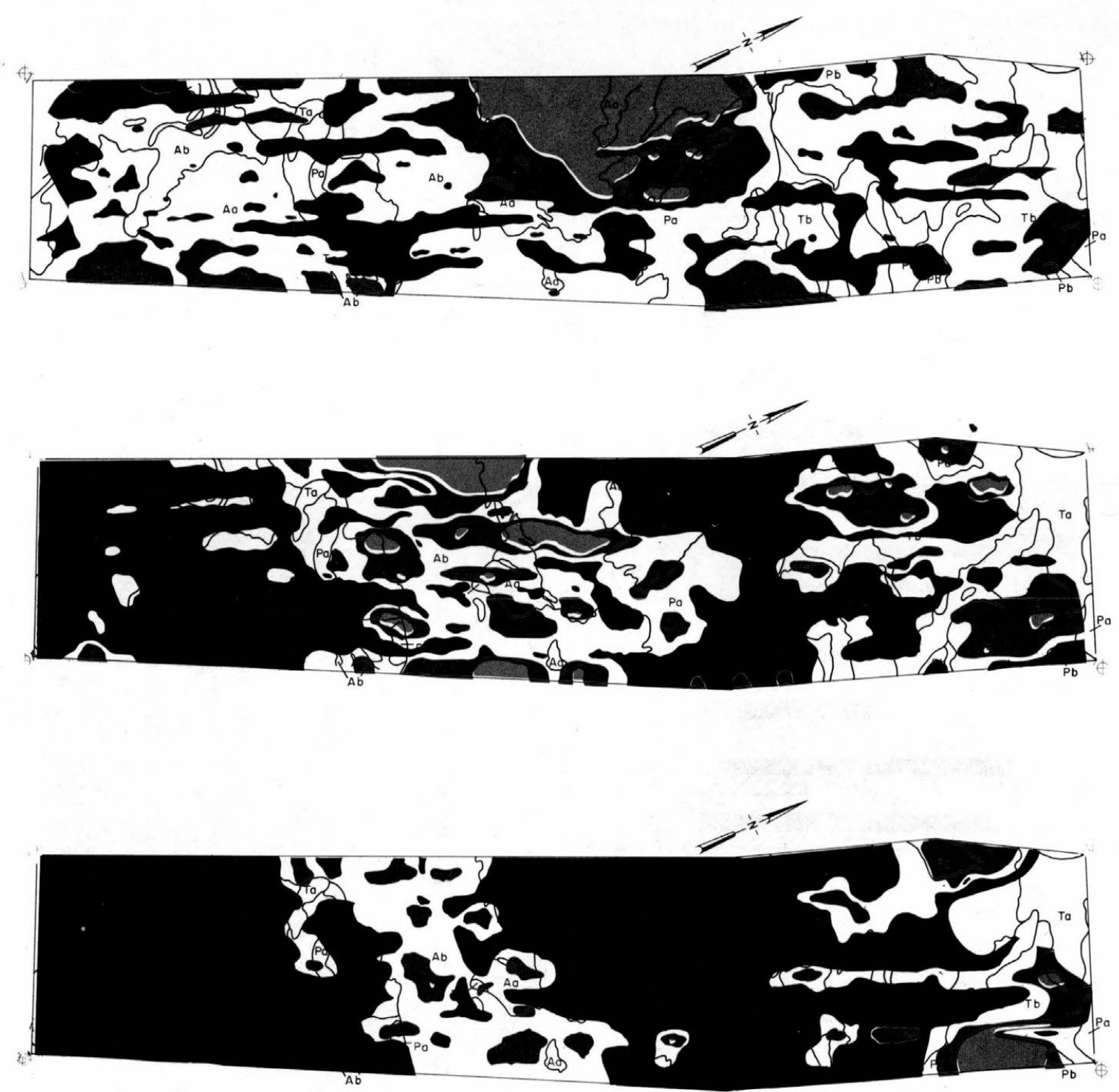

Figure 30. The VLF, $L F$ and $B C B$ apparent resistivity contour map of site 2 , with soils map. Blue $=<250$, white $=250-<500$, yellow $=500-1000$, and red $>1000 \mathrm{ohm}-\mathrm{m}$. 


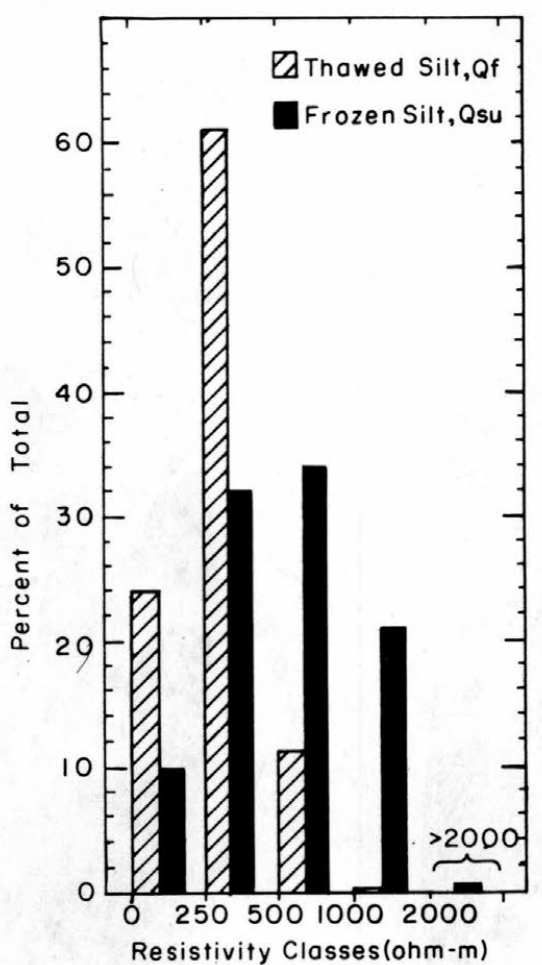

a. $V L F$.

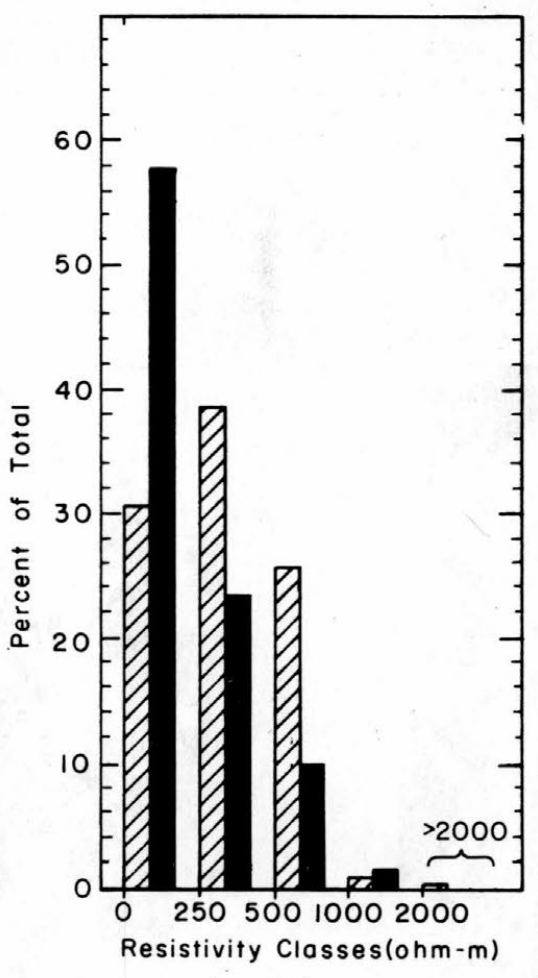

b. $L F$.

Figure 31. Normalized distribution histograms of resistivities on the units $Q f, Q \mathrm{su}$ and $Q \mathrm{~s} o$.

Table IX. Grouping of the soil units from the Fairbanks, Alaska, soil survey (Rieger et al. 1963).

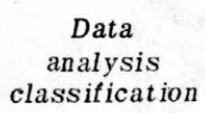

Aa

$\mathrm{Ab}$

$\mathrm{Pa}$

$\mathrm{Pb}$

$\mathrm{Ta}$

$\mathrm{Tb}$

Me
USDA*

soil survey classification

$\mathrm{Br}$

$\mathrm{Ta}$

Sc

Srn

Gt

Su

Lp

Es

Mn

Gr

Gm

$\mathrm{Fm}$

$\mathrm{Fa}$

Me

\section{Permafrost \\ table}

(m)

1 to 1.2

Bradway fine sandy loam

Tanana silt loam

Salchaket fine sandy loam

Salchaket fine sandy loam

Goldstream silt loam

Saulich silt loam

Lemetapeat

Ester silt loam

Minto silt loam

Gilmore silt loam

Gilmore silt loam

Fairbanks silt loam

Fairbanks silt loam

Mine tailings
Depth to bedrock or alluvial gravel

(m)

More than 1.8

1.2 to $1.8+$

0.3 to 1.8

0.3 to 1.8

More than 1.8

1 to $1.8+$

More than 1.8

0.3 to 0.6

More than 1.8

More than 1

0.3 to 0.6

0.6 to 1

1 to 1.8

* U.S. Department of Agriculture. 


\begin{tabular}{|c|c|}
\hline \multicolumn{2}{|c|}{ LF and BCB } \\
\hline A & B \\
\hline $\begin{array}{c}\text { Mineral Soil. } \\
\text { Active Layer }\end{array}$ & Highly Organic Surface Soils. \\
Active Layer
\end{tabular}

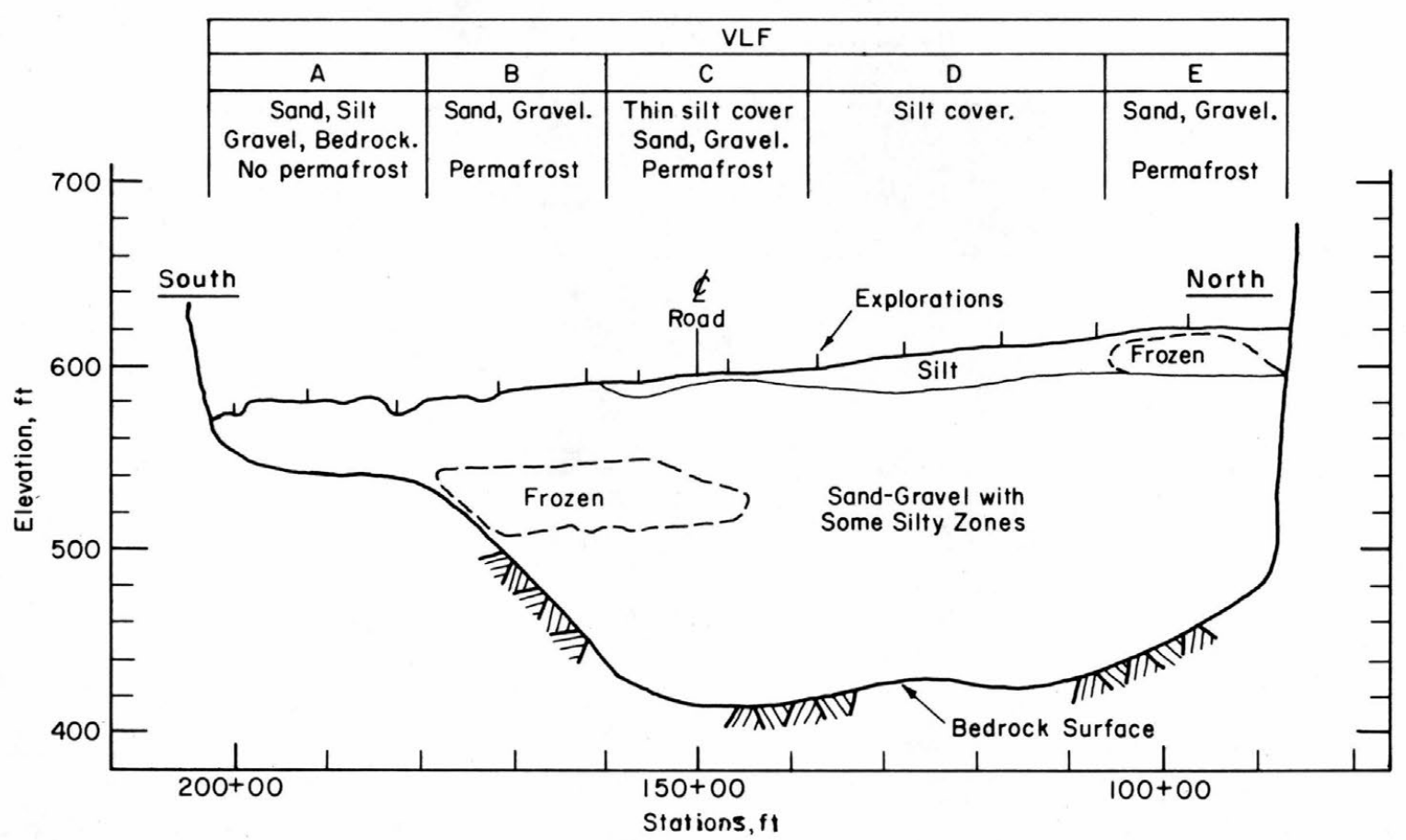

Figure 32. Geological cross section across Little Chena Valley, 28 miles along the Chena Hot Springs Road. The cross section is based on drill logs provided by the Alaska District, Corps of Engineers.

Correlating the soils map with resistivity demonstrates that the decrease in resistivity with frequency is associated with soils having organic surface layers, or partially thawed silt covers; and LF and BCB values in excess of $500 \mathrm{ohm}-\mathrm{m}$ appear to be associated with soils without organic surface layers or without completely frozen active layers. These relationships will have to be examined in some detail in future field studies. The mapped Qsu unit in the northern part of the study area, which behaved anomalously at VLF, continues to behave differently at LF and BCB compared with the Qsu unit in the central part of the study area.

\section{Chena Hot Springs Road}

This small study area is in the flood plain where the variation in ground conditions often makes interpretation difficult. The sediment types found vary from clean gravels to silt beds which may have sections that are continuously frozen. The degree of interpretation that can be made from airborne resistivity data in such environments depends on the amount of ground truth available, and at this site unusually good subsurface control was available. The Alaska District, Corps of Engineers, has drilled several test holes across the Little Chena Valley for a preliminary investigation for a dam site. The geological cross section obtained from this work is shown in Figure 32 , and the location of the cross section is shown on the resistivity map in Figure 33. In addition, several Wenner resistivity soundings were made along the cross sections. 

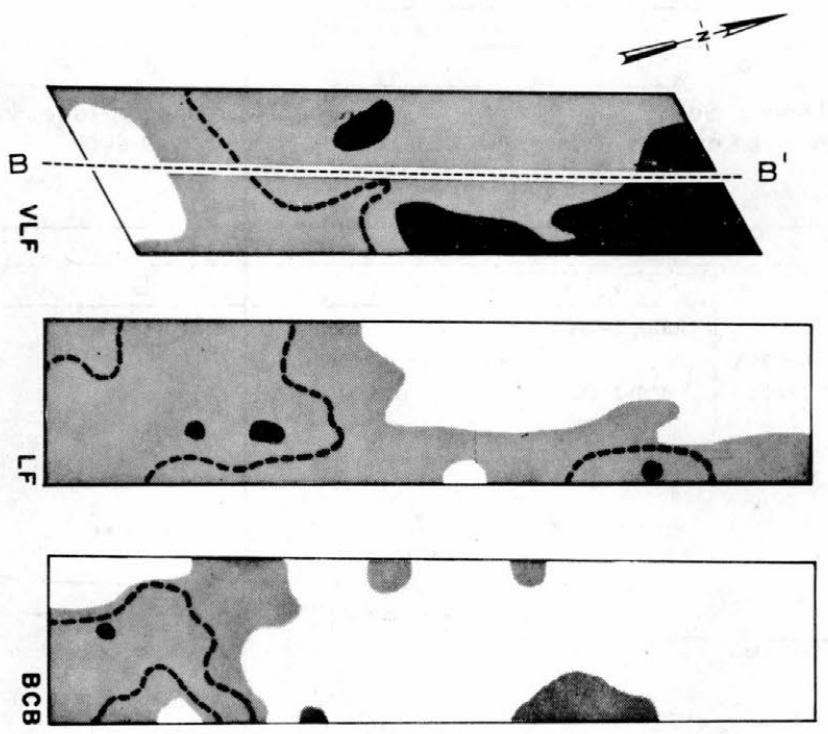

Figure 33. The contoured resistivity map for a section in the Little Chena Valley, 28 miles along the Chena Hot Springs Road. The dotted line indicates the location of the cross section in Figure 32.

The contoured resistivity maps of the three-frequency airborne survey are shown in Figure 33 . The LF and BCB survey was flown across the valley in a $\mathrm{N}-\mathrm{S}$ direction at a 0.1 -mile line spacing, while the VLF survey was flown at a 0.2 -mile line spacing along the valley in a general $\mathrm{E}-\mathrm{W}$ direction. Figure 32 indicates the soil and geological features that influence resistivity at each frequency.

Figure 33 shows that at the southern end of the area shallow, conductive bedrock appears to affect the VLF data, and resistivities less than $250 \mathrm{ohm}-\mathrm{m}$ are encountered. When the bedrock slopes away, the VLF resistivity increases. Farther north a silt cover blankets the gravel and its thickness gradually increases to the north. The thawed silt blanket in the central part of the area partially screens the high resistivity in the gravel at VLF, so that VLF resistivities are limited to from 500 to $1000 \mathrm{ohm}-\mathrm{m}$. The areas where resistivities at VLF are in excess of $1000 \mathrm{ohm}-\mathrm{m}$ probably indicate portions of the section where the silt cover is entirely or partially frozen.

The resistivities at $\mathrm{LF}$ and $\mathrm{BCB}$ decrease towards the north. This decrease is caused by a conductive layer at the surface; the conductor is probably an organic surface layer and a partially thawed silt cover.

At the southern end, where there is no silt cover, the resistivity values increase with frequency. The skin depth at LF and BCB is insufficient to be much influenced by conductive bedrock.

Because of the detailed cross section available, as well as several resistivity measurements on the ground, the results were compared with model studies. Figure 34 shows the resistivity profiles along the cross section $\mathrm{BB}^{\prime}$ shown in Figure 33. The cross section here was divided into 3 sections, and in each section at least one Wenner spread was made.

A Wenner spread in section $\mathrm{A}$ is shown in Figure 35. A layer of gravel $d_{2}$ with resistivities in excess of $1000 \mathrm{ohm}-\mathrm{m}$ overlies a conductive stratum, which is apparently severely decomposed bedrock, with a resistivity $\rho_{3}$ of about $50 \mathrm{ohm}-\mathrm{m}$. The very high resistivities in the gravel could indicate frost in this section as the drill logs showed. 


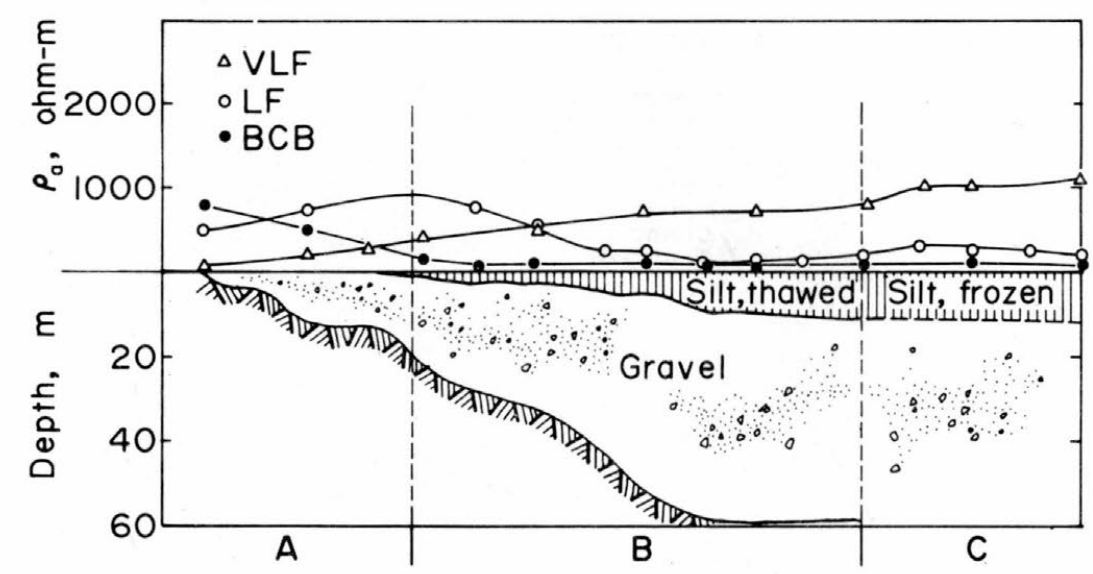

Figure 34. Resistivity profiles along the cross section $B B^{\prime}$ of Little Chena Valley and the geological cross section derived from the measured resistivity data and modeling studies.

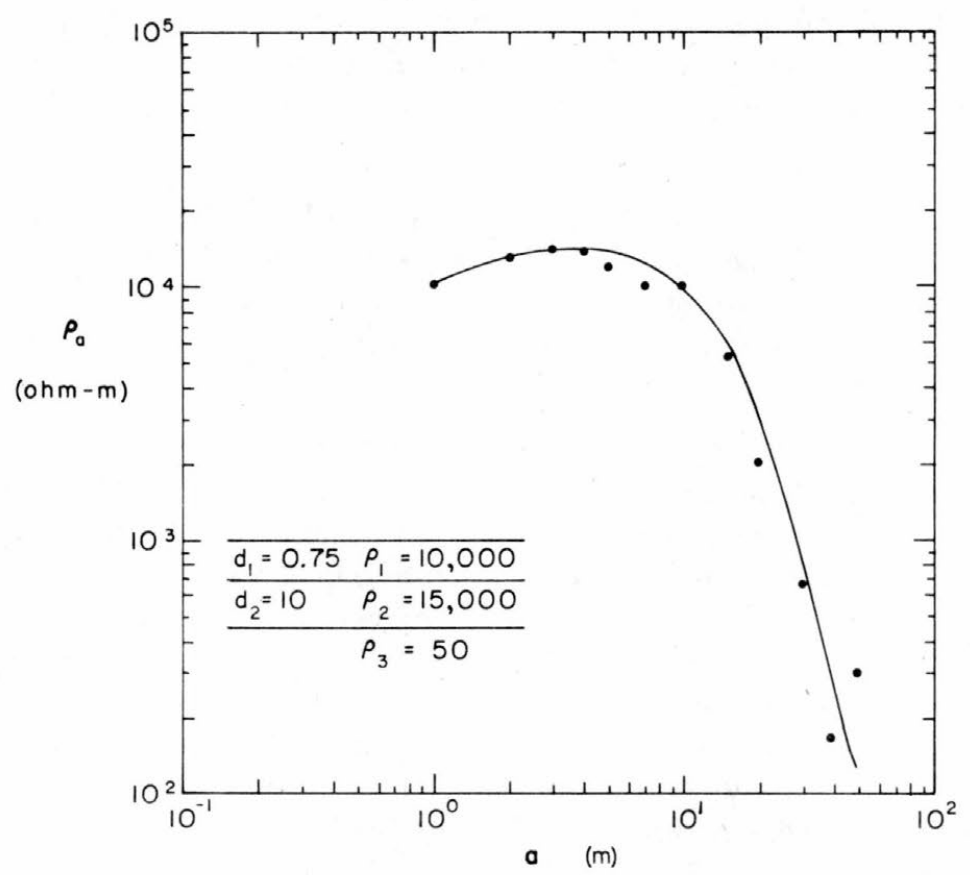

Figure 35. A Wenner spread in the Little Chena Valley, in section $A$ of Figure 34. The solid line represents the computed values for the ground conditions indicated.

A Wenner spread in section B is shown in Figure 20e. A layer of seasonal frost in the silt cover causes relatively high resistivities at the surface; a subsequent decrease in $\rho_{\mathrm{a}}$ is caused by a layer of unfrozen silt $d_{2}$; the silt cover in turn overlies a layer of gravels. Because the gravels are of lower resistivity here than in section A, they are most likely unfrozen.

In section $\mathrm{C}$, part of the silt cover may be frozen. That some changes occur in ground conditions is evident from a small increase in both the VLF and LF frequencies. Because of an ice layer on the surface in this section in April 1973, the Wenner spreads are of low quality because of contact resistance problems. 


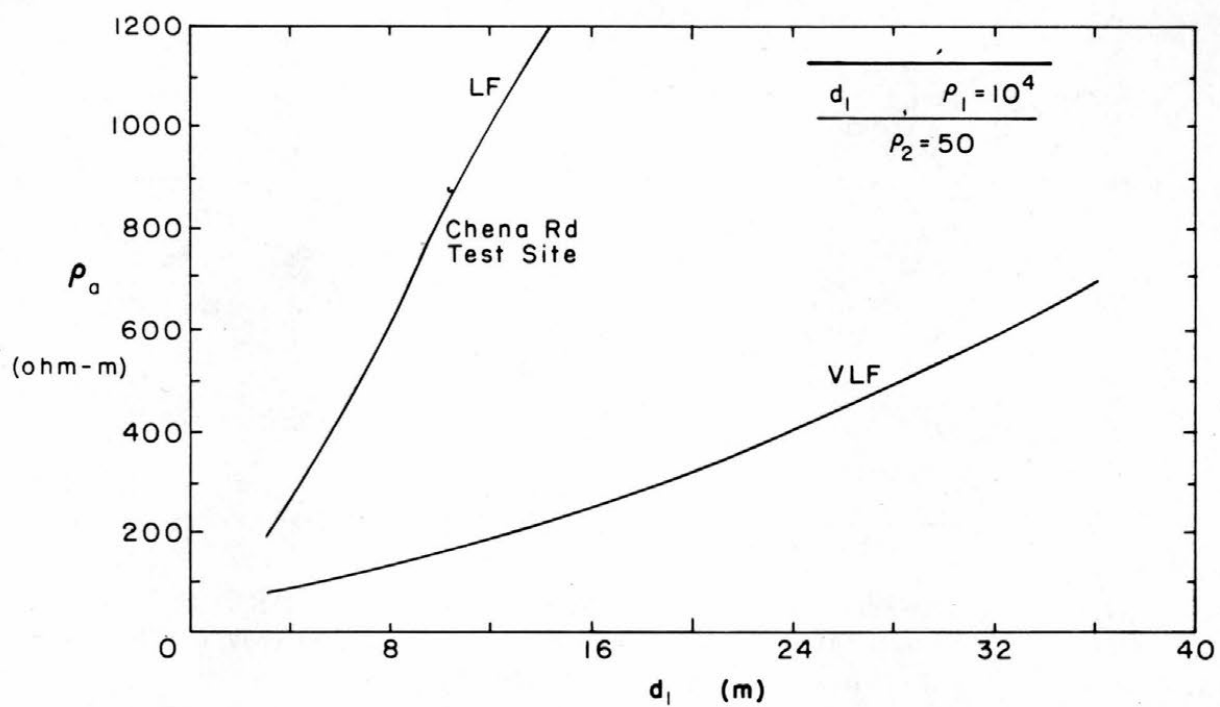

Figure 36. The computed values of apparent resistivity at $V L F$ and $L F$ in section $A$, Chena Hot Springs Road, for the E-phase method as a function of the thickness of a highly resistant gravel layer.

The situation in section A is modeled in Figure 36 at VLF and LF; $\rho_{\mathrm{a}}$ is plotted as a function of depth to bedrock. In accordance with the measurement of the Wenner spreads, the gravel $d_{1}$ has been given a high resistivity of $10^{4} \mathrm{ohm}-\mathrm{m}$, whereas the bedrock is given a value of $50 \mathrm{ohm}-\mathrm{m}$. Figure 36 shows that a higher value for $\rho_{\mathrm{a}}$ is predicted at LF than at VLF. Figure 36 was used to predict depth to bedrock in section A, and the predicted depth to bedrock is plotted in Figure 34 .

The drill logs show that a silt blanket begins to overlie the flood plain gravels in section B. That a new geological setting occurs is also evident from the LF resistivity data obtained with airborne equipment, which show a reversal in trend. In Figure 22 the effect of an unfrozen silt blanket is computed; $\rho_{\mathrm{a}}$ is given as a function of depth to bedrock at three different thicknesses of the silt cover at VLF. The gravel $d_{2}$ has been assigned a resistivity of $1000 \mathrm{ohm}-\mathrm{m}$ consistent with the data of the Wenner spread in Figure 20e. The depth of silt refers to the thickness of unfrozen silt. In Figure 23, $\rho_{\mathrm{a}}$ is plotted at LF as a function of the thickness of the silt cover $d_{1}$. The apparent resistivity at LF becomes insensitive to the thickness of the gravel layer and the basement resistivity. From Figure 23 the thickness of the silt cover can be estimated and from Figure 36 the depth to bedrock. Bedrock at a depth greater than $50 \mathrm{~m}$ cannot be distinguished.

In section $\mathrm{C}$ part of the silt cover is frozen and part is unfrozen. Both VLF and LF show an anomaly in section C. It is difficult to model this complicated situation realistically. When the cross section shown in Figure 34, obtained from the resistivity measurements and computer modeling, is compared with the cross section derived from drill logs, shown in Figure 32, the results in sections A and B of Figure 34 show that modeling a simple 2- or 3-layer situation yields good agreement. Such a detailed interpretation can only be made if good ground truth data are available.

\section{Moose Creek Dam}

This large study area lies almost exclusively on the alluvial section of the Chena River. The sediment types and local stratigraphy are inherently variable, including interbedded sands, silts and gravels. Zones in the finer grained material, and in some cases the sands and gravels, may be perennially frozen. 

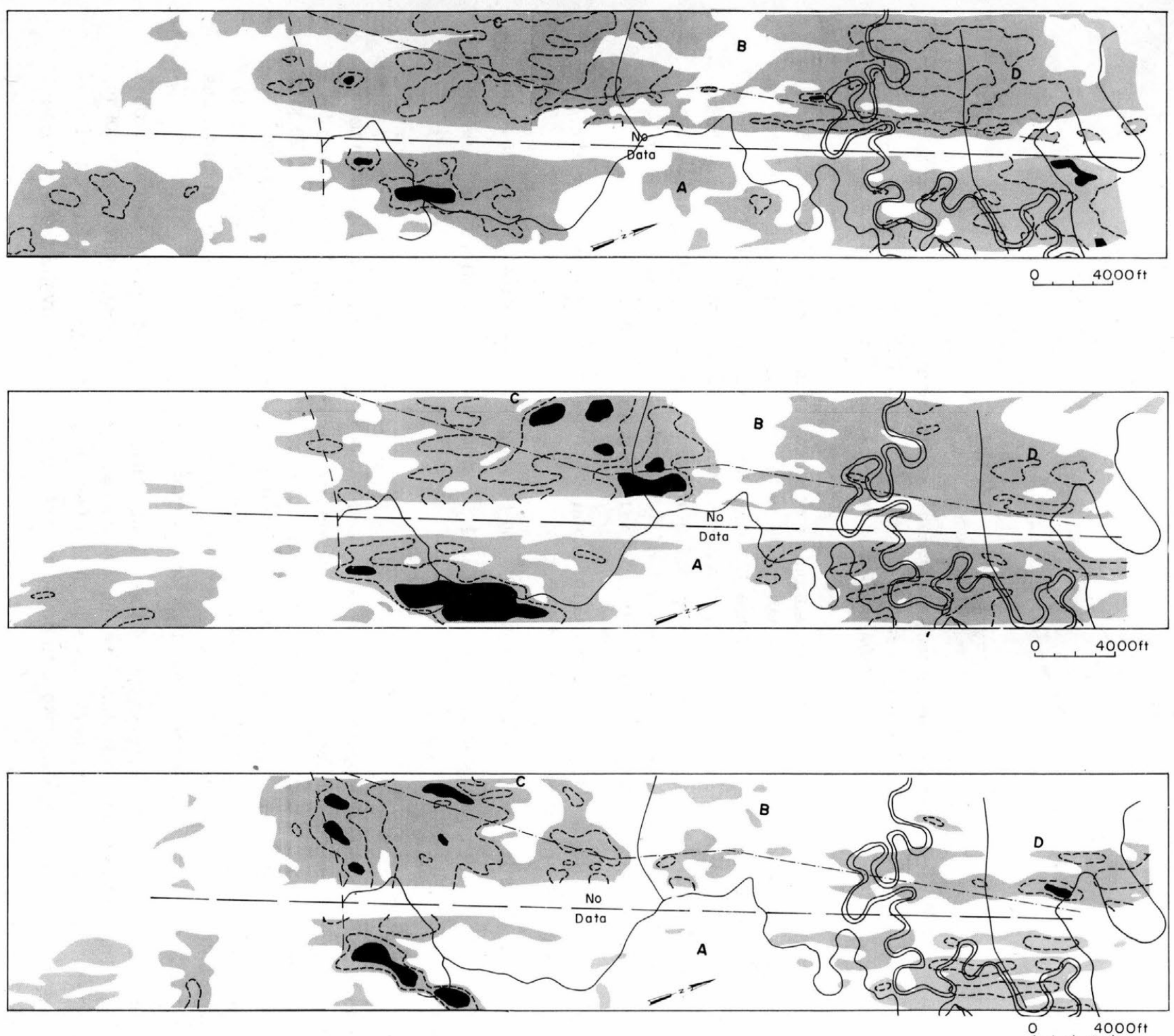

Figure 37. The apparent resistivity contour maps at $V L F, L F$ and $B C B$ in the Moose Creek Dam area, with a preliminary surficial geological $\stackrel{\oplus}{\bullet}$ map mainly indicating the depth of silt cover. Clear $<250$, shaded 250-1000, -- 500, solid $>1000$ ohm-m. 


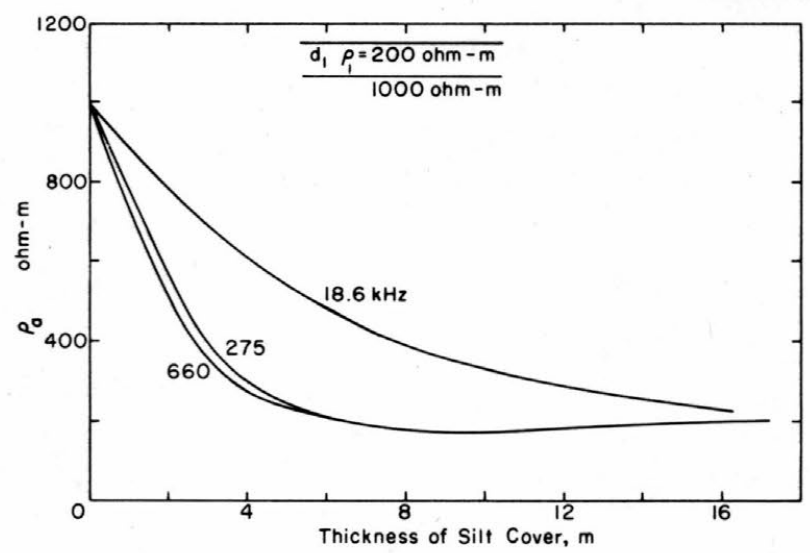

Figure 38. The computed apparent resistivity at three frequencies for two layers of silt over gravel as a function of the thickness of silt cover.

The area was flown over at three frequencies and represents one of the most difficult areas to interpret because of the mixture of sand, silts and gravel in the flood plain. The contoured resistivities at VLF, LF and BCB are shown in Figure 37. In general, resistivity variation in this area must be attributed to varying thicknesses of silt cover over poorly graded gravels and sands, and the presence or absence of perennially frozen sections in the silt. The geological map, also presented in Figure 37, shows the preliminary ground data provided by the Corps of Engineers, Alaska District. The solid line roughly delineates sections of varying silt cover overlying gravel:

1. In area $\mathrm{A}$ the silt cover is more than $7 \mathrm{~m}$ thick and apparently permafrost is frequently present in the silt, either in the entire depth or in part of it.

2. In area B the silt cover is $1.5 \mathrm{~m}$ to $5 \mathrm{~m}$ thick and only sporadic permafrost is present in the silt.

3. In area $\mathrm{C}$ the silt cover is in general less than $1.5 \mathrm{~m}$ thick and the old stream channels are occasionally filled with silt.

4. In area $\mathrm{D}$ the silt cover is 0 to $3 \mathrm{~m}$ deep.

In Figure 38 the computed apparent resistivity for two layers of silt over gravel is computed at the three frequencies used in the survey. The apparent resistivity at all three frequencies. decreases with increasing silt cover. Very little difference is expected between data at $\mathrm{LF}(275 \mathrm{kHz})$ and data at $\mathrm{BCB}(660 \mathrm{kHz})$. For this type of layering, the resistivity decreases with frequency. Thus, from the modeling curve there are predicted: a silt cover less than $2 \mathrm{~m}$ thick in areas where $\mathrm{LF}$ and $\mathrm{BCB}$ values are in excess of $500 \mathrm{ohm}-\mathrm{m}$, and a silt cover more than $14 \mathrm{~m}$ thick in situations where the VLF resistivity $(18.6 \mathrm{kHz})$ is less than $250 \mathrm{ohm}-\mathrm{m}$ :

The modeled curves refer to the amount of thawed silt, and frozen layers in the silt will probbably be indistinguishable from gravels. Also, bedrock is assumed to be deep enough so as not to affect VLF resistivities. When bedrock comes to the surface, it will change the interpretation. In comparing the resistivity contour map with boundaries of the silt cover, several areas of agreement are observed:

1. Blocks of high resistivities ( $>500$ ohm-m) are observed to coincide with area $\mathrm{C}$ and the occurrence is consistent at all three frequencies. Area $\mathrm{C}$ has a thin silt cover, and a thin silt cover is also predicted from the modeling curve. The consistency with frequency in this area is encouraging. 
2. A belt of low resistivity at all three frequencies is observed in area A but also extends to the north of it in area B. From the modeling curves, silt thicknesses in excess of $15 \mathrm{~m}$ are expected because of the low VLF resistivities encountered. A large part of the area of low resistivity coincides with area A, but is more extensive to the north than indicated by the map provided by the Alaska District, Corps of Engineers.

3. A block of higher resistivities is again encountered at LF and VLF in areas B and D. The silt cover here is mapped to be less than $5 \mathrm{~m}$ thick.

In summary, the resistivity data in this area are difficult to interpret because of the complex and random geology. However, from what ground truth is available, a reasonable agreement between resistivity contours and soil types is observed.

\section{CONCLUSIONS}

The results of the survey in the four study areas discussed indicate that the VLF contour maps show the most apparent correlation between surficial geology and resistivity. The VLF resistivity data permit a distinction between thawed and frozen zones on fine-grained sediments. Both in Goldstream and at site 2 the $500 \mathrm{ohm}-\mathrm{m}$ contour line often closely follows the mapped geology boundary of thawed and frozen units. When the surficial geology is complicated, as is often the case in the flood plain, a correct interpretation of resistivity data requires much ground truth. However, when good ground truth data are available, as on the site on the Chena Hot Springs Road, much information can be extracted from resistivity data, and resistivity data provide an excellent source of continuous information between drill holes.

Although the LF resistivity data are useful for study purposes, the additional information obtained from the data would have to be weighed against the extra cost. In addition, the three frequencies were not ideally separated in this survey. Probably the ideal frequencies would have been VLF and a station on the SLF (70-140 kHz) band. An SLF station, however, was not available in Fairbanks, Alaska.

Finally, it can be concluded that the study has provided an adequate test of multifrequency airborne resistivity mapping in the discontinuous permafrost zone, and that several important geotechnical objectives can be derived from airborne resistivity mapping.

\section{LITERATURE CITED}

Anderson, D.M. and N.R. Morgenstern (1973) Physics, chemistry and mechanics of frozen ground. In The North American Contribution to the Second International Conference on Permafrost. National Research Council, National Academy of Sciences, p. 298.

Barringer, A.R. and J.D. McNeill (1969) The radiophase technique of airborne resistivity mapping (abs.). Geophysics, vol. 34, no. 6 .

Blomquist, A. (1970) Equipment for in-situ measurement of the dielectric properties of ground and ice. Proceedings of the International Meeting on Radio Glaciology, Lyngby, Denmark, p. 54-70.

Eliassen, K.E. (1956) A survey of ground conductivity and dielectric constant in Norway within the frequency range 0.2-10 MC. Geofys. Publ. (Oslo), vol. 19, no. 11 , p. 1-30. 
Frischknecht, F.C. (1973) Electromagnetic scale model studies of geophysical methods using a plane wave source. University of Colorado, Ph.D. Thesis.

Heiland, C.D. (1940) Geophysical exploration. New York: Prentice Hall, Inc.

Hoekstra, P. and A. Delaney (1973) Ground resistivity survey in the area of the Tennessee-Tombigbee Waterway. U.S. Army Cold Regions Research and Engineering Laboratory (USA CRREL) Special Report 191. AD 767246.

Hoekstra, P. and D. McNeill (1973) Electromagnetic probing of permafrost. In The North American Contribution to the Second International Conference on Permafrost. National Research Council, National Academy of Sciences, p. 517.

Keller, G.V. and F.C. Frischknecht (1966) Electrical methods in geophysical prospecting. New York: Pergamon Press.

Keller, G.V., A.B. Level and F.L. Avsman (1970) Evaluation of airborne electromagnetic surveying for mapping variations in rock strength. Colorado School of Mines, Air Force Cambridge Research Laboratories, Contract Report No. F19628-69-C-0281.

King, P.J. (1968) Crossed dipole method of measuring wavetilt. Radio Science, vol. 3 , no. 4 , p. 345 .

Kraichman, M.B. (1970) Handbook of electromagnetic propagation in conducting media. Headquarters, U.S. Naval Materiel Command, Washington, DC, U.S. Government Printing Office.

Ogilvy, A.A. (1967) Geophysical studies in permafrost regions in USSR. Mining and Groundwater Geophysics, Geological Survey, Canada, Econ. Geol., no. 26, p. $641-650$.

Parkhomenko, E.I. (1967) Electrical properties of rock. Translated from Russian by G.V. Keller. New York: Plenum Press.

Péwé, T.L. (1958) Geology of the Fairbanks (D-2) Quadrangle, Alaska. U.S. Geological Survey Geological Quadrangle Map GQ-110.

Rieger, S., J.A. Dement and D. Sanders (1963) Soil survey of Fairbanks area, Alaska. U.S. Department of Agriculture, Series 1959, no. 25.

Sellmann, P.V., P. Hoekstra and A. Delaney (1974) Airborne resistivity survey: An aid in bedrock geology reconnaissance. USA CRREL Special Report 202. AD 777792.

U.S. Army Engineer Waterways Experiment Station (1960) The Unified Soil Classification System. Technical Memorandum no. 3-357, vol. 1.

Wait, J.R. (1962) Electromagnetic waves in stratified media. New York: Pergamon Press.

Williams, J.R., T.L. Péwé and R.A. Paige (1959) Geological map of Fairbanks D-1 Quadrangle. U.S. Geological Survey, Map CQ-124. 


\section{DOCUMENT CONTROL DATA - R \& D}

Security classification of title, body of abstract and indexing annotation must be entered when the overall report is classified) ORIGINATING ACTIVITY (Corporate author) TE. REPORT SECURITY CLASSIFICATION

U.S. Army Cold Regions Research and Engineering Laboratory Hanover, New Hampshire Unclassified

3. REPORT TITLE

AIRBORNE RESISTIVITY MAPPING OF PERMAFROST NEAR FAIRBANKS, ALASKA

4. OESCRIP TIVE NOTES (TYPe of report and inclusive dates)

5. AUTHOR(S) (First name, middle intial, last namo)

P. Hoekstra, P.V. Sellmann and A.J. Delaney

\begin{tabular}{|l|l|l|}
\hline 6. REPOKY DATE September 1974 & $\begin{array}{l}\text { a. TOTAL NO. OFPAGES } \\
49\end{array}$ & $\begin{array}{c}\text { 7b. NO. OF REFS } \\
20\end{array}$ \\
\hline BE. OONTRACT OR GRANTNO. & 9a. ORIGINATOR'S REPORT RIUMBER(S)
\end{tabular}

t. pajectino. DA Project 4A162121A894

Task 03

c. Work Unit 008

Research Report 324

i.

TO DISTRIBUT:ON STATEMENT

Approved for public release; distribution unlimited.

11. SUPPLEMENTARY NOTES

Co-sponsored by:

U.S. Army Engineer District, Alaska
Office, Chief of Engineers

Washington, D.C.

13. ABSTRACT

Airborne resistivity methods using radio waves in three frequency bands were tested in the vicinity of Fairbanks, Alaska. The test sites were selected because much ground control is available for this area. The objectives of this study were to determine the ability of these methods to map permafrost and other soils and to investigate the advantages of multifrequency mapping. Investigations in permafrost regions for such geotechnical endeavors as route selection for roads and pipelines and site investigation for building and dam construction often require that a careful assessment be made of the presence or absence of frozen ground, of the ice content of frozen ground, and of the depth of frozen ground. The airborne resistivity data obtained in this study were contoured and the contour maps were compared with surficial geological maps and other ground truth data available. The following conclusions were reached: 1) in areas where the nearsurface sediments are relatively uniform, VLF resistivity best delineates permafrost; and 2) in areas where surface sediments vary widely (e.g., recent flood plains), resistivity at all frequencies gives little information on permafrost conditions, but provides other important information, such as bedrock type, depth to bedrock, soil type and layering.

\section{KEY WORDS}

Aerial surveys

Electrical resistivity

Geological surveys
Soil surveys

Subsurface investigations 